\title{
A HYBRID METHOD TO DESIGN AND OPTIMIZE A BATTERY CLOSED-LOOP SUPPLY CHAIN: MULTI-OBJECTIVE APPROACH
}

\author{
by Babak Mohamadpour Tosarkani \\ Master of Business Administrations (MBA) in Finance, Multimedia University, Malaysia, \\ 2012 \\ Bachelor of Science in Industrial Engineering (Systems Analysis and Planning), Azad \\ University, Iran, 2007
}

A thesis presented to Ryerson University

in partial fulfillment of the

requirement for the degree of

Master of Applied Science

in the program of

Mechanical and Industrial Engineering

Toronto, Ontario, Canada, 2017

(C) Babak Mohamadpour Tosarkani, 2017 


\begin{abstract}
AUTHOR'S DECLARATION
I hereby declare that I am the sole author of this thesis. This is a true copy of the thesis, including any required final reversion, as accepted by my examiners.

I authorize Ryerson University to lend this thesis to other institutions or individuals for the purpose of scholarly research.

I further authorize Ryerson University to reproduce this thesis by photocopying or by other means, in total or in part, at the request of other institutions or individuals for the purpose of scholarly research.

I understand that my thesis may be made electronically available to the public.
\end{abstract}




\title{
ABSTRACT \\ A HYBRID METHOD TO DESIGN AND OPTIMIZE A BATTERY CLOSED-LOOP SUPPLY CHAIN: MULTI-OBJECTIVE APPROACH
}

\author{
Master of Applied Science, 2017 \\ Babak Mohamadpour Tosarkani \\ Mechanical and Industrial Engineering \\ Ryerson University
}

There are a variety of prominent factors associated with total expected profit of a closed-loop supply chain (CLSC). In a forward flow, volatility in transportation cost, inventory cost, and forecasting the market's demand are the most challenging issues for decision makers, while determining the rate of returned products and efficiency in recycling the returned products are crucial parameters to predict in reverse flow. In this thesis, it is aimed to develop and apply mixed-integer linear programming (MILP), scenario-based analysis, and fully fuzzy programming (FFP) methods to maximize the profit for a multi-echelon, multi-components, multi-product, multi-period battery CLSC in Vancouver, Canada. Furthermore, the proposed model is extended to multi-objective to consider the green factors related to plants and battery recovery centers. Fuzzy analytic network process (Fuzzy ANP) is utilized to convert the qualitative factors to the measurable parameters. Then, distance technique and E-constraint method are utilized for solving the multi-objective problem. 


\section{ACKNOWLEDGEMENTS}

I would like to acknowledge Dr. Saman Hassanzadeh Amin, from the department of Mechanical and Industrial at Ryerson University for helpful suggestions, invaluable advice, comments and constructive criticism throughout all the phases of this thesis. It is recognized that without his guidance, this research would not have been accomplished successfully.

I also would like to thank other members of my committee, Dr. Ahmad Ghasempoor, Dr. Mohamed Wahab Mohamed Ismail, Dr. Sharareh Taghipour for their encouragement throughout my master's program especially for their professional comments and advice that provided me great help in the preparation of this thesis.

My sincere gratitude goes to my parents, Farkhondeh Amiri and Ali Mohamadpour, and especially to my lovely wife Maryam Samiee Farisar for their inspiration and encouragement during my study.

Furthermore, I am very thankful to the department of Mechanical and Industrial Engineering at Ryerson University for giving me all the support that I needed to accomplish the Mechanical and Industrial Engineering (MASc). 


\section{TABLE OF CONTENTS}

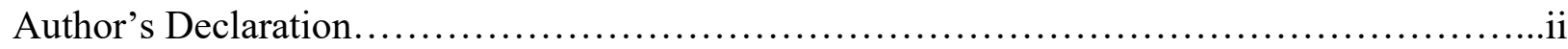

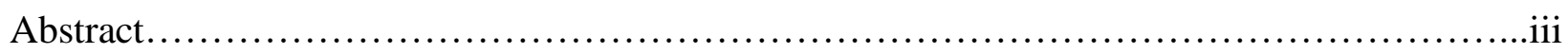

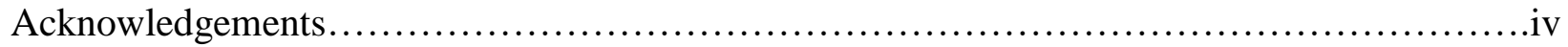

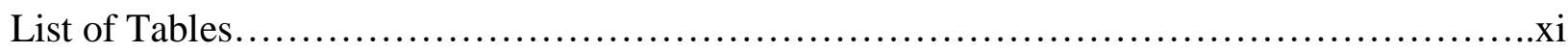

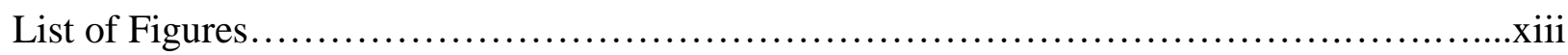

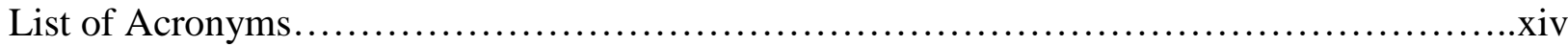

\section{CHAPTER 1. INTRODUCTION}

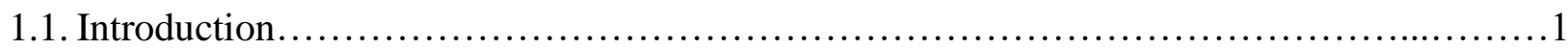

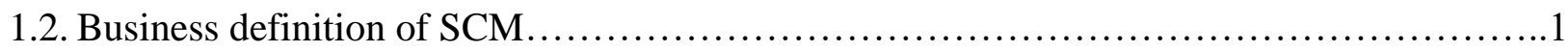

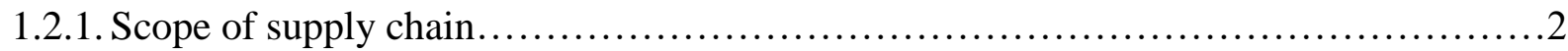

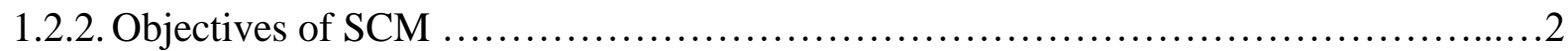

1.2.3. Distinguishing SCM from logistic management...................................

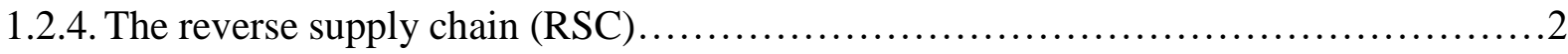

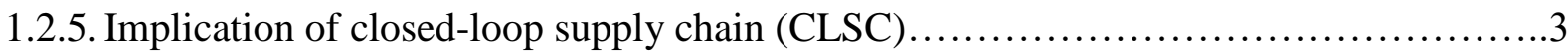

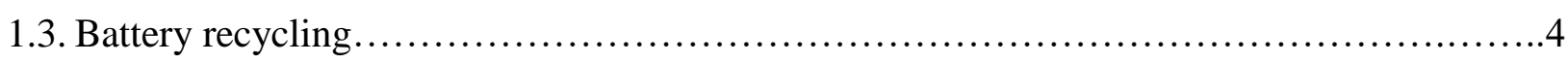

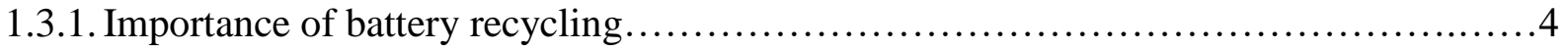

1.3.2. The different types of batteries and related recycling method.........................5

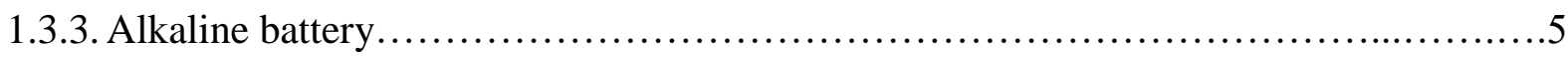

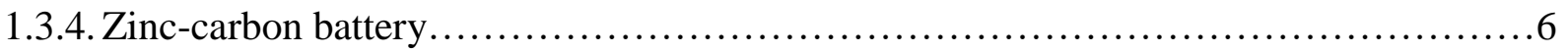

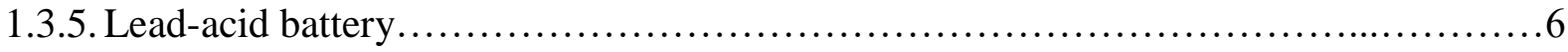

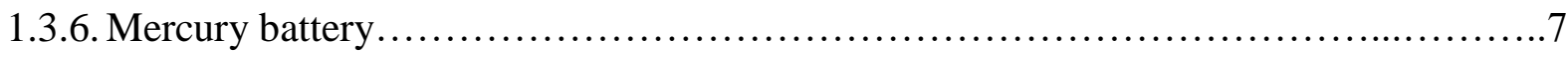

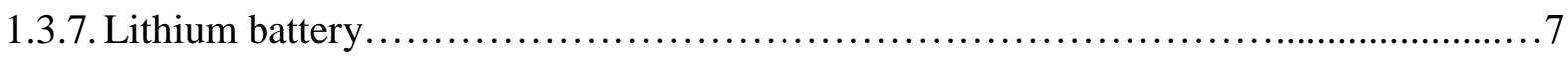

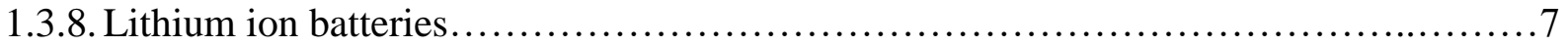

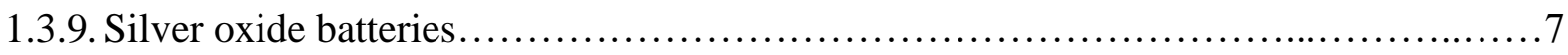

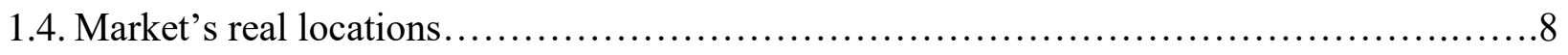

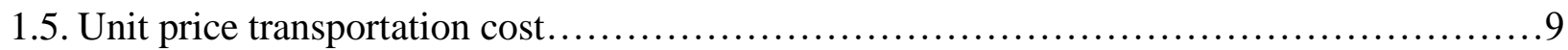

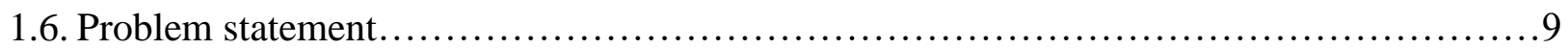


1.7. Aim and research contributions..................................................... 10

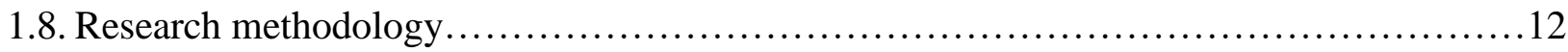

1.8.1. Mixed-integer linear programming (MILP) .................................... 12

1.8.2. Multi-objective linear programming (MOLP) ....................................... 12

1.8.3. Fuzzy analytic network process (FANP) .......................................... 12

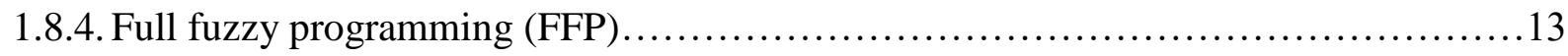

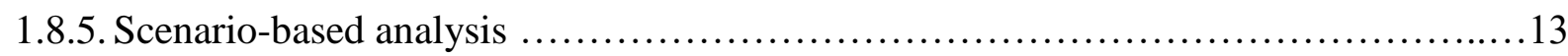

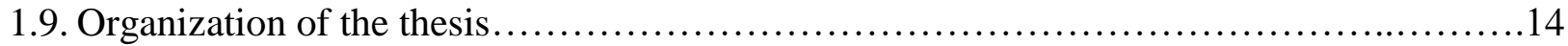

\section{CHAPTER 2. REVIEW OF LITERATURE}

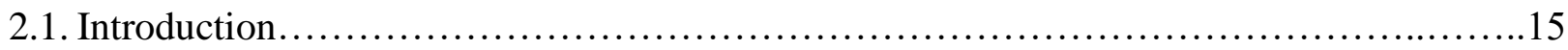

2.2. Deterministic models applied in CLSC .............................................. 15

2.3. Multi-objective models for CLSC ................................................

2.4. Stochastic programming (scenario-based analysis) in CLSC ..............................18

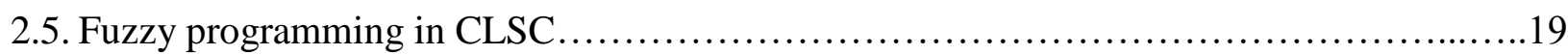

\section{CHAPTER 3. APPLICATION OF MILP AND SCENARIO-BASED ANALYSIS TO DESIGN A BATTERY CLSC}

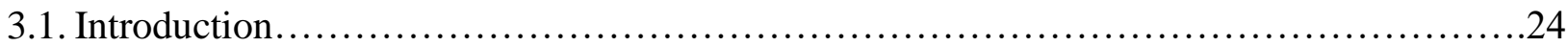

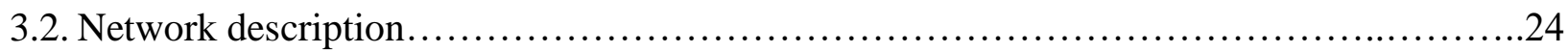

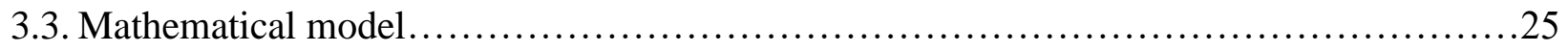

3.4. Application of the proposed model and solution approach.............................29

3.5. An extension to consider uncertainty ................................................... 31

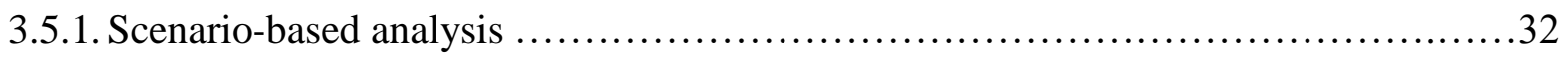

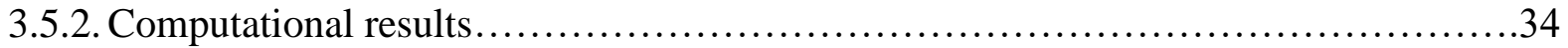

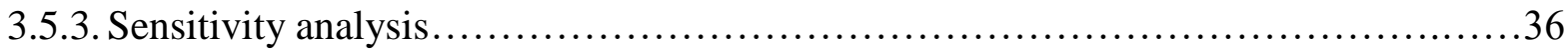

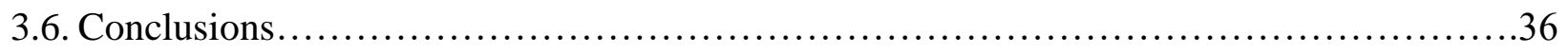




\section{CHAPTER 4. APPLICATION OF FUZZY ANP TO RANK PLANTS AND BATTERY RECOVERY CENTERS BASED ON GREEN PERFORMANCE}

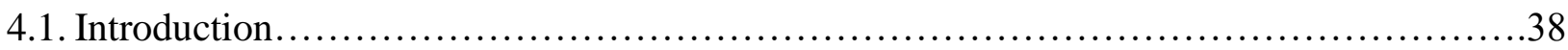

4.2. Review of some related studies to identify the green performance indicators.................38

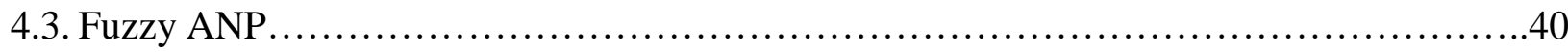

4.4. ANP model to determine plants priority based on green performance......................43

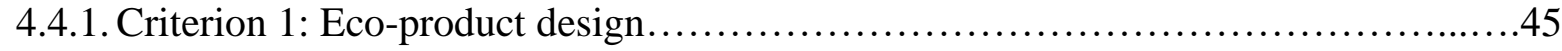

4.4.1.1. Sub- criterion 1: Designing the recyclable product........................45

4.4.1.2. Sub- criterion 2: Designing the product needing less hazardous material....45

4.4.1.3. Sub- criterion 3: Collaborating with customers for eco-design..............45

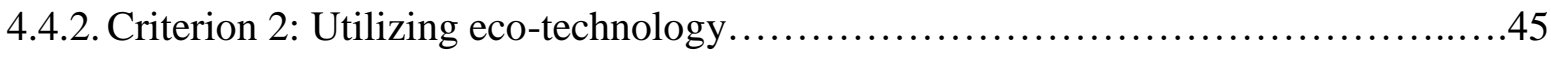

4.4.2.1. Sub- criterion 4: Utilizing eco- technology in production (renewable source

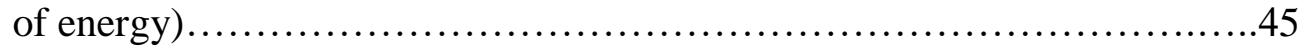

4.4.2.2. Sub- criterion 5: Utilizing eco-tech for manufacturing (producing less carbon emission) ......................................................... 45

4.4.3. Criterion 3: Green purchasing .................................................. 46

4.4.3.1. Sub- criterion 6: Collaborating with supplier for protecting the environment........................................................... 46

4.4.3.2. Sub- criterion 7: Purchasing from suppliers having ISO 14001 standard environmental management systems..................................46

4.4.4. Criterion 4: Sustainable packaging ........................................... 46

4.4.4.1. Sub- criterion 8: Reusable packaging .................................46

4.4.4.2. Sub- criterion 9: Using minimal material and layers for packaging..........46

4.4.4.3. Sub- criterion 10: Packaging from recycled material.......................47

4.5.ANP model to determine priority of battery recovery centers based on green

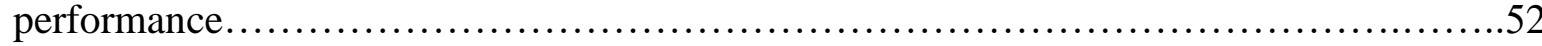

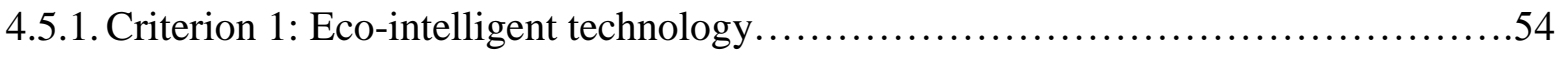

4.5.1.1. Sub- criterion 1: Utilizing eco-intelligent technology for sorting returned

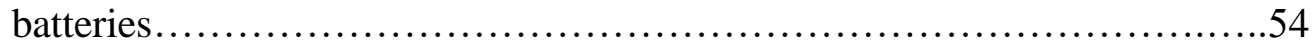


4.5.1.2. Sub- criterion 2: Utilizing eco-intelligent technology for recycling

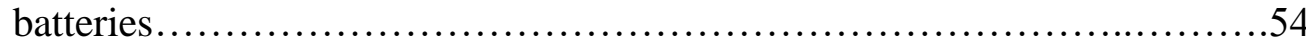

4.5.2. Criterion 2: Environmental practice......................................54

4.5.2.1. Sub- criterion 3: Responsible Recycling@ (R2) Certification..............54

4.5.2.2. Sub- criterion 4: Solid and septic waste management...................54

4.5.2.3. Sub- criterion 5: Environmental Regulatory Compliance.................55

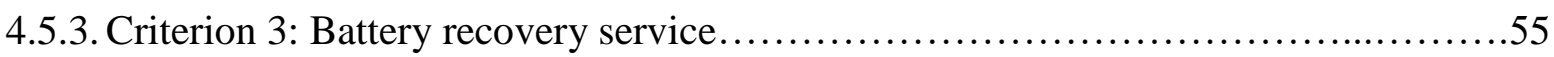

4.5.3.1. Sub- criterion 6: Collaborating with customer.........................55

4.5.3.2. Sub- criterion 7: Maintenance and inspection for reducing scrap rate........55

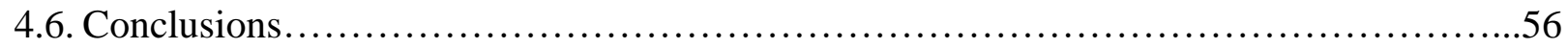

\section{CHAPTER 5. A POSSIBILISTIC SOLUTION TO CONFIGURE A BATTERY CLOSED-LOOP SUPPLY CHAIN: MULTI-OBJECTIVE APPROACH}

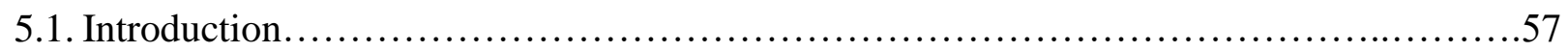

5.2. Review of some related studies to fuzzy programming method.....................57

5.3. An overview of triangular fuzzy number operations ..............................58

5.4. FFP model in closed-loop supply chain.........................................59

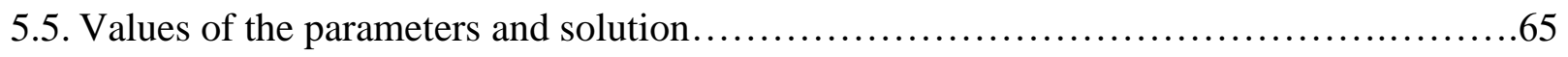

5.6. Comparison between the solution of deterministic and FFP model.....................66

5.7. Application of FFP with regard to scenario-based analysis to address uncertainty.........68

5.8. An extension to multi-objective............................................... 70

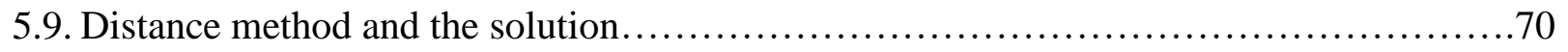

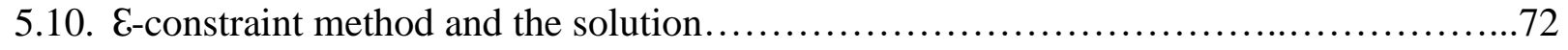

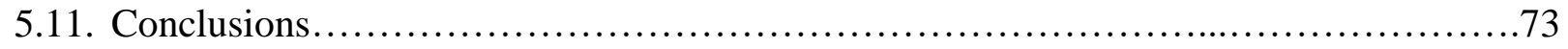

\section{CHAPTER 6. CONCLUSIONS AND FUTURE RESEARCH}

6.1. Research contributions ................................................... 74

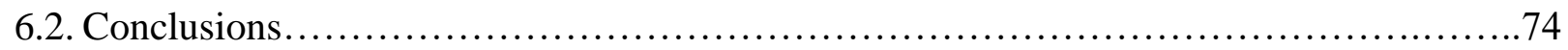

6.3. Recommendations for future research...................................... 76 
APPENDIX A. FUZZY ANP ANALYSES TO RANK THE PLANTS BASED ON THE

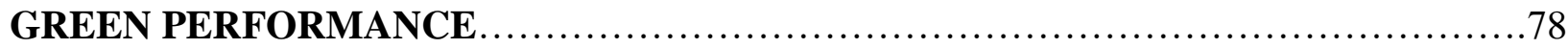

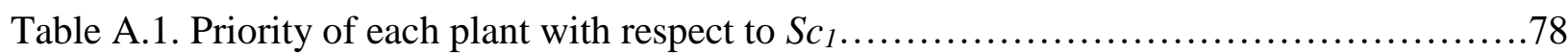

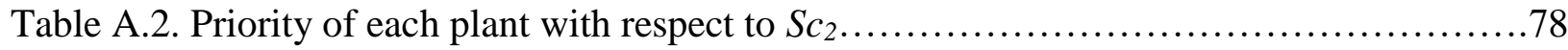

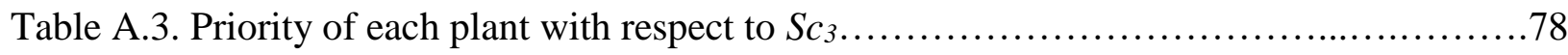

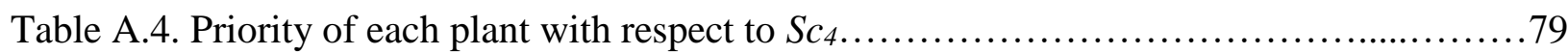

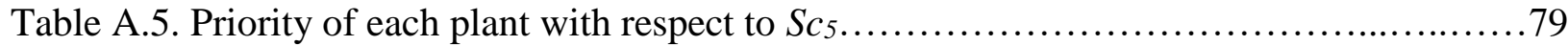

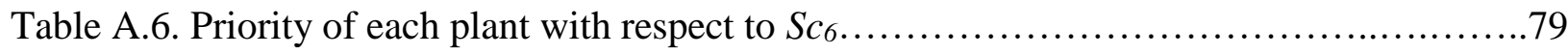

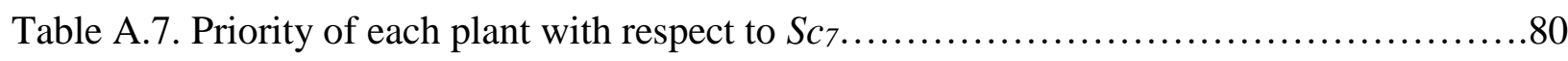

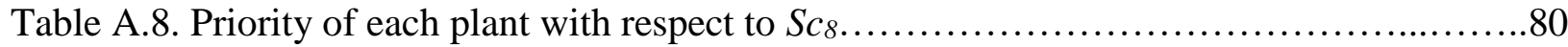

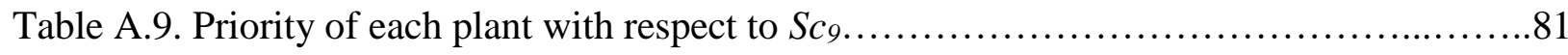

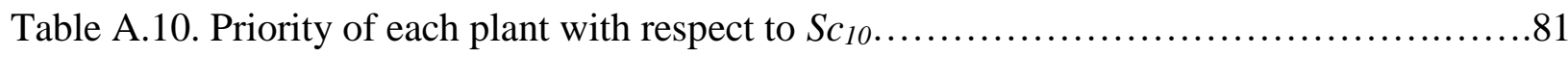

APPENDIX B. FUZZY ANP ANALYSES TO RANK THE BATTERY RECOVERY

CENTERS BASED ON THE GREEN PERFORMANCE .............................. 82

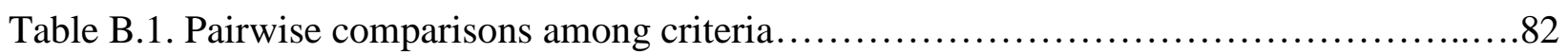

Table B.2.The inner dependence matrix and relative importance weight with respect to $C_{1} \ldots \ldots 82$

Table B.3.The inner dependence matrix and relative importance weight with respect to $C_{2} \ldots \ldots . .82$

Table B.4.The inner dependence matrix and relative importance weight with respect to $C_{3} \ldots \ldots .82$

Table B.5. The related priorities of the green performance criteria for battery recovery centers. 83

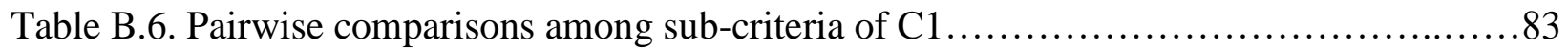

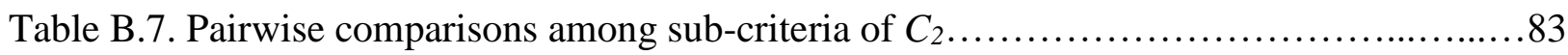

Table B.8. Pairwise comparisons among sub-criteria of $C_{3} \ldots \ldots \ldots \ldots \ldots \ldots \ldots \ldots \ldots \ldots \ldots \ldots$

Table B.9. Overall priority of the sub-criteria of green performance for potential battery recovery

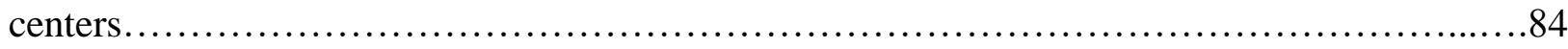

Table B.10. Priority of each battery recovery center with respect to $S c_{1} \ldots \ldots \ldots \ldots \ldots \ldots \ldots \ldots . \ldots . \ldots \ldots$

Table B.11. Priority of each battery recovery center with respect to $S c_{2} \ldots \ldots \ldots \ldots \ldots \ldots \ldots \ldots . .85$

Table B.12. Priority of each battery recovery center with respect to $S c_{3} \ldots \ldots \ldots \ldots \ldots \ldots \ldots \ldots \ldots . . \ldots 6$

Table B.13. Priority of each battery recovery center with respect to $S c 4 \ldots \ldots \ldots \ldots \ldots \ldots \ldots \ldots . . . .16$

Table B.14. Priority of each battery recovery center with respect to $S c_{5} \ldots \ldots \ldots \ldots \ldots \ldots \ldots \ldots . . . \ldots 7$

Table B.15. Priority of each battery recovery center with respect to $S c 6 \ldots \ldots \ldots \ldots \ldots \ldots \ldots \ldots \ldots . . .17$ 
Table B.16. Priority of each battery recovery center with respect to $S c_{7} \ldots \ldots \ldots \ldots \ldots \ldots \ldots . \ldots 8$

Table B.17. Overall priority of each battery recovery center with respect to each sub-criterion..88

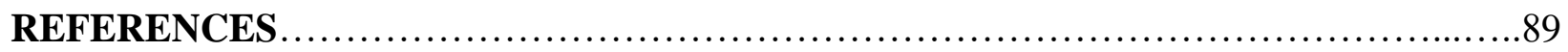




\section{LIST OF TABLES}

\section{CHAPTER 1}

Table 1.1. Vancouver wards along with their related population based on census $2011 \ldots \ldots \ldots \ldots 8$

\section{CHAPTER 2}

Table 2.1. Review of some mathematical programming approaches utilized in CLSCs modeling

\section{CHAPTER 3}

Table 3.1. Values of parameters that have been applied to solve the proposed model

Table 3.2. Solution for the proposed battery CLSC .31

Table 3.3. Comparison of 9 scenarios and scenario-based model.

\section{CHAPTER 4}

Table 4.1. The linguistic scale. .47

Table 4.2. Pairwise comparisons among criteria.

Table 4.3. The inner dependence matrix and relative importance weight with respect to Eco-

product design.

Table 4.4. The inner dependence matrix and relative importance weight with respect to Ecotechnology

Table 4.5. The inner dependence matrix and relative importance weight with respect to Green

purchasing.

Table 4.6. The inner dependence matrix and relative importance weight with respect to

Sustainable

packaging. .49

Table 4.7. The inner dependence matrix of green performance criteria......................49

Table 4.8. The related priorities of the green performance criteria.........................49

Table 4.9. Pairwise comparisons among sub-criteria of Eco-product design...................50

Table 4.10. Pairwise comparisons among sub-criteria of Eco-technology....................50

Table 4.11. Pairwise comparisons among sub-criteria of Green purchasing....................50

Table 4.12. Pairwise comparisons among sub-criteria of Sustainable packaging.................50

Table 4.13. Overall priority of the sub-criteria of green performance for potential plants. 
Table 4.14. Overall priority of each plant associated with each sub-criterion..................51

Table 4.15. Results of the fuzzy ANP method for the plants............................52

Table 4.16. Results of the fuzzy ANP method for the recovery centers.......................55

\section{CHAPTER 5}

Table 5.1. Values of some parameters applied to solve the proposed FFP model..............66

Table 5.2. Solution of the FFP model.............................................67

Table 5.3. Solution of FFP with regard to scenario-based analysis.........................69

Table 5.4. Optimal value of each fuzzy objective obtained separately subject to the defined

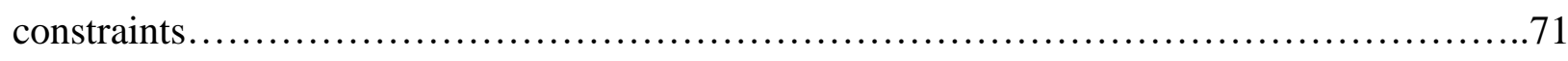

Table 5.5. Solutions for the 1 st and 2 nd objectives (middle values, distance method)..........71

Table 5.6. Solutions of the problem (middle values, $E$-constraint method) ...................73 


\section{LIST OF FIGURES}

\section{CHAPTER 1}

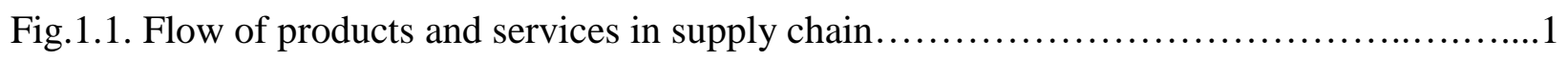

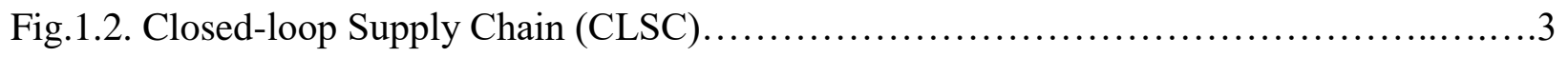

Fig.1.3. The recycling method of lead acid battery ....................................

Fig.1.4. Comparison of fuel price between Vancouver in BC and other area in Canada..........9

\section{CHAPTER 2}

Fig.2.1. Uncertain parameters......................................................20

\section{CHAPTER 3}

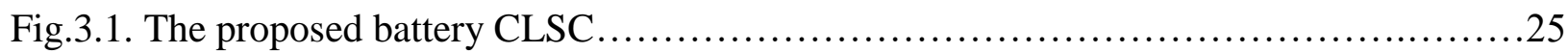

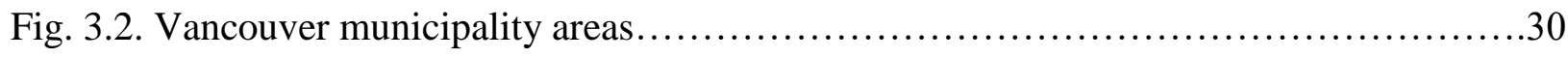

Fig. 3.3. Total expected profit of 9 scenarios and the scenario-based model....................35

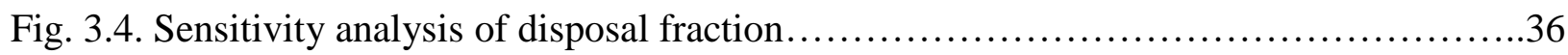

\section{CHAPTER 4}

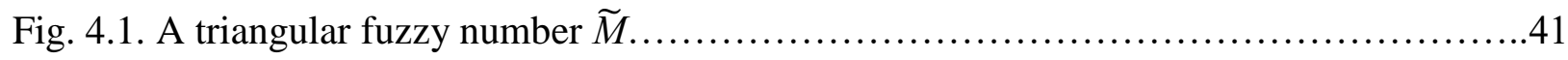

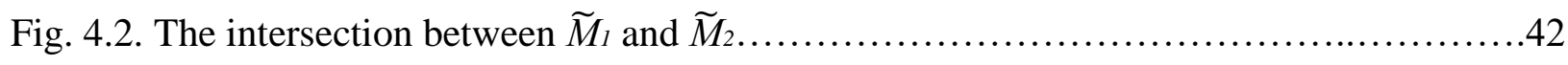

Fig. 4.3. The ANP model for prioritizing plants based on their green performance.............44

Fig. 4.4. Linguistic scale for relative importance....................................47

Fig. 4.5. Inner dependence between green performance criteria.........................48

Fig. 4.6. The ANP model for prioritizing recovery centers based on their green performance...53

\section{CHAPTER 5}

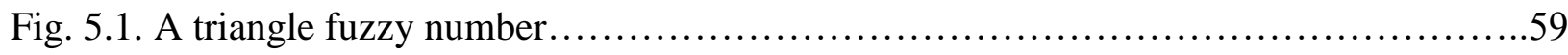

Fig. 5.2. Total expected profit of FFP with regard to scenario-based analysis..................69

Fig. 5.3. Trade-off surface for the middle values of the $1^{\text {st }}$ and $2^{\text {nd }}$ objectives..................72 


\section{LIST OF ACRONYMS}

Analytic Network Process (ANP)

Analytic Hierarchy Process (AHP)

Closed-Loop Supply Chain (CLSC)

Closed-Loop Supply Chain Management (CLSCM)

Environmental Protection Agency (EPA)

Fully Fuzzy Programming (FFP)

Green Closed-Loop Supply Chain Management (GCLSC)

Green Supply Chain Management (GSCM)

High Temperature Metal Reclamation (HTMR)

International Standards Organization (ISO)

Mixed-Integer Linear Programming (MILP)

Mixed-Integer Non-Linear Programming (MINLP)

Multi-Objective Linear Programming (MOLP)

Net Present Value (NPV)

Multi-Criteria Decision Making (MCDM)

Possibilistic Linear Programming (PLP)

Quality Function Development (QFD)

Returns On Investment (ROI),

Return On Asset (ROA)

Reverse Supply Chain (RSC)

Supply Chain Management (SCM)

Sealed Lead Acid (SLA).

Triangular Fuzzy Numbers (TFNs) 


\section{CHAPTER 1}

\subsection{Introduction}

Nowadays, companies are more enthusiastic about considering a variety of strategies related to supply chain management (SCM). Supply chain is a multi-echelon network creating relationships between multiple businesses (Lambert et al., 1998). In the competitive global market, competition occurs among supply chains. For such reasons, companies are supposed to manage their relationships with others existing in the same supply chain. Furthermore, potential benefits of SCM such as improvement in returns on investment (ROI), and return on asset (ROA) are other logical reasons to consider SCM by organizations. Therefore, improvement of SCM leads to more probable profits for all entities taking part in supply chain. These are a great number of advantages (including lower inventory level, reduction of demand's uncertainties, shorter lead time) stem from development of SCM.

\subsection{Business definition of SCM}

As indicated by Fig.1.1, SCM can be defined as the planning, managing, executing and analysing of all activities comprising of procurement, production, research and development, customer service, marketing, sale, purchasing, and logistic through the collaboration of suppliers, producers, intermediaries, and customers with the view of creating value.

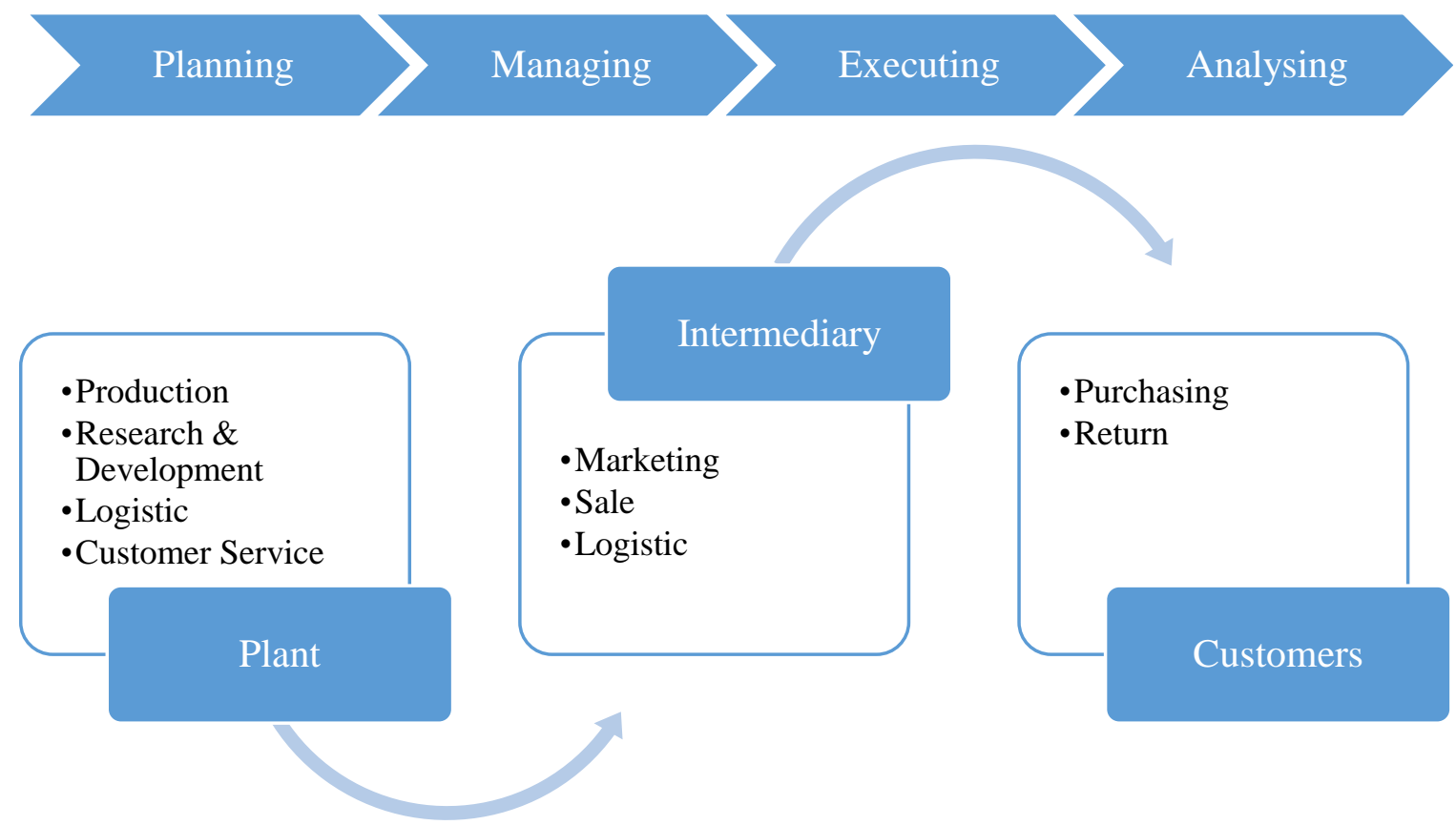

Fig.1.1. Flow of products and services in supply chain 


\subsubsection{Scope of supply chain}

The scope of supply chain can be identified in terms of the number of firms, products, and activities involving in supply chain. SCM is defined as the integration of all efforts associated with fulfilling the market's demand through the transferring goods and services from the first stage to the end user. Such efforts may include management, procurement, production, inventory management, order processing, transportation, and customer service (Cooke, 1997). SCM may also entail collaborative activities between chain members such as operation management, research and development, product design, and marketing research (Mentzer, 1993).

\subsubsection{Objectives of SCM}

The objectives of SCM can be defined as the efficient usage of resources to satisfy customer's demand, matching product's specification with customer's expectation, reducing the holding inventory and work-in-process (WIP) with the aim of building competitive advantage for supply chain (Cooper, 1993; Cavinato, 1991; Houlihan, 1985).

\subsubsection{Distinguishing SCM from logistic management}

Logistic typically refers to the activities occurring under the supervision of a single organization such as production planning and transportation, while supply chains refer to the coordination of companies collaborating with each other to deliver a product to customers such as planning, implementing, and controlling of the networks.

\subsubsection{The reverse supply chain (RSC)}

The RSC (including activities related to collection and recovery of returned products) has emerged as a necessary part of business on account of environmental issues and economic aspects. Under the British Columbia recycling regulation (environmental management act), producers are not allowed to sell battery in province unless they take part in a stewardship plan consisting of free collection and recycling of used batteries. Remanufacturing of returned product makes impact on saving natural resources, and reduces the environmental issues. 


\subsubsection{Implication of closed-loop supply chain (CLSC)}

The CLSC has been emerged to consider returned products for the purpose of recovering added value by remanufacturing or recycling the whole products or some of their subassemblies. The business definition of CLSC is to make the best use of value creation over the entire life cycle of a product with dynamics recovery of value from different types and volumes of return over time during the design, control, and operation of a system (Guide et al., 2003). As shown by Fig.1.2, the CLSC is comprised of forward and reverse flows. Forward flow consists of all actions that result in the transformation of raw materials to finished products. In the forward supply chain, facilities receive raw materials from suppliers, and manufacture the products to send to retailers. Thereafter, retailers are responsible to fulfill market's demand and hold some of the products as the inventory for the next periods. Activities of the collection and recovery of the returned product in supply chain management (SCM) are classified under the RSC. Therefore, the integration of the forward and reverse flows in supply chain creates the CLSC.

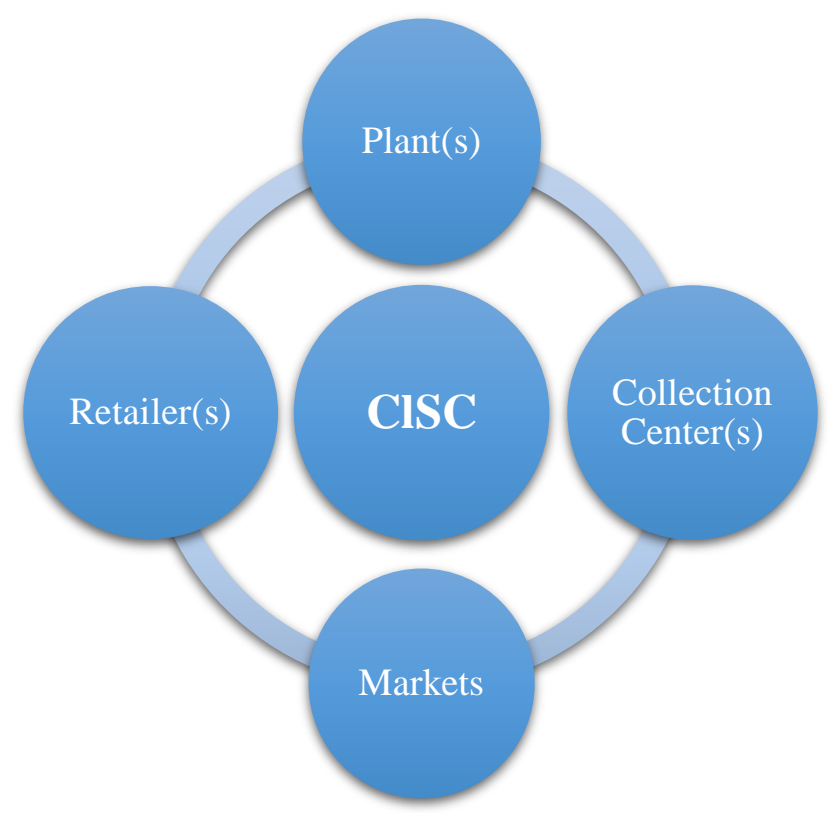

Fig.1.2. Closed-loop Supply Chain (CLSC)

There is a significant profit associated with CLSC due to the value recovery of the returned product. In SCM, economic aspects have been considered as a single objective, while in closedloop supply chain management (CLSCM) both economic and environmental aspects are emphasized. 
Customers may return products to the supply chain in account of different reasons including commercial return, end of use return, end of life return, repair and warranty return over the product life cycle. Therefore, CLSC should comprise of all activities related to product recovery consisting of returned product acquisition, product disassembly, remanufacturing and remarketing. In this sense, market's demand for remanufactured product, cost of remanufacturing and accessibility to returned product are three elements influencing the profitability of CLSC.

In this thesis, it is intended to design a battery CLSC in Vancouver, Canada. In this field, there is a stewardship organization named Call2Recycle Canada, Inc. committed to collect and recycle used batteries at no cost for consumers. Based on their official announcement published in call2recycle.ca, more than 4.5 million $\mathrm{kg}$ of batteries were collected in 2012. They aim to bring together battery and electronics industries, businesses, consumers, government agencies, non-profit organizations, and retailers for the purpose of minimizing the environmental impacts of batteries at the end of their lives.

\subsection{Battery recycling}

Call2Recycle has been recognised as the premier product stewardship organization in North America. According to their vision, protecting the environment is their main objective by managing the product life cycle and setting environmental standards for processing and material management. Call2Recycle hires independent third-party auditors to assure that process of collecting material through its program comply with assigned standards. Call2Recycle does not believe that just collecting battery is good enough, besides it is important to optimise the recycled portion of used battery in making a new product.

The most elements of batteries depending on type of battery (including Carbon, Iron, Lithium, Manganese, Sulphur, Zinc) can be used in making new batteries and the remainder, which is less than1 percent, can become slag as the input for roads construction.

\subsubsection{Importance of battery recycling}

There is a great deal of concern associated with battery recycling on account of incremental demand by households, and industries as their power resources. Hence, it is supposed to have a comprehensive plan to collect used batteries; otherwise left batteries in environment may harm humans and habitat due to comprising of toxic materials. Although there is no threat to human 
health associated with battery's usage, it will become dangerous when it is discarded improperly or ended up in landfills due to spreading out its chemical material into soil and groundwater.

\subsubsection{The different types of batteries and related recycling method}

Batteries are mostly categorized as the electrochemical devices made of Anode, Cathode, Electrolyte, Separator, and Case. Characteristic of each type of battery can be defined as the utilization of materials for electrolyte, electrodes, etc. For instance, separator and external cases are usually made of polymeric materials and steels, while the other parts such as electrodes and electrolytes are varied in different types of batteries.

Batteries are divided in two main categories of disposable and rechargeable in different common sizes of AAA, AA, C, D, 9V, coin cell, button cell, and sealed lead acid (SLA). Alkaline, Lithium, Silver-oxide, Zinc-carbon are the main types of disposable batteries, while Lead-acid, Lithium ion, Nickel-metal hybrid (NiMH), Nickel-zinc (NiZn) are categorized as the rechargeable batteries.

\subsubsection{Alkaline battery}

Alkaline batteries are obtained their names due to the usage of potassium hydroxide (Alkaline) as the electrolyte along with zinc powder as the anode, and manganese dioxide as the cathode. The Alkaline batteries provide almost 4 to 5 times more energy compared to zincchloride batteries with the same size. The typical voltage of Alkaline battery is $1.5 \mathrm{~V}$. This type of battery is the most common type designed for different appliances in various cylindrical shapes.

Alkaline batteries in different sizes of AAA, AA, C, D, 9V can be 100 percent recycled and reused in new products. The returned alkaline batteries are separated into different components of zinc, manganese, potassium, steel, nickel, and plastic. The first three components of zinc, manganese and potassium are utilized as a premium micro-nutrient to grow corn. Furthermore, 100 percent of the nickel and steel used in returned alkaline batteries can be recycled (RMC Technology). 


\subsubsection{Zinc-carbon battery}

This type of battery comprises of a carbon rod as the cathode in a mixture of manganese dioxide and carbon powder packed in a zinc container as the anode. This type of battery is durable with voltage value of $1.5 \mathrm{~V}$. Since zinc-carbon battery has cheaper price than the other common types of batteries in the market, electronic appliances are lunched to the market with these batteries.

The zinc-carbon batteries can be also recycled the same as Alkaline batteries or by utilizing high temperature metal reclamation (HTMR) method.

\subsubsection{Lead-acid battery}

Lead-acid batteries are used in automobiles for the purpose of fulfilling the high current needing for the heavy motors. The other form of such battery known as wet cell battery has been applied for backup power supply and portable emergency light.

As illustrated by Fig.1.3, 99 percent of vehicle batteries can be recycled and reused for the purpose of making new lead-acid batteries and other products such as cleaners. In this way returned lead-acid batteries are disassembled to lead, plastic, and battery acid. The lead and heavy materials are gathered and shaped to lead ingots which are then melted down to produce lead plates using for new battery. Similarly, plastic cases can be remanufactured for new battery, while the returned battery acid is converted to sodium sulphate using in detergent.

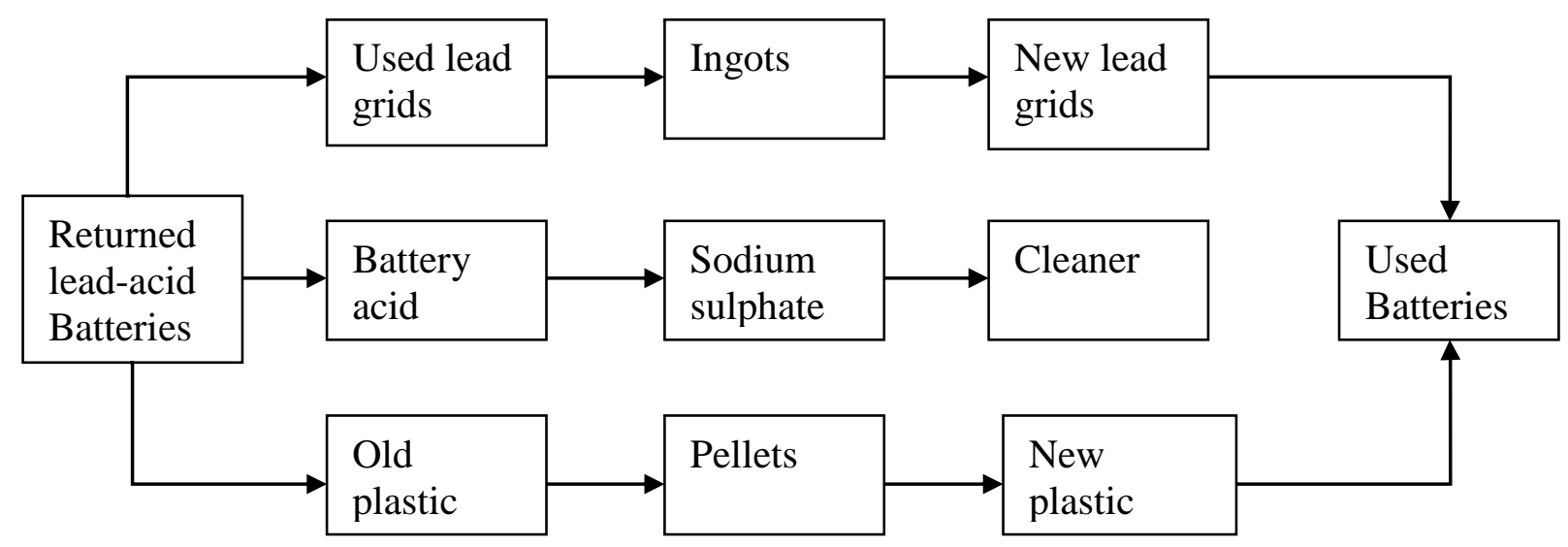

Fig.1.3. The recycling method of lead acid battery adopted from (how are batteries recycled, 2017). 


\subsubsection{Mercury battery}

Mercury battery is a type of non-rechargeable battery including mercuric oxide and zinc oxide in an alkaline electrolyte. Such type of battery is less popular due to low output of voltage and usage of mercury which is toxic and harmful for humans. Mercury battery was produced in a shape of button cell for cameras, calculators, and watches. The metal used in such type of battery can be recovered by controlled-temperature process. Since the passage of Mercury-Containing and Rechargeable Battery Management Act in 1996, production of batteries using mercuric oxide has been decreased.

\subsubsection{Lithium battery}

Lithium batteries are in the category of batteries with capability of producing voltages in the range of 1.5 to $3.2 \mathrm{~V}$. Therefore, the voltage production of such type of battery can be almost two times more than zinc-carbon and alkaline batteries. They comprise metallic lithium as the anode and cathode. Although lithium batteries are more expensive, they can be used in place of alkaline battery in various appliances such as clocks, and cameras due to the longer life.

The lithium batteries are disassembled by using shredder. The contents are submerged in caustic water; thereafter metals are separated from caustic solution, and sent to recyclers. Continuously, lithium can be recycled from filter solution which may be used to produce lithium ingot.

\subsubsection{Lithium ion batteries}

Lithium ion battery is one of the most popular types of rechargeable battery for portable electronics. They are generally lighter than other types of rechargeable batteries. The electrode of lithium ion battery includes the lightweight lithium and carbon compared to the metallic lithium utilizing in non-rechargeable lithium battery. The metal used in this type of battery can be recycled 100 percent through HTMR method.

\subsubsection{Silver oxide batteries}

This type of battery includes zinc as the anode and silver oxide as the cathode with alkaline electrolyte (either potassium hydroxide $(\mathrm{KOH})$ or sodium hydroxide $(\mathrm{NaOH})$ ). Although silver 
oxide batteries are more expensive than alkaline batteries, they are more durable and have been designed for watches and calculators in small sizes, and for military applications in larger sizes.

\subsection{Market's real locations}

In this thesis, it is aimed to assume real locations for potential plant(s), retailer(s), markets, and collection center(s) with the aim of estimating real distances affecting the transportation cost. According to the official website of Vancouver, areas of the city are divided to 22 wards which are indicated in Table 1.1 (Areas of the city, 2017). Furthermore, the population of each ward can be applied for estimating the market's demand.

Table 1.1.

Vancouver wards along with their related population based on census 2011

\begin{tabular}{|l|c|l|c|}
\hline 1. Downtown & 54,690 & 12. Shaughnessy & 8,810 \\
\hline 2. West End & 44,540 & 13. South Cambie & 7,680 \\
\hline 3. Strathcona & 12,165 & 14. Riley Park & 21,795 \\
\hline $\begin{array}{l}\text { 4. Grandview- } \\
\text { Woodland }\end{array}$ & 27,305 & $\begin{array}{l}\text { 15. Kensington-Cedar } \\
\text { Cottage }\end{array}$ & 47,470 \\
\hline $\begin{array}{l}\text { 5. Hastings- } \\
\text { Sunrise }\end{array}$ & 33,990 & $\begin{array}{l}16 . \text { Renfrew- } \\
\text { Collingwood }\end{array}$ & 50,500 \\
\hline 6. Mount Pleasant & 26,400 & 17. Kerrisdale & 14,735 \\
\hline 7. Fairview & 31,440 & 18. Oakridge & 23,440 \\
\hline 8. Kitsilano & 41,375 & 19. Marpole & 36,290 \\
\hline 9. West Point & 12,795 & 20. Sunset & 30,710 \\
\hline Grey & 21,745 & 21. Victoria-Fraserview & 28,455 \\
\hline 10. Dunbar & 15,910 & 22. Killarney & \\
\hline 11. Arbutus-Ridge & & & \\
\hline
\end{tabular}




\subsection{Unit price transportation cost}

As illustrated by Fig.1.4, there is a significant difference between average retail price for gasoline in Vancouver and other area in Canada. The average price of gasoline in Canada was 119.03 cents per litre between January 2016 to January 2017 with a minimum of 105.9 cents on February 2016, and a minimum of 128.3 cents per litre on October 2016. As indicated by Fig.1.4, there is a significant fluctuation in gasoline price during 2016. Therefore, it will not rational to assume a specific unit transportation cost per kilometre for our proposed model. In this sense, it is aimed to apply possibilistic programming method in order to have a realistic model.

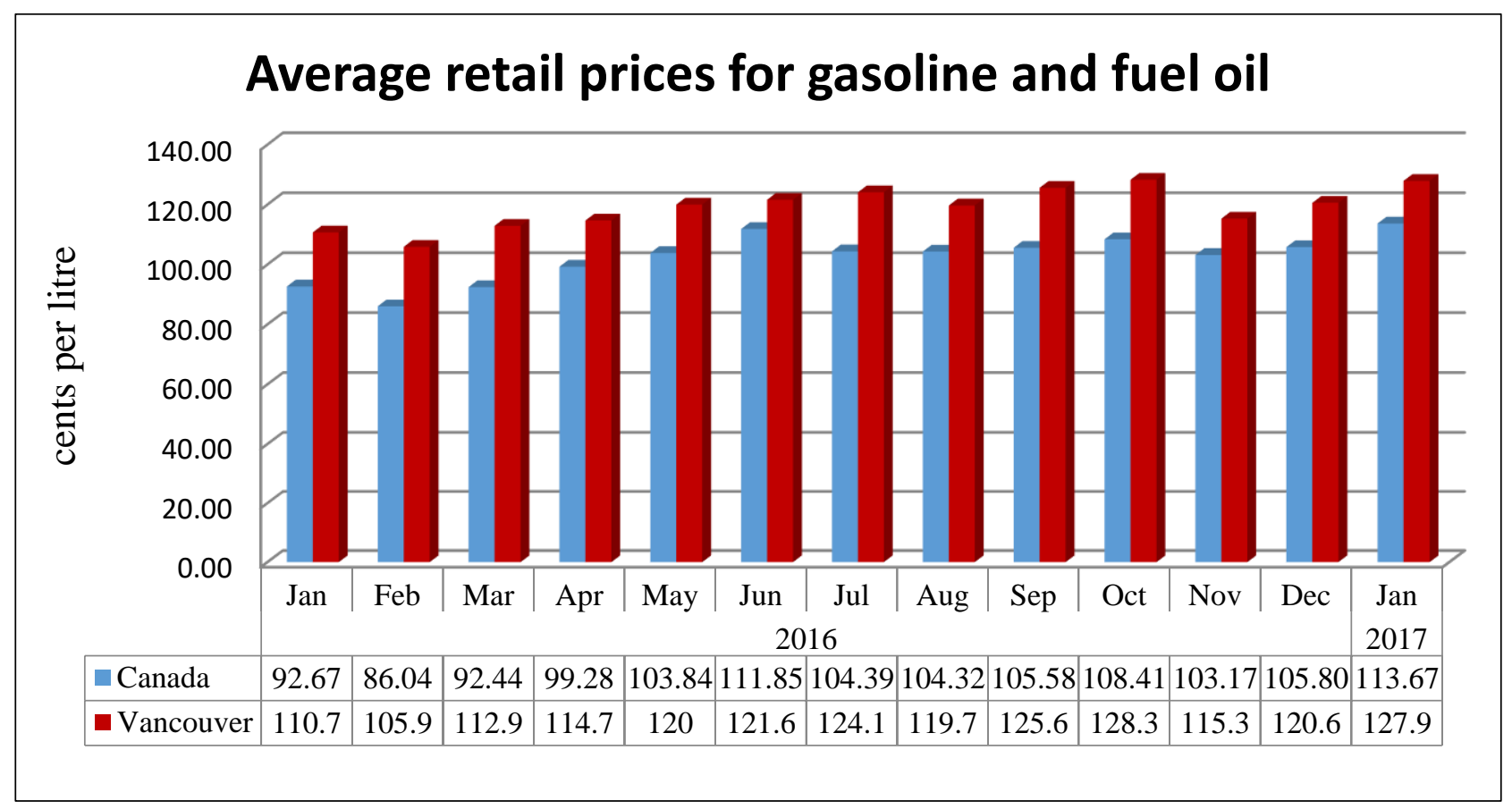

Fig.1.4. Comparison of fuel price between Vancouver in BC and other area in Canada.

(Data is adopted from Statistics Canada, 2017)

\subsection{Problem statement}

Decision makers are supposed to deal with a variety of ambiguities associated with profitability of CLSC. Market's demand is the most important factor affecting both cost and profit of CLSC. If there is no volatility in demand, market's behaviour will comply with a specific trend. Then, decision makers are free to set up optimised policy for supply chain in aspect of inventory level. However, often there is too much imprecise information which does not allow decision makers to establish a stable method to deal with market's demand in real-life. 
Furthermore, some other factors also influence the policy implementing in CLSC in aspects of production and inventory levels such as back order cost, remanufacturing cost, and disposal cost. The other prominent factor is a collection rate of the returned products which has massive impact on profit of CLSC. However, collecting of returned batteries is irregular, and decision makers are not able to forecast the receiving of used batteries.

Unit transportation cost is one of the main elements of variable costs incurred in CLSC. It is mostly related to economic factors such as oil price and inflation rate. In addition, transportation cost is one of those factors which affects the relation between producers and retailers in aspect of meeting customers' demand.

Accordingly, it is tried to apply possibilistic approach to interpret the behaviour of the proposed CLSC under uncertainties in aspect of fluctuation in market's demand, returned product, and volatility of transportation cost.

In this thesis, it is aimed to answer the following questions:

- Which supplier(s) should be chosen?

- Which location(s) should be chosen for plant(s)?

- Which retailer(s) should be chosen?

- Which battery recovery center(s) should be assumed to collect the used batteries?

- How many components should be purchased from each supplier?

- How many products should be produced by plants, held by retailers, and sold to the markets in the proposed CLSC?

\subsection{Aim and research contributions}

In this thesis, a multi-objective CLSC model is introduced for battery recycling under uncertainty of demand, return, selling price, and the cost associated with purchasing raw materials, transportation, production, inventory, disposal (variable costs), opening plant, retailer, and battery recovery center (fixed costs). Hence, it is aimed to maximize the total profit as the $1^{\text {st }}$ objective, and to consider green performance of plants and battery recovery centers as the $2^{\text {nd }}$ objective. It is intended to apply real transportation cost to evaluate the effects of uncertainty and volatility in fuel price. For such reasons, fuel consumption rate obtained from the fuel consumption guide (Natural Resources Canada, 2014), and monthly average retail price of gasoline in Vancouver for 2016-2017 are considered. In author's view, this study is the first 
examination that considers a battery CLSC network in Vancouver. Initially, a deterministic model is introduced for a battery CLSC. The proposed model is considered for a multi-echelon, multi-components, multi-products CLSC in multiple periods. Thereafter, scenario-based analysis is applied to evaluate the deterministic model under different scenarios of alteration in market's demand and returned products. In order to develop the model, fuzzy ANP is utilized to consider the green performance of plants and battery recovery centres.

To deal with uncertainty, FFP method is developed and utilized to calculate the triangular fuzzy profit, and green performance separately. Accordingly, it is tried to find the trade-off surface of solution for those objectives through the distance technique and $E$-constraint method. The proposed methodology can be helpful to determine the best CLSC network under imprecise information.

The research contributions of this thesis are introduced as follows:

- Designing and examining CLSC network of battery in Vancouver with regard to the related organizations in Canada.

- Application of scenario-based analysis to develop the proposed model under the risk of unexpected changes in demand and return.

- Employing Fuzzy ANP to convert the qualitative factors to the quantitative parameters.

- Application of fully fuzzy programming (FFP) method to evaluate the impacts of several sources of uncertainty on CLSC network simultaneously. Since, the configuration of battery CLSC may be applied for making strategic decision and it is impossible to change in a short-term, it is necessary to consider all possible optimal range of decision variables and objective function.

- Employing the combination of possibilistic (fuzzy) and scenario-based analysis to involve more one alternative for lower, middle, and upper range of demand and return.

- Utilization of distance technique and $E$-constraint method to determine the tradeoff surface of solution.

- Assuming real distances in the proposed multi-echelon CLSC through Google Maps for estimating real transportation cost. 


\subsection{Research methodology}

In this section, some methods that are applied in this thesis are described.

\subsubsection{Mixed-integer linear programming (MILP)}

MILP is usually applied to optimize linear objective function with respect to linear constraints. In this approach, variables participating in objective function and constraints are categorized as non-negative variables, integer variables, and binary variables.

\subsubsection{Multi-objective linear programming (MOLP)}

MOLP can be applied in various fields of engineering, economics, and science when it is required to optimize more than one objective function simultaneously. However, the different objectives are not usually homogenous leading to difficulties for integration. Such type of programming will provide a set of solutions that are called Pareto optimal solutions instead of unique solution. Deb et al. (2008) categorized the process of multi-objective optimization into three phases; building the model, optimization, and making decision.

Here is the mathematical development of the mono-objective (1.1) to the multi-objective optimization (1.2). Instead of one objective function $f(\vec{x})$, there are multiple objectives in (1.2) which are shown by $\vec{f}(\vec{x})$.

Minimize $f(\vec{x})$

Subject to.

$$
\begin{aligned}
& \vec{g}(\vec{x}) \leq 0, \\
& \vec{h}(\vec{x})=0
\end{aligned}
$$

$$
\text { Minimize } \vec{f}(\vec{x})
$$

Subject to.

$$
\vec{g}(\vec{x}) \leq 0,
$$$$
\vec{h}(\vec{x})=0
$$

$$
\vec{k}(\vec{x}) \leq 0,
$$

\subsubsection{Fuzzy analytic network process (FANP)}

FANP is a method of measurement based on experts' judgment under uncertainties. Preferences of human for making decision in many real situations is uncertain. Therefore, applying exact numerical values for comparison can be unfavourable. On the other hand, evaluation of factors may be influenced by characteristics of the decision makers (Nilashi et al., 2016). For such reasons, fuzzy methods can be applied in the process of making decision. In this 
thesis, FANP (which is the extension of ANP method in the case of fuzziness) is considered for ranking the potential plants and battery recover centers based on green performance.

\subsubsection{Fully fuzzy programming (FFP)}

There is often imprecise information in real life particularly in CLSC under uncertainties. Therefore, fuzzy numbers and variables should be applied in modeling CLSC. In this way, there are a variety of methods to deal with uncertainty as follows:

- Verdegay approach which can be applied for linear programming with fuzzy resources.

- Zimmermann approach which can be utilized for programming with fuzzy objective.

- Fuzzy integer programming which can be used for programming with fuzzy resources and objective.

- FFP method which can be employed for programming with fuzzy resources, objective, and decision variables.

In this thesis, it is intended to apply FFP method to interpret the proposed CLSC under uncertainty of demand, returned product, transportation cost, and other related cost to manufacturing process such as production cost, and holding inventory cost.

\subsubsection{Scenario-based analysis}

It is intended to employ the scenario-based analysis for finding a solution with respect to any probable circumstances of random parameters. Rosenhead et al. (1972) categorized the environment of decision making to certain, uncertain, and risky situations. In certain situation, all parameters are deterministic, while there is imprecise information in both risky and uncertain situations. In risky situation, uncertain parameters comply with probability distributions which are known by decision makers, but in uncertain situation parameters are unknown and there is not enough information about the probability distribution of them. Scenario-based analysis is applied for risky situation for the purpose of optimizing the expected value of the objective function. In this thesis, it is aimed to maximize profit with regard to any possible changes in market's demand, and returned product. 


\subsection{Organization of the thesis}

Chapter I was commenced with the introduction of some basic information about background of CLSC, battery recycling and stewardship plan, market's location, problem statement, and thereafter research objectives and methodology were explained, respectively. Chapter II includes the review of related literatures. In Chapter III, a deterministic model is introduced for a battery CLSC network, and thereafter scenario-based analysis is utilized. In Chapter IV, the fuzzy ANP method is utilized to convert the qualitative factors to the quantitative parameters. In Chapter V, FFP algorithm is defined comprehensively and applied for the proposed battery CLSC network. To solve the proposed multi-objective model, each fuzzy problem is solved separately, and then distance method along with $\mathcal{E}$-constraint method are applied to address the multi-objective model. In Chapter VI, conclusions of this thesis along with future works are discussed. 


\section{CHAPTER 2. REVIEW OF LITERATURE}

\subsection{Introduction}

In this chapter, several papers and methodologies related to RL and CLSC are reviewed. Since it is aimed to evaluate decision making in certain, uncertain, and risky situations in this thesis, MILP, stochastic (scenario-based analysis), and fuzzy programming are chosen as the main fields. Accordingly, related studies for designing the deterministic model are discussed in Section 2.2. Thereafter, review of some investigations including multi-objective models are classified in Section 2.3. Applications of stochastic programming (scenario-based analysis) in CLSC are discussed in Section 2.4. In addition, several studies associated with utilization of fuzzy programming are provided in Section 2.5.

\subsection{Deterministic models applied in CLSC}

There are a variety of studies associated with RL and CLSC configuration. Designing a deterministic model for facility locations has been applied in the most cases. Jayaraman et al. (1999) employed MILP to determine the location of remanufacturing and distribution centres along with optimal numbers of products to be produced, transported, and held as the inventory. Fleischmann et al. (2001) configured CLSC with regard to forward facility locations. They applied copier remanufacturing example to evaluate the accuracy of the proposed CLSC. Kim et al (2006) introduced mathematical model for a CLSC to maximize the profit. Ko and Evans (2007) utilized MILP model for a multi-product, multi-period, two-echelon network included forward and reverse flows at the same time. Wang and Hsu (2010a) examined the integration of forward and reverse flows for generalized CLSC by application of MILP. Achillas et al. (2010) used MILP to optimize RL network due to increase of waste in the electronic industry. Sasikumar et al. (2010) designed a multi-echelon RL network for a case study of truck tire. They employed MINLP to maximize the profit of the proposed model.

Fahimnia et al. (2013) developed an integrated mathematical model for environmental CLSC in which carbon emission was represented by dollar carbon cost. MILP was applied to formulate the proposed multi-product, multi-period CLSC for the purpose of minimizing the total cost of manufacturing, transportation, and carbon cost.

Cardoso et al. (2013) applied MILP for planning the supply chain combined by reverse logistic activities. They also utilized scenario tree method to deal with uncertainty of demand for 
the purpose of maximization of expected net present value related to discounted cash flows. Oh and Jeong (2014) considered CLSC configuration in fashion industry on account of increasing usage of synthetic fiber leading to growth of $\mathrm{CO}_{2}$ emission. They employed multi-objective MILP to find the optimal trade-off between CLSC profit and $\mathrm{CO}_{2}$ emission. Hashemi et al. (2014) applied MILP to maximize the total profit of a CLSC in aerospace industry. Kalaitzidou et al. (2105) proposed a general mathematical model for multi-echelon, multi-product CLSC network. They applied multi-period MILP to minimize the operational cost.

Amin et al. (2017) examined a CLSC network concentrated on a tire remanufacturing. The reason why they considered such case was high incentive of tire remanufacturing due to profit and responsibility for protecting environment. They aimed to maximize the total profit of the proposed model comprised of multiple products, suppliers, plants, demand markets, and collection centers in multiple periods. They also applied decision-tree methodology to calculate net present value (NPV) of the problem in case of uncertainty in demand and returns of tires by customers based on a realistic network in Toronto, Canada. Özceylan et al. (In press) examined CLSC in automotive industry, since a great number of manufacturers are supposed to collect and recycle their end-of-life products. They employed deterministic linear programming to address their multi-echelon, multi-products, multi-period model. Similarly, Shimada and Wassenhove (In press) considered the effects of recycling law on CLSC in home appliances and computer industry in Japan.

Al-salem et al. (2016) employed an MINPL to minimize the total cost of forward and reverse supply chain. The non-linear objective function was linearized by performing the piecewise method. According to their findings, significant cost saving can be achieved as result of integration the forward and reverse flows which leads to CLSC. Kaya and Urek (2016) applied MINLP to maximize the profit in CLSC. They also developed heuristic for the solution of their proposed multi-echelon model. Kisomi et al. (2016) proposed an integrated model considering robust optimization theory in account of addressing uncertain environment related to supply chain configuration and supplier selection. They compared the obtained results with deterministic model, and utilized sensitivity analysis in order to validate their proposed multiechelon, multi-product, and robust model. 


\subsection{Multi-objective models for CLSC}

Nowadays, applications of multi-objective models seem inseparable with formulation of CLSC networks due to the importance of environmental issues. Sheu et al. (2005) presented a multi-objective model for green supply chain. Return ratio of used product and related governmental subsidies were considered to formulate RL. Das and Posinasetti (2015) presented mathematical model integrated with environmental concerns for multi-product CLSC. They aimed to maximize profit with regard to optimization of consumed energy and harmful emission. The multi-objective model was solved by goal programming.

Shakourloo et al. (2016) applied a multi-objective integer linear programming along with fuzzy analytic hierarchy process (AHP) to examine their proposed CLSC. They aimed to optimize the number of products providing by suppliers along with number of returned products required to be remanufactured. Ruimin et al. (2016) utilized a robust multi-objective MINLP to examine environmental CLSC under uncertainty of demand and cost parameters in the realistic network. They intended to minimize the total cost and environmental impacts of CLSC simultaneously in the proposed multi-objective model.

Talaei et al. (2016) utilized MILP to design a closed-loop green supply chain network with regard to environmental issues such as rate of carbon dioxide emission. In addition, they examined their proposed model under uncertainty of demand and variable cost by utilizing a robust fuzzy programming. Mohammed et al. (2017) proposed a multi-period, multi-product CLSC model with the aim of minimizing the total cost and carbon emission. Robust optimization approach was applied to address uncertainties. Chen et al. (2017) believed that reducing carbon dioxide emission should be prioritized in implementing the sustainable strategy in a CLSC. For such reasons, two objectives comprising total cost and reducing carbon emission were determined for the proposed multi-objective CLSC. A deterministic mixed-integer programming (MILP) was applied as the methodology for the proposed model. According to their findings enterprise should use an appropriate recycling strategy to reach an efficient economic situation in case of applying the carbon emission regulation. Xu et al. (2017) introduced a novel global reverse supply chain emphasizing the uncertainty of waste collection, carbon emission, and some issues existing in global supply chain such as exchange rate and transportation cost. Mixed integer-linear programming and robust optimization were applied to address a multi-echelon, multi-product, multi-period model. 


\subsection{Stochastic programming (scenario-based analysis) in CLSC}

To design CLSCs, stochastic programming can be employed in optimization models to deal with imprecise information when probability of each scenario is known. Hu and Bidanda (2009) utilized stochastic dynamic programming to design a network based on product life cycle. They aimed to determine the optimal strategy to maximize the total profit of the proposed model.

Paksoy et al. (2011) proposed an optimization model to examine the efficiency and environmental practices in a multi-product CLSC. Stochastic programming was utilized to investigate the trade-off solution in a proposed realistic network. Amin and Zhang (2013) introduced three-stage model for CLSC. In the first step, quality function development (QFD) was applied to evaluate suppliers and remanufacturing centers. Furthermore, fuzzy sets theory was utilized to deal with uncertainty in the process of decision making. In the second step, stochastic mixed-integer non-linear programming was employed to design the CLSC network with regard to uncertain demand. In the third step, multi-objective MILP was used to identify the trade-off solutions between the total cost, importance of facilities (suppliers, refurbishing, and remanufacturing centers), defect rate, and on-time delivery.

Litvinchev et al. (2014) discussed about designing an RL network including locations of distribution and inspection centers along with remanufacturing facilities. They employed stochastic programming to formulate a multi-product CLSC with respect to scenario-base demand. Zeballos et al. (2014) utilized stochastic programming for a multi-period, multi-product CLSC. Multiple scenarios were assumed to consider the effects of uncertain demand and raw material supplies. In the proposed model, a scenario tree approach was applied to indicate all possible discrete events. Each node of scenario tree represented a possible outcome estimated by given probability. Francie et al. (2015) employed stochastic programming for a printer cartridge CLSC. They aimed to minimize the total cost incurred by occurrence of waiting customers and holding inventories related to the finished and returned products. Vahdani and mohammadi (2015) introduced a bi-objective optimization model for the purpose of minimizing the total cost and waiting time in the queue. They applied a hybrid solution method according to stochastic programming and robust optimization to deal with uncertainty in the model.

Soleimani et al. (2016) believed that an integrated approach is necessary for designing and planning decision levels to achieve the best performance of CLSC. They also said that real markets can be unpredictable in the case of demands and products' price. An MILP was applied 
for a multi-product, multi-period CLSC in order to deal with stochastic demand and products' price. Dutta et al. (2016) introduced a recovery model for a multi-period CLSC with the aim of improving rate of returned products by utilizing the buy-back offer. They applied chance constrained programming to convert the probabilistic demand constraints to the deterministic equivalents. Zhalechian et al. (2016) designed a sustainable CLSC with regard to economic, environmental, and social aspects. They considered $\mathrm{CO}_{2}$ emission, fuel consumption, and wasted energy as the environmental issues, creating job opportunities as the social aspects, and economic growth rate. The stochastic-possibilistic programming was applied to address uncertainty of the proposed CLSC. Keyvanshokooh et al. (2016) proposed a profit optimization model for CLSC network by considering the economic, environmental, and social concerns. They developed a hybrid robust-stochastic programming method to deal with two different types of uncertainties comprised of stochastic scenarios for transportation costs along with multi-level uncertainty of demand and return.

Feitó-Cespón et al. (2017) employed a stochastic programming along with a multi-criteria programming for the purpose of considering various objectives to deal with uncertainty in a sustainable supply chain network. They also proposed a performance indicator with the aim of evaluating the obtained solution and reducing the effects of uncertainty on decision making. Jeihoonian et al. (2017) applied a two-stage stochastic mixed-integer programming to address uncertainty of returned products quality in CLSC. A scenario reduction method was utilized to cope with several scenarios existing in their proposed model. Thereafter, they used L-shaped algorithm and Pareto-optimal cut to solve the reduced stochastic problem.

\subsection{Fuzzy programming in CLSC}

There are several studies that have considered fuzzy programming to deal with uncertainties. In this sense, different fuzzy methods (e.g., Verdegay approach, Zimmermann approach, fuzzy goal programming, fuzzy intervals, and fuzzy integer programming) have been employed. In the

case of nondeterministic approaches, some parameters are assumed to be uncertain. As illustrated in Fig.2.1, demand and return have been assumed as uncertain parameters in the most studies due to the significant contributions to the profit of CLSCs. Furthermore, some other uncertain parameters are lead time (Lieckens and Vandaele, 2007), environmental issues (Wang and Hsu, 2010b), delivery time (Pishvaee and Torabi, 2010), and risk factor (Lundin, 2012). 


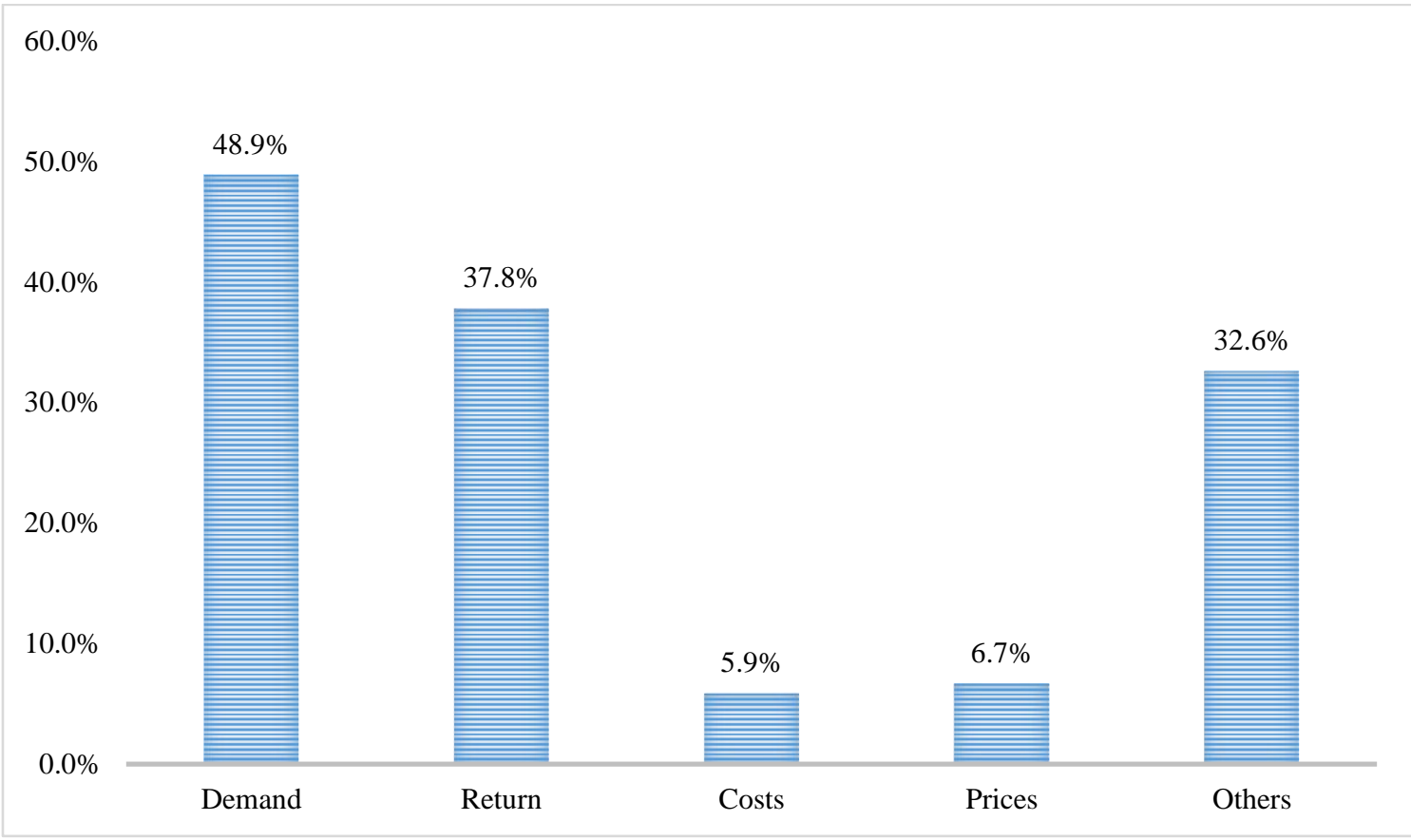

Fig.2.1. Uncertain parameters adopted from (Govindan et al., 2015)

Zarandi et al. (2011) designed a network distribution for a CLSC. They solved the proposed model by a fuzzy goal programming method. Pishvaee and Razmi (2012) offered a multiobjective fuzzy model for an environmental supply chain. They applied an interactive fuzzy approach to minimize the total cost of supply chain and environmental issues. Costantino et al. (2012) utilized a fuzzy programming approach to examine the sustainable CLSC. They aimed to minimize the total cost, consumption rate of energy, and $\mathrm{CO}_{2}$ emission in the case of desktop computer supply chain. Vahdani et al. (2013) offered optimization model for a multi-echelon, multi-product CLSC in the iron and steel industry. They applied fuzzy programming to solve the mathematical model.

Ramezani et al. (2014) designed a multi-product, multi-period CLSC. They proposed a fuzzy multi-objective model to maximize the profit and the quality along with optimization of delivery time. In the proposed fuzzy model, all coefficients were assumed to be fuzzy due to the uncertain environment. They employed fuzzy optimization approach to convert the fuzzy multi-objective model to the equivalent crisp version.

Jindal and Sangwan (2014) employed fuzzy MILP for a multi-facility, multi-product CLSC in a single period. They aimed to maximize the proposed model under uncertainty of demand along 
with all types of possible costs related to CLSC. Alimoradi et al. (2014) developed a fuzzy MILP model to deal with uncertain returned products for a single-period, multi-product CLSC. FallahTafti et al. (2014) designed a multi-period CLSC network with regard to uncertain costs and demand. A novel interactive fuzzy programming was employed to find the trade-off solution for the proposed multi-objective model (including minimization of the total cost and the delivery time along with maximization of suppliers' ranks).

Mirakhorli (2014) discussed about designing a CLSC which may have impacts on the performance of a logistic network. He applied an interactive fuzzy programming to address the fuzzy multi-objective optimization model. It was aimed to find an efficient solution for the objective functions comprised of total cost and delivery time with regard to uncertain demand and return.

Subulan et al. (2015) applied an interactive fuzzy goal programming method to solve the fuzzy multi-objective, multi-echelon, multi-period network for a tire CLSC. They expressed that recycling and remanufacturing should be taken more seriously on account of growing the environmental issues of used products. They believed that designing the efficient CLSC through the application of fitting disposal method along with appropriate collection and storage can diminish the environmental impacts of used products. Dai and Zheng (2015) designed a multiechelon, multi-product CLSC under uncertain demand and disposal rate. They applied stochastic and fuzzy programming to maximize the total profit of the model. Mohajeri and Fallah (2016) considered the recycling of product's end-of-life in a notebook CLSC. In the proposed model, it was aimed to minimize the total cost along with $\mathrm{CO}_{2}$ emission during distribution, delivery, and recycling of the products. A fuzzy programming was applied to deal with uncertain parameters (recovery rate, landfilling rate, and demand) in a realistic CLSC network. Pham and Yenradee (2017) described that the supply chain performance is definitely affected by the design of its network. They claimed that considering facility location to design the supply chain may make the model more complicated. For such reasons, they introduced an alternative approach to design the supply chain network through a multi-echelon, multi-product manufacturing process. In addition, uncertain factors were taken into account by applying fuzzy theory. According to their findings, the fuzzy model was more reliable compared to the deterministic approach in case of cost effectiveness. 
Table 2.1.

Review of some mathematical programming approaches utilized in CLSCs modeling

\begin{tabular}{|c|c|c|c|c|c|c|c|}
\hline $\begin{array}{c}\text { Authors } \\
\text {.......... }\end{array}$ & Uncertainty & $\begin{array}{l}\text { Multi- } \\
\text { product }\end{array}$ & $\begin{array}{l}\text { Type of } \\
\text { products }\end{array}$ & $\begin{array}{l}\text { Multi- } \\
\text { period }\end{array}$ & $\begin{array}{l}\text { Multi- } \\
\text { objective }\end{array}$ & $\begin{array}{l}\text { Mathematical } \\
\text { programming } \\
\text { approach }\end{array}$ & $\begin{array}{l}\text { Real } \\
\text { locations }\end{array}$ \\
\hline $\begin{array}{l}\text { Cardoso et al. } \\
(2013)\end{array}$ & Demand & $\checkmark$ & - & $\checkmark$ & - & $\begin{array}{l}\text { MILP, decision } \\
\text { tree }\end{array}$ & - \\
\hline $\begin{array}{l}\text { Fahimnia et } \\
\text { al. }(2013)\end{array}$ & - & $\checkmark$ & - & $\checkmark$ & $\checkmark$ & MILP & - \\
\hline $\begin{array}{l}\text { Hashemi et al. } \\
\text { (2014) }\end{array}$ & - & $\checkmark$ & $\begin{array}{l}\text { Aerospace } \\
\text { industry }\end{array}$ & $\checkmark$ & - & MILP & - \\
\hline $\begin{array}{l}\text { Kalaitzidou et } \\
\text { al. (2105) }\end{array}$ & - & $\checkmark$ & - & $\checkmark$ & - & MILP & - \\
\hline $\begin{array}{l}\text { Özceylan et } \\
\text { al. (In press) }\end{array}$ & & $\checkmark$ & $\begin{array}{l}\text { Automotive } \\
\text { industry }\end{array}$ & $\checkmark$ & - & MILP & $\checkmark$ \\
\hline $\begin{array}{l}\text { Amin et al. } \\
(2017)\end{array}$ & $\begin{array}{l}\text { Demand, } \\
\text { return }\end{array}$ & $\checkmark$ & Tire & $\checkmark$ & - & $\begin{array}{l}\text { MILP, decision } \\
\text { tree }\end{array}$ & $\checkmark$ \\
\hline $\begin{array}{l}\text { Chen et al. } \\
(2017)\end{array}$ & - & - & $\begin{array}{c}\text { Solar } \\
\text { energy }\end{array}$ & & $\checkmark$ & MILP & - \\
\hline $\begin{array}{l}\text { Shakourloo et } \\
\text { al. (2016) }\end{array}$ & & $\checkmark$ & - & - & $\checkmark$ & $\begin{array}{l}\text { multi-objective } \\
\text { integer linear } \\
\text { programming }\end{array}$ & - \\
\hline $\begin{array}{l}\text { Amin and } \\
\text { Zhang (2013) }\end{array}$ & Demand & $\checkmark$ & - & - & $\checkmark$ & $\begin{array}{l}\text { MILP, QFD, } \\
\text { Stochastic } \\
\text { programming }\end{array}$ & - \\
\hline $\begin{array}{l}\text { Zeballos et al. } \\
\text { (2014) }\end{array}$ & $\begin{array}{l}\text { Demand, raw } \\
\text { material } \\
\text { supplies }\end{array}$ & $\checkmark$ & - & $\checkmark$ & & $\begin{array}{l}\text { Stochastic } \\
\text { programming }\end{array}$ & - \\
\hline $\begin{array}{l}\text { Vahdani and } \\
\text { Mohammadi } \\
(2015)\end{array}$ & Cost, capacity & $\checkmark$ & - & - & $\checkmark$ & $\begin{array}{l}\text { Stochastic } \\
\text { programming, } \\
\text { Robust } \\
\text { optimization }\end{array}$ & - \\
\hline $\begin{array}{l}\text { Soleimani et } \\
\text { al. (2016) }\end{array}$ & $\begin{array}{l}\text { Demand, } \\
\text { product's price }\end{array}$ & $\checkmark$ & - & $\checkmark$ & - & $\begin{array}{l}\text { Stochastic } \\
\text { programming }\end{array}$ & - \\
\hline $\begin{array}{l}\text { Dutta et al. } \\
(2016)\end{array}$ & Demand & $\checkmark$ & - & $\checkmark$ & - & $\begin{array}{l}\text { Stochastic } \\
\text { programming }\end{array}$ & - \\
\hline $\begin{array}{l}\text { Jeihoonian et } \\
\text { al. (2017) }\end{array}$ & $\begin{array}{l}\text { Stochastic } \\
\text { variable } \\
\text { (quality of } \\
\text { returned } \\
\text { products) }\end{array}$ & $\checkmark$ & - & - & - & $\begin{array}{l}\text { Stochastic } \\
\text { programming }\end{array}$ & - \\
\hline $\begin{array}{l}\text { Feitó-Cespón } \\
\text { et al. (2017) }\end{array}$ & $\begin{array}{l}\text { Stochastic } \\
\text { variable } \\
\text { (demand and } \\
\text { waste } \\
\text { generation) }\end{array}$ & $\checkmark$ & - & - & - & $\begin{array}{l}\text { Stochastic } \\
\text { programming }\end{array}$ & - \\
\hline $\begin{array}{l}\text { Ruimin et al. } \\
(2016)\end{array}$ & $\begin{array}{l}\text { Demand, cost } \\
\text { parameters }\end{array}$ & $\checkmark$ & - & - & $\checkmark$ & $\begin{array}{l}\text { Robust multi- } \\
\text { objective MINLP }\end{array}$ & $\checkmark$ \\
\hline $\begin{array}{l}\text { Talaei et al. } \\
(2016)\end{array}$ & $\begin{array}{l}\text { Demand, } \\
\text { variable cost }\end{array}$ & $\checkmark$ & - & - & $\checkmark$ & $\begin{array}{l}\text { Robust } \\
\text { optimization }\end{array}$ & - \\
\hline Kisomi et al. & Demand, & $\checkmark$ & - & - & - & Robust & - \\
\hline
\end{tabular}




\begin{tabular}{|c|c|c|c|c|c|c|c|}
\hline Authors & Uncertainty & $\begin{array}{l}\text { Multi- } \\
\text { product }\end{array}$ & $\begin{array}{l}\text { Type of } \\
\text { products }\end{array}$ & $\begin{array}{l}\text { Multi- } \\
\text { period }\end{array}$ & $\begin{array}{l}\text { Multi- } \\
\text { objective }\end{array}$ & $\begin{array}{l}\text { Mathematical } \\
\text { programming } \\
\text { approach }\end{array}$ & $\begin{array}{l}\text { Real } \\
\text { locations }\end{array}$ \\
\hline (2016) & $\begin{array}{l}\text { transportation } \\
\text { cost }\end{array}$ & & & & & optimization & \\
\hline $\begin{array}{l}\text { Xu et al. } \\
\text { (2017) }\end{array}$ & $\begin{array}{l}\text { Waste } \\
\text { collection } \\
\text { level }\end{array}$ & $\checkmark$ & - & $\checkmark$ & & $\begin{array}{l}\text { Robust } \\
\text { optimization }\end{array}$ & - \\
\hline $\begin{array}{l}\text { Mohammed et } \\
\text { al. (2017) }\end{array}$ & $\begin{array}{l}\text { Demand, } \\
\text { return, carbon } \\
\text { emission }\end{array}$ & $\checkmark$ & - & $\checkmark$ & $\checkmark$ & $\begin{array}{l}\text { Robust } \\
\text { optimization }\end{array}$ & $\checkmark$ \\
\hline $\begin{array}{l}\text { Fallah-Tafti et } \\
\text { al. (2014) }\end{array}$ & $\begin{array}{l}\text { Costs and } \\
\text { demand }\end{array}$ & $\checkmark$ & - & $\checkmark$ & $\checkmark$ & $\begin{array}{l}\text { Fuzzy } \\
\text { programming }\end{array}$ & - \\
\hline $\begin{array}{l}\text { Mirakhorli } \\
\text { (2014) }\end{array}$ & $\begin{array}{l}\text { Demand, } \\
\text { return }\end{array}$ & - & - & - & $\checkmark$ & $\begin{array}{l}\text { Interactive fuzzy } \\
\text { programming }\end{array}$ & - \\
\hline $\begin{array}{l}\text { Ramezani et } \\
\text { al. (2014) }\end{array}$ & All parameters & $\checkmark$ & - & $\checkmark$ & $\checkmark$ & $\begin{array}{l}\text { Fuzzy } \\
\text { optimization } \\
\text { approach }\end{array}$ & - \\
\hline $\begin{array}{l}\text { Jindal and } \\
\text { Sangwan } \\
\text { (2014) }\end{array}$ & $\begin{array}{l}\text { Demand, } \\
\text { variable cost }\end{array}$ & $\checkmark$ & - & - & - & $\begin{array}{l}\text { Fuzzy } \\
\text { programming }\end{array}$ & - \\
\hline $\begin{array}{l}\text { Mohajeri and } \\
\text { Fallah (2016) }\end{array}$ & $\begin{array}{l}\text { Recovery rate, } \\
\text { landfilling } \\
\text { rate, demand }\end{array}$ & - & $\begin{array}{l}\text { Notebook } \\
\text { (laptop) } \\
\text { industry }\end{array}$ & - & - & $\begin{array}{l}\text { Fuzzy } \\
\text { programming }\end{array}$ & $\checkmark$ \\
\hline $\begin{array}{l}\text { Subulan et al. } \\
\text { (2015) }\end{array}$ & - & $\checkmark$ & Tire & $\checkmark$ & $\checkmark$ & $\begin{array}{l}\text { MILP, Interactive } \\
\text { fuzzy goal } \\
\text { programming }\end{array}$ & $\checkmark$ \\
\hline $\begin{array}{l}\text { Pham and } \\
\text { Yenradee } \\
\text { (2017) }\end{array}$ & $\begin{array}{l}\text { Demand, cost } \\
\text { of opening } \\
\text { location- } \\
\text { production, } \\
\text { setup cost }\end{array}$ & $\checkmark$ & - & $\checkmark$ & - & $\begin{array}{l}\text { Fuzzy } \\
\text { programming }\end{array}$ & - \\
\hline $\begin{array}{l}\text { Proposed } \\
\text { model }\end{array}$ & $\begin{array}{l}\text { All parameters } \\
\text { and decision } \\
\text { variables }\end{array}$ & $\checkmark$ & Battery & $\checkmark$ & $\checkmark$ & $\begin{array}{l}\text { MILP, scenario- } \\
\text { based analysis, } \\
\text { fully fuzzy } \\
\text { programming, } \\
\text { fuzzy ANP }\end{array}$ & $\checkmark$ \\
\hline
\end{tabular}




\section{CHAPTER 3. APPLICATION OF MILP AND SCENARIO-BASED ANALYSIS TO DESIGN A BATTERY CLSC}

\subsection{Introduction}

In this chapter, it is intended to introduce a deterministic model for a battery CLSC. The proposed model is considered for a multi-echelon (multiple suppliers, plants, retailers, markets, battery recovery centers, and disposal center), multi-component, multi-product CLSC in multiple periods. It is aimed to figure out which plant(s), retailer(s), and battery recovery center(s) should be chosen, how many components should be purchased, and how many products should be produced and sent to the market or kept as inventory to maximize the profit of the battery CLSC. The introduced model is evaluated under different scenarios based on market's demand and returned products through the application of scenario-based analysis.

The structure of this chapter is arranged as follows: Initially, the proposed battery CLSC network is explained comprehensively in Section 3.2. Subsequently, a related mathematical model is provided in Section 3.3. Therefore, some associated assumptions regarding the number of demand markets, quantity of demands and returned products along with the solutions are provided in Section 3.4. The definition and application of scenario-based analysis are provided in Section 3.5. Finally, summary of this chapter is discussed in Section 3.6.

\subsection{Network description}

As illustrated in Fig.3.1, it is assumed a multi-echelon CLSC model with multi-components, and multi-products in multiple-periods. The proposed CLSC is comprised of suppliers, plants, retailers, markets in the forward flow, and reverse flow includes battery recovery centers and disposal center. The structure of the CLSC integrates both forward and reverse flows. The plants purchase the main components of battery (including Anode, Cathode, Electrolyte, Separator, and Case) from suppliers, and produce three different types of batteries, and then such products are shipped to the retailers. Furthermore, retailers are willing to meet market's demand by keeping cumulative inventory as least as possible to reduce the holding inventory cost.

Thereafter, customers purchase the batteries. Some of the batteries are returned to the battery recovery centers. The returned batteries are decomposed to the main components. Some of the main components can be recycled and returned to the plants, while other unrecoverable parts are sent to the disposal center. 


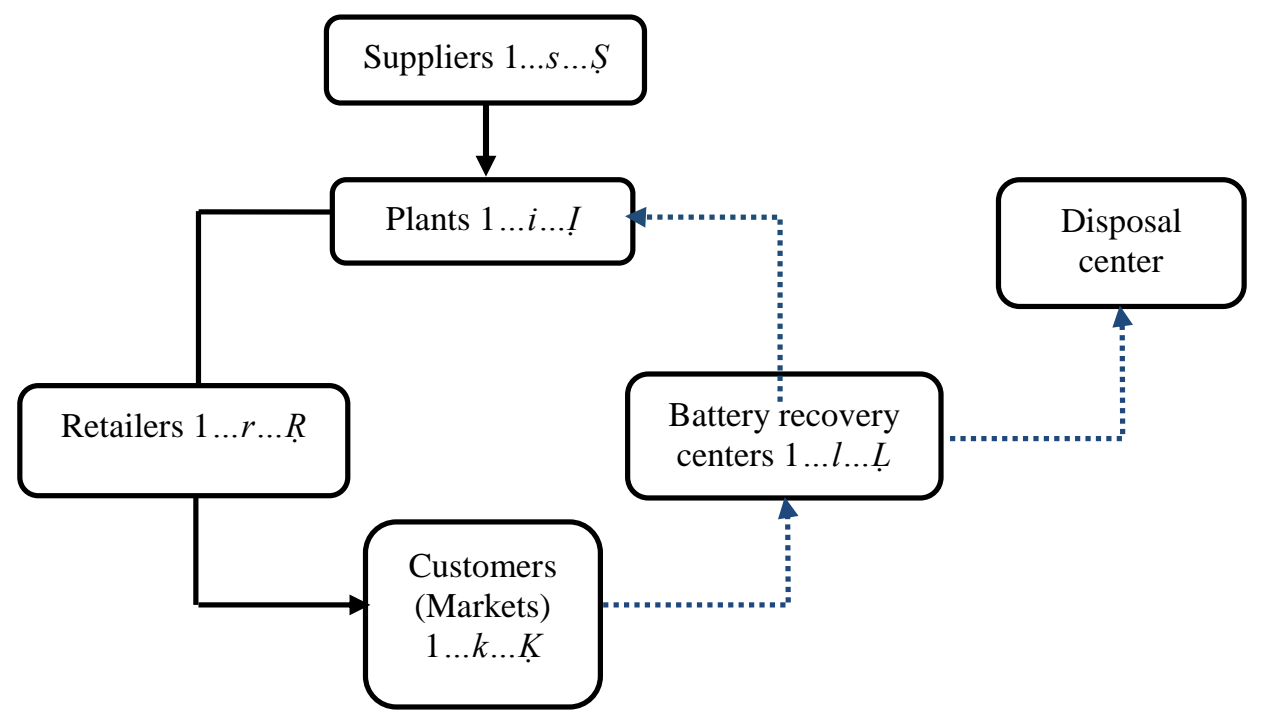

Fig.3.1. The proposed battery CLSC

\subsection{Mathematical model}

A deterministic mixed-integer linear programming model is employed to optimise the proposed network. Following sets, parameters, and decision variables are utilized:

\section{Sets}

$J=$ set related to products $(1 \ldots j \ldots J)$

$N=$ set related to components $(1 \ldots i \ldots N)$

$S=$ set related to suppliers $\left(\begin{array}{llll}1 & \ldots & s & \ldots\end{array}\right)$

$I=$ set related to possible plant sites $(1 \ldots i \ldots l)$

$R=$ set related to possible retailer sites $(1 \ldots r \ldots R)$

$K=$ set related to customers (market) sites $(1 \ldots k \ldots K)$

$L=$ set related to locations of battery recovery centers $(1 \ldots l \ldots L)$

$T=$ set related to periods $(1 \ldots t \ldots T)$

\section{Parameters}

$\delta_{j}=$ selling price of product $j$

$A_{s}=$ fixed-cost associated with supplier $s$

$B_{i}=$ fixed-cost associated with opening plant $i$

$R_{r}=$ fixed-cost associated with opening retailer $r$

$C_{l}=$ fixed-cost associated with opening the recovery centers $l$ 
$N_{s \eta}=$ purchasing cost of components $\eta$ from supplier $s$

$P_{j}=$ cost of production related to product $j$

$F_{\eta}=$ unit cost of transportation related to components $\eta$ from suppliers to plants

$E_{s i}=$ the distance between locations $s$ and $i$

$E_{l}=$ the distance between recovery centers $l$ and disposal center

$G_{j}=$ unit cost of transportation related to product $j$ from plants to retailers

$H_{j}=$ unit cost of transportation related to product $j$ from retailers to markets

$M_{j}=$ unit cost of transportation related to product $j$ from markets to battery recovery centers

$O_{\eta}=$ unit cost of transportation related to components $\eta$ from battery recovery centers to plants

$\theta_{\eta}=$ unit cost of transportation related to components $\eta$ from battery recovery centers to disposal center

$a_{\eta}=$ cost saving of components $\eta$ due to product recovery

$f_{\eta}=$ disposal cost of components $\eta$

$d_{k j t}=$ demand of customer (market) $k$ for product $j$ related to period $t$

$\varepsilon_{\eta}=$ disposal fraction of the components $\eta$

$z_{k j t}=$ returned product $j$ related to customer (market) $k$ in period $t$

$g_{i \eta}=$ number of capacity of plant $i$ for components $\eta$

$h_{r j}=$ number of capacity of retailer $r$ for product $j$

$n_{l j}=$ number of capacity of battery recovery center $l$ for product $j$

$u_{s \eta}=$ number of capacity of supplier $s$ for components $\eta$

$v_{j \eta}=$ number of components $\eta$ in product $j$

$\alpha_{j}=$ holding cost for product $j$

\section{Decision Variables}

$Q_{s i \eta}=$ number of components $\eta$ shipped to plant $i$ by supplier $s$ related to period $t$

$R_{i r j t}=$ number of product $j$ manufactured by plant $i$ for retailer $r$ related to period $t$

$S_{r k j t}=$ number of product $j$ sold by retailer $r$ to customer $k$ related to period $t$

$T_{k j j}=$ number of returned product $j$ from customer $k$ to battery recovery centers $l$ related to period

$t$

$U_{l i \eta \eta}=$ number of components $\eta$ shipped to plant $i$ from battery recovery centers $l$ related to period 
$\lambda_{l \eta t}=$ number of components $\eta$ shipped to disposal center from battery recovery centers $l$ related to period $t$

$I_{r j t}=$ number of product $j$ holding as the inventory in retailer $r$ related to period $t$

$V_{i}=1$, if a plant of the manufacturer is located and set up at potential site $i, 0$, otherwise.

$W_{r}=1$, if the retailer located in site $r$ is utilized to sell the products, 0 , otherwise.

$X_{l}=1$, if the battery recovery centers located in site $l$ is utilized to remanufacture the used products, 0 , otherwise.

$Y_{s}=1$, if the supplier $s$ is selected, 0 , otherwise.

$$
\begin{aligned}
& \operatorname{Max} z_{1}=\sum_{r} \sum_{k} \sum_{j} \sum_{t}\left(\delta_{j}-H_{j} E_{r k}\right) S_{r k j t}-\left(\sum_{s} \sum_{i} \sum_{\eta} \sum_{t}\left(N_{s \eta}+F_{\eta} E_{s i}\right) Q_{s i \eta t}+\sum_{i} \sum_{r} \sum_{j} \sum_{t}\left(P_{j}+G_{j} E_{i r}\right) R_{i r j t}\right. \\
& +\sum_{r} \sum_{t} \sum_{j} \alpha_{j} I_{r i j}+\sum_{k} \sum_{l} \sum_{j} \sum_{t} M_{j} E_{k l} T_{k j t}+\sum_{l} \sum_{i} \sum_{\eta} \sum_{t}\left(-a_{\eta}+O_{\eta} E_{l i}\right) U_{l i \eta t}+\sum_{l} \sum_{\eta} \sum_{t}\left(f_{\eta}+\theta_{\eta} E_{l}\right) \lambda_{l \eta t} \\
& \left.+\sum_{s} A_{s} Y_{s}+\sum_{i} B_{i} V_{i}+\sum_{r} R_{r} W_{r}+\sum_{l} C_{l} X_{l}\right)
\end{aligned}
$$

s.t.

$$
\begin{array}{lr}
I_{r j t}=I_{r j t-1}+\sum_{i} R_{i r j t}-\sum_{k} S_{r k j t} & \forall r, j, t \\
\sum_{s} Q_{s i \eta t}+\sum_{l} U_{l i \eta t}=\sum_{r} \sum_{j}\left(R_{i r j t}\right) v_{j n} & \forall i, \eta, t \\
\sum_{i} R_{i r j t}+I_{r j t} \geq \sum_{k} S_{r k j t} & \forall r, j, t
\end{array}
$$

$\sum_{r} S_{r k j t} \leq d_{k j t}$

$$
\forall k, j, t
$$

$\sum_{r} S_{r k j t} \geq \sum_{l} T_{k j t}$

$\forall k, j, t$

$\sum_{l} T_{k l j t}=z_{k j t}$

$$
\forall k, j, t
$$

$$
\begin{array}{ll}
\varepsilon_{\eta} \sum_{k} \sum_{j}\left(T_{k l j t}\right) v_{j \eta} \leq \lambda_{l \eta t} & \forall l, \eta, t \\
\sum_{k} \sum_{j}\left(T_{k j t}\right) v_{j \eta}=\sum_{i} U_{l i \eta t}+\lambda_{l \eta t} & \forall l, \eta, t
\end{array}
$$




$$
\begin{array}{ll}
\sum_{s} \sum_{\eta} Q_{s i \eta t}+\sum_{l} \sum_{\eta} U_{l i \eta t} \leq V_{i} \sum_{\eta} g_{i \eta} & \forall i, t \\
\sum_{i} \sum_{j} R_{i r j t}+\sum_{j} I_{r j t} \leq W_{r} \sum_{j} h_{r j} & \forall r, t \\
\sum_{k} \sum_{j} T_{k j j t} \leq X_{l} \sum_{j} n_{l j} & \forall l, t \\
\sum_{i} \sum_{\eta} Q_{s i \eta \eta t} \leq Y_{s} \sum_{\eta} u_{s \eta} & \forall s, t \\
V_{i}, W_{r}, X_{l}, Y_{s} \in\{0,1\} & \forall i, r, l, s \\
Q_{s i \eta \eta}, R_{i r j t}, S_{r k j t}, T_{k j l t}, U_{l i \eta t}, I_{r j i t}, \lambda_{l \eta \eta t} \geq 0 & \forall s, i, \eta, t, r, j, k, l
\end{array}
$$

The objective function is aimed to maximize the total profit in the battery CLSC network. The first part is associated with net revenue of selling product which is defined as the subtraction of transportation cost between retailers and markets from gross revenue obtaining from selling products to the market. The next part includes purchasing and shipping costs of components from suppliers to the plants. Cost of manufacturing and transportation between the plants and the retailers are two types of cost imposed to the production phase. It is assumed that the retailers deal with two types of cost consisting of inventory holding cost and transportation cost of products from the retailers to the markets. The next part of objective function is implied the shipping cost of used batteries from the markets to the battery recovery centers. According to the assumption, used batteries are decomposed to the main components, which may result in the revenue of $a_{\eta}$ defining as the saving costs due to the product recovery. The next section is the costs associated with carrying unrecoverable components from the battery recovery centers to the disposal center and disposal cost. Furthermore, the total fixed-costs related to the location of suppliers, plants, retailers, battery recovery centers are mentioned respectively in the objective function.

Constraint (3.1) is related to the inventory in period $t$ comprising of inventory in last period ( $t$ $1)$, and difference between the quantity of products shipping from the plants to the retailers $\left(R_{i r j t}\right)$, and selling to the market $\left(S_{r k j t}\right)$ in period $t$. The left part of Constraint (3.2) implies the summation of components either purchasing from suppliers or coming from battery recovery 
centers which should be equal to the number of components of products manufactured by plants. Constraint (3.3) obligates retailers to request products and keep the inventory either equal or greater than the selling products to the customers. Constraint $(3.4,3.5,3.6)$ consider the trade-off between the selling products, the markets' demand and the returned products. Constraint (3.7) indicates the disposal fraction of the returned products. Constraint (3.8) is the trade-off between the components of returned products and recycled components shipping back to the plants along with unrecoverable components sending to the disposal center. Constraint (3.9) specifies the restriction in the capacities of plants for the components purchasing from suppliers and coming from battery recovery centers. Constraint (3.10) is related to the capacities of the retailers for the batteries produced by the plants and holding inventory in period $t$. Constraint (3.11) is associated with the capacities of the battery recovery centers for returned products. Similarly, Constraint (3.12) is related to the capacities of the suppliers to provide components $\eta$ for plants. Finally, constraints (3.13) and (3.14) represent binary and non-negative decision variables.

\subsection{Application of the proposed model and solution approach}

The model has been applied for a battery CLSC network in Vancouver, Canada. The Vancouver municipality areas have been indicated in Fig. 3.2. There are 22 areas in Vancouver that each of them has been assumed as a demand market. In addition, 5 suppliers, 6 locations for plants, 7 locations for retailers, 10 locations for battery recovery centers, and 1 location for disposal center have been considered. Google Maps have been utilized to calculate the distances among the echelons (suppliers, plants, retailers, demand markets, battery recovery centers, and disposal center). The demand value of market $k$ related to product $j\left(d_{k j t}\right)$ has been assumed as one percent of the population of each municipality area based on 2011 census of Canada. The return value of market $k$ for product $j$ in each period $t\left(z_{k j t}\right)$ has been considered as ten percent of each market demand. Furthermore, other values related to the parameters applied to solve the proposed model are indicated in Table 3.1. 


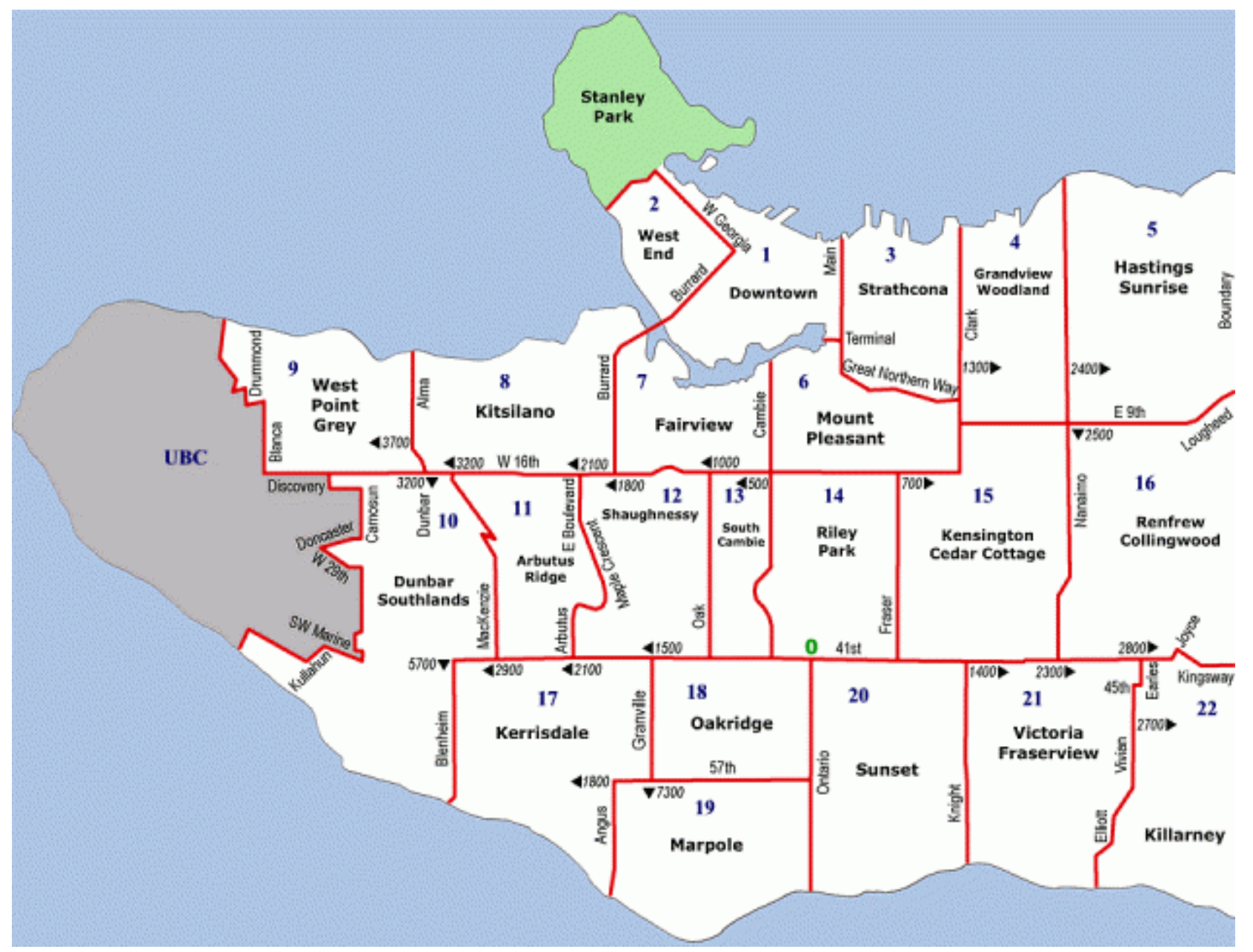

Fig. 3.2. Vancouver municipality areas

Table 3.1.

Values of parameters that have been applied to solve the proposed model

\begin{tabular}{lll}
\hline$J=3$ & $A_{s}=1,000$ & $\varepsilon_{\eta}=0.10$ \\
$N=5$ & $B_{i}=1,000,000$ & $P_{j}=15$ \\
$S=5$ & $R_{r}=1,500$ & $f_{\eta}=1$ \\
$I=6$ & $C_{l}=1,500$ & $g_{i \eta}=(2,500,000)_{6 * 5}$ \\
$R=7$ & $\delta_{j}=150$ & $h_{r j}=(10,000)_{7 * 3}$ \\
$K=22$ & $G_{j}=H_{j}=M_{j}=0.097$ & $n_{l j}=(10,000)_{10^{* 3}}$ \\
$L=10$ & $F_{\eta}=O_{\eta}=\theta_{\eta}=0.0194$ & $u_{s \eta}=(30,000)_{5 * 5}$ \\
$T=3$ & $a_{\eta}=10$ & $\alpha_{j}=40$ \\
\hline
\end{tabular}

IBM ILOG CPLEX 12.7.1.0 is utilized to solve the mathematical model. The model is solved in 2.84 seconds. There are 797 constraints, 3,560 single variables, 28 binary variables, and 28,569 non-zero coefficients. The results are written in Table 3.2. 
Table 3.2

Solution for the proposed battery CLSC

\begin{tabular}{|c|c|c|c|c|}
\hline \multicolumn{4}{|c|}{ Optimal value } & Binary variables $\left(Y_{s}, V_{i}, W_{r}, X_{l}\right)$ \\
\hline Obje & & 19,031, & & \multirow{5}{*}{$\begin{array}{l}\text { Supplier Location }\left(Y_{s}\right): Y_{l} \text { (Downtown), } Y_{5} \\
\text { (Downtown) }\end{array}$} \\
\hline \multirow{2}{*}{$Q_{s i \eta t}$} & \multirow{2}{*}{$206,466.82$} & Period 1: & 0 & \\
\hline & & Period 2: & $206,466.82$ & \\
\hline \multirow{2}{*}{$R_{i r j t}$} & \multirow{2}{*}{$57,655.90$} & Period 1: & $8,181.27$ & \\
\hline & & Period 2: & $49,474.635$ & \\
\hline \multirow{2}{*}{$S_{r k j t}$} & \multirow{2}{*}{181,536} & Period 1: & 90,768 & \multirow[t]{2}{*}{ Plant Location $\left(V_{i}\right): V_{2}$ (Downtown) } \\
\hline & & Period 2: & 90,768 & \\
\hline \multirow{2}{*}{$T_{k l j t}$} & \multirow{2}{*}{$18,180.60$} & Period 1: & $9,090.3$ & \multirow{3}{*}{$\begin{array}{l}\text { Retailer Location }\left(W_{r}\right): W_{l}\left(\text { Strathcona) } W_{2}\right. \\
\text { (Strathcona), } W_{3} \text { (Grandview Woodland), } W_{4} \\
\text { (Grandview Woodland), } W_{7} \text { (Downtown) }\end{array}$} \\
\hline & & Period 2: & $9,090.3$ & \\
\hline \multirow{2}{*}{$U_{l i \eta t}$} & \multirow{2}{*}{$81,812.70$} & Period 1: & $40,906.35$ & \\
\hline & & Period 2: & $40,906.35$ & \multirow{6}{*}{$\begin{array}{l}\text { Battery recovery center location }\left(X_{l}\right): X_{3} \\
\text { (Strathcona), } X_{5} \text { (Renfrew- Collinwood) }\end{array}$} \\
\hline \multirow{3}{*}{$I_{r t}$} & \multirow{3}{*}{$289,053.55$} & Period 0: & $165,173.46$ & \\
\hline & & Period 1: & $82,586.73$ & \\
\hline & & Period 2: & $41,293.365$ & \\
\hline \multirow{2}{*}{$\lambda_{\ln t}$} & \multirow{2}{*}{$9,090.3$} & Period 1: & $4,545.15$ & \\
\hline & & Period 2: & $4,545.15$ & \\
\hline
\end{tabular}

\subsection{An extension to consider uncertainty}

In real life, most of parameters are imprecise due to uncertain environment. In this part, it is tried to take into account the impacts of uncertain demand and return on a battery CLSC profit. Hence, scenario-based analysis is applied to identify a solution associated with any random parameters. In this sense, discrete scenarios are utilized to cover different random variables on account of addressing uncertainty. For further information, it is suggested to refer to Snyder, 2006; Amin and Zhang, 2013; Al-Othman et al., 2008.

It is assumed that Problem 3.15 is solved to maximize the objective function. In this problem $x$ and $¥$ are assumed as non-negative and binary variables, respectively. $\dot{d}, \dot{c}$, and $\dot{g}$ are defined vectors associated with selling price, variable, and fixed costs. Accordingly, $a, b, \dot{e}$, and $\dot{f}$ are assumed as matrices.

$\operatorname{Max} z=(\dot{d}-\dot{c}) x-\dot{g}_{Y}$

s.t. 
$a ́ \mathfrak{x} \leq b$

$\dot{e} \mathfrak{x} \leq \dot{f}_{Y}$

$Y \in\{0,1\} x \geq 0$

It is assumed that there are $\Omega$ scenarios which may happen by the probability of $\Phi_{\omega}$. Therefore, Problem 3.15 can be written as follows:

$\operatorname{Max} z=\sum_{\omega} \Phi_{\omega}\left(\dot{d}_{\omega}-\dot{c}_{\omega}\right) x_{\omega}-\dot{g}_{Y}$

s.t.

$\dot{a}_{\omega} \mathfrak{X}_{\omega} \leq b_{\omega} \quad \forall \omega$,

$\dot{e}_{\omega} \mathfrak{X}_{\omega} \leq \dot{f}_{Y} \quad \forall \omega$,

$\forall \in\{0,1\} x_{\omega} \geq 0 \forall \omega$,

In order to address the uncertainty of demand and return in the proposed battery CLSC, the following new set, parameters, and decision variables are defined.

\subsubsection{Scenario-based analysis}

Set

$\Omega=$ set of scenarios $(1 \ldots \omega \ldots \Omega)$

\section{Parameters}

$d_{k j t \omega}=$ number of demand from customer (market) $k$ for product $j$ related to period $t$ in scenario $\omega$ $z_{k j t \omega}=$ number of returned product $j$ from customer (market) $k$ related to period $t$ in scenario $\omega$ $\Phi_{\omega}=$ probability of scenario $\omega$

\section{Decision Variables}

$Q_{\text {sint } \omega}=$ number of components $\eta$ shipped to plant $i$ by supplier $s$ related to period $t$ in scenario $\omega$ $R_{i r j t \omega}=$ number of product $j$ produced by plant $i$ for retailer $r$ related to period $t$ in scenario $\omega$ $S_{r k j t \omega}=$ number of product $j$ sold by retailer $r$ to customer $k$ related to period $t$ in scenario $\omega$ $T_{k l j t \omega}=$ number of returned product $j$ from customer $k$ to recovery center $l$ related to period $t$ in scenario $\omega$

$U_{\text {lint } \omega}=$ number of components $\eta$ shipped to plant $i$ from recovery center $l$ related to period $t$ in scenario $\omega$

$\lambda_{l \eta t \omega}=$ number of components $\eta$ shipped to disposal center from recovery center $l$ related to period $t$ in scenario $\omega$ 
$I_{r j t \omega}=$ number of product $j$ holding as the inventory in retailer $r$ related to period $t$ in scenario $\omega$

$$
\begin{aligned}
& \operatorname{Max} z_{1}=\sum_{\omega} \sum_{r} \sum_{k} \sum_{j} \sum_{t} \Phi_{\omega}\left(\delta_{j}-H_{j} E_{r k}\right) S_{r j i t \omega}-\left(\sum_{\omega} \sum_{s} \sum_{i} \sum_{\eta} \sum_{t} \Phi_{\omega}\left(N_{s \eta}+F_{\eta} E_{s i}\right) Q_{s i \eta t \omega}+\right. \\
& \sum_{\omega} \sum_{i} \sum_{r} \sum_{j} \sum_{t} \Phi_{\omega}\left(P_{j}+G_{j} E_{i r}\right) R_{i r j t \omega}+\sum_{\omega} \sum_{r} \sum_{t} \sum_{j} \Phi_{\omega} \alpha_{j} I_{r i j \omega}+\sum_{\omega} \sum_{k} \sum_{l} \sum_{j} \sum_{t} \Phi_{\omega} M_{j} E_{k l} T_{k j l t \omega}+ \\
& \sum_{\omega} \sum_{l} \sum_{i} \sum_{\eta} \sum_{t} \Phi_{\omega}\left(-a_{\eta}+O_{\eta} E_{l i}\right) U_{l i \eta t \omega}+\sum_{\omega} \sum_{l} \sum_{\eta} \sum_{t} \Phi_{\omega}\left(f_{\eta}+\theta_{\eta} E_{l}\right) \lambda_{l \eta t \omega}+ \\
& \left.\sum_{s} A_{s} Y_{s}+\sum_{i} B_{i} V_{i}+\sum_{r} R_{r} W_{r}+\sum_{l} C_{l} X_{l}\right)
\end{aligned}
$$

s.t.

$$
I_{r j i t \omega}=I_{r j t-1 \omega}+\sum_{i} R_{i j j t \omega}-\sum_{k} S_{r j i t \omega} \quad \forall r, j, t, \omega
$$$$
\sum_{s} Q_{s i \eta t \omega}+\sum_{l} U_{l i \eta t \omega}=\sum_{r} \sum_{j}\left(R_{i j i t \omega}\right) v_{j n} \quad \forall i, \eta, t, \omega
$$$$
\sum_{i} R_{i r j t \omega}+I_{r j t \omega} \geq \sum_{k} S_{r k j t \omega} \quad \forall r, j, t, \omega
$$$$
\sum_{r} S_{r k j t \omega} \leq d_{k j t \omega} \quad \forall k, j, t, \omega
$$

$\sum_{r} S_{r k j t \omega} \geq \sum_{l} T_{k j j t \omega} \quad \forall k, j, t, \omega$

$\sum_{l} T_{k l j t \omega}=z_{k j t \omega}$

$\forall k, j, t, \omega$

$\varepsilon_{\eta} \sum_{k} \sum_{j}\left(T_{k j j t o}\right) v_{j \eta} \leq \lambda_{l \eta t \omega} \quad \forall l, \eta, t, \omega$

$$
\sum_{k} \sum_{j}\left(T_{k j l \omega}\right) v_{j \eta}=\sum_{i} U_{l i \eta t \omega}+\lambda_{l \eta t \omega} \quad \forall l, \eta, t, \omega
$$

$$
\sum_{s} \sum_{\eta} Q_{\text {sint } \omega}+\sum_{l} \sum_{\eta} U_{\text {lint } \omega} \leq V_{i} \sum_{\eta} g_{i \eta} \quad \forall i, t, \omega
$$

$$
\sum_{i} \sum_{j} R_{i r j t \omega}+\sum_{j} I_{r j i t \omega} \leq W_{r} \sum_{j} h_{r j} \quad \forall r, t, \omega
$$

$$
\sum_{k} \sum_{j} T_{k j i t \omega} \leq X_{l} \sum_{j} n_{l j} \quad \forall l, t, \omega
$$




$$
\begin{array}{ll}
\sum_{i} \sum_{\eta} Q_{s i \eta t \omega} \leq Y_{s} \sum_{\eta} u_{s \eta} & \forall s, t, \omega \\
V_{i}, W_{r}, X_{l}, Y_{s} \in\{0,1\} & \forall i, r, l, s \\
Q_{s i \eta t \omega}, R_{i j i t \omega}, S_{r k j t \omega}, T_{k j i t \omega}, U_{l i \eta t \omega}, I_{r j i t \omega}, \lambda_{l \eta t \omega o} \geq 0 & \forall s, i, \eta, t, r, j, k, l, \omega
\end{array}
$$

\subsubsection{Computational results}

Scenario-based analysis is performed to identify the effects of uncertain demand and return on the proposed battery CLSC profit. According to the assumption, the value of market's demand and returned products in Scenario 5 is assumed the same as deterministic model in Section 3.4. As a matter of fact, all possible combinations of 10 percent changes in market's demand and returned products are considered. As indicated by Table 3.3, the values of objective functions are compared with regard to Scenario 5 (e.g. change\% in Scenario 1: (20,770,924.8619,031,814.217) $/ 19,031,814.217=9.14 \%$ ). Furthermore, the scenario-based model (comprising of 7,165 constraints, 32,032 non-negative variables, 28 binary variables) is applied, and the results are indicated in Table 3.3 as well. The scenario-based model is assumed to include all possible 9 scenarios with probability of $0.075,0.075,0.1,0.1,0.3,0.1,0.1,0.075,0.075$, respectively. The total expected profit of the 9 scenarios and the scenario-based model have been depicted in Fig. 3.3.

As shown in Table 3.3, comparing the objective values of the provided scenarios verifies that the profit of the battery CLSC is very sensitive to the alteration of market's demand and returned products. Accordingly, increasing the market's demand by 10 percent leads to increase the profit of the CLSC by $9.82 \%$ percent, while decreasing the market's demand by 10 percent leads to reducing the profit of CLSC by $9.83 \%$.

Furthermore, it is noticeable that the impact of alteration in market's demand is more than the returned products on the profit of the CLSC. The proposed scenario-based model indicates the consideration of risks associated with different combinations of demand and return. 
Table 3.3

Comparison of 9 scenarios and scenario-based model

\begin{tabular}{lllll}
\hline Scenarios & Demand change\% & Return change\% & Total expected profit & change \% \\
\hline 1 & $10 \%$ increase & $10 \%$ decrease & $20,770,924.86$ & $9.14 \%$ \\
2 & $10 \%$ decrease & $10 \%$ increase & $17,292,004.647$ & $-9.14 \%$ \\
3 & No change & $10 \%$ increase & $19,162,255.752$ & $0.69 \%$ \\
4 & No change & $10 \%$ decrease & $18,901,372.683$ & $-0.69 \%$ \\
5 (base-case) & No change & No change & $19,031,814.217$ & $0.00 \%$ \\
6 & $10 \%$ increase & No change & $20,901,366.394$ & $9.82 \%$ \\
7 & $10 \%$ decrease & No change & $17,161,541.565$ & $-9.83 \%$ \\
8 & $10 \%$ increase & $10 \%$ increase & $21,031,807.92$ & $10.51 \%$ \\
9 & $10 \%$ decrease & $10 \%$ decrease & $17,031,121.578$ & $-10.51 \%$ \\
10 (scenario-based & Combination of nine scenarios & $19,030,998.425$ & $-0.0043 \%$ \\
model) & & & \\
\hline
\end{tabular}

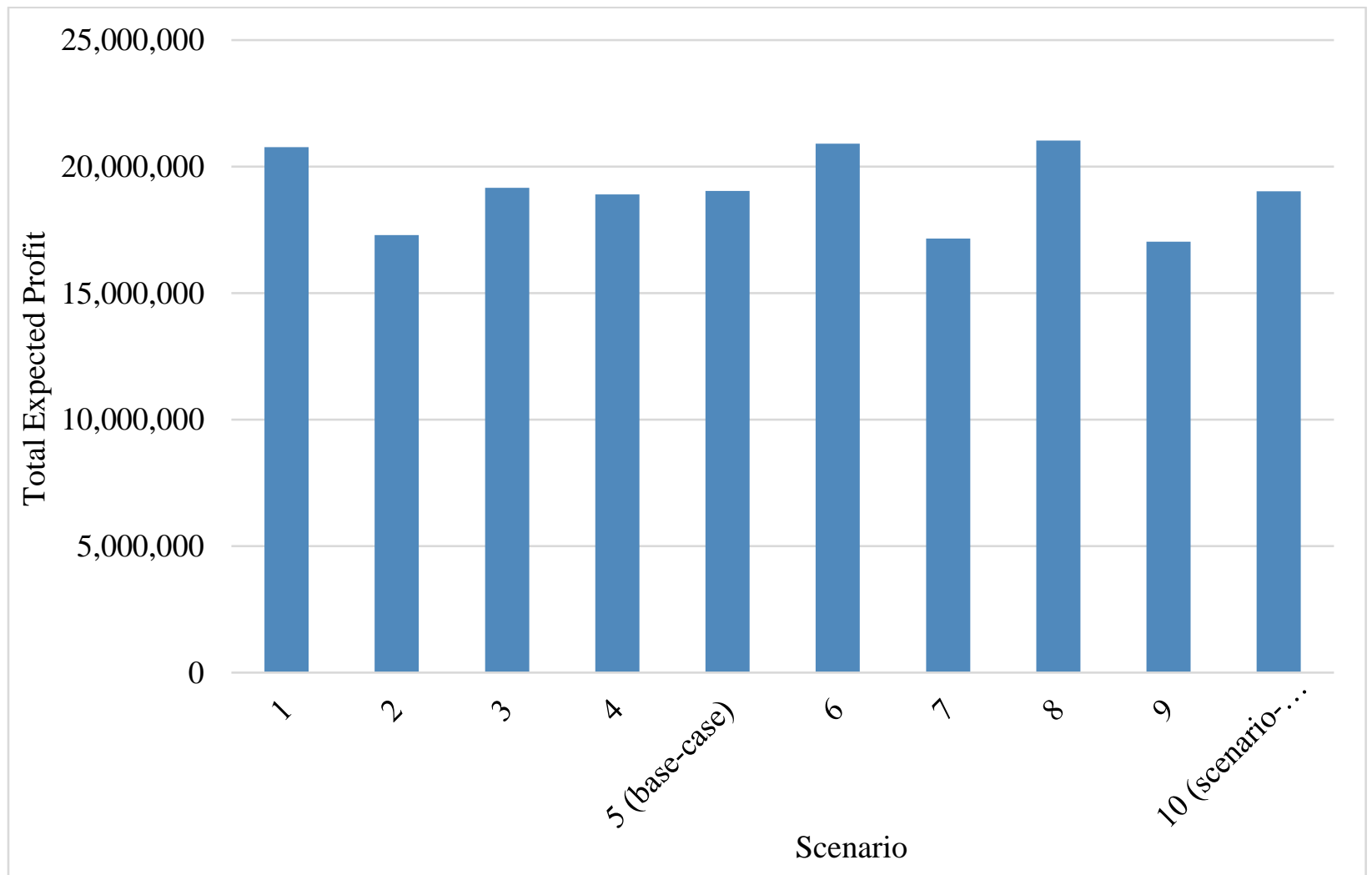

Fig. 3.3. Total expected profit of 9 scenarios and the scenario-based model 


\subsubsection{Sensitivity analysis}

As defined in Section 3.1, $\varepsilon_{\eta}$ is the disposal fraction of components $\eta$. In order to consider the impact of efficiency in recycling on the profit of the CLSC, sensitivity analysis is applied. As indicated by Fig. 3.4, increasing the disposal fraction has reverse impact on the profit of the battery CLSC in both deterministic and scenario-based models. In other words, efficiency in recycling the components leads to higher profit for the CLSC.

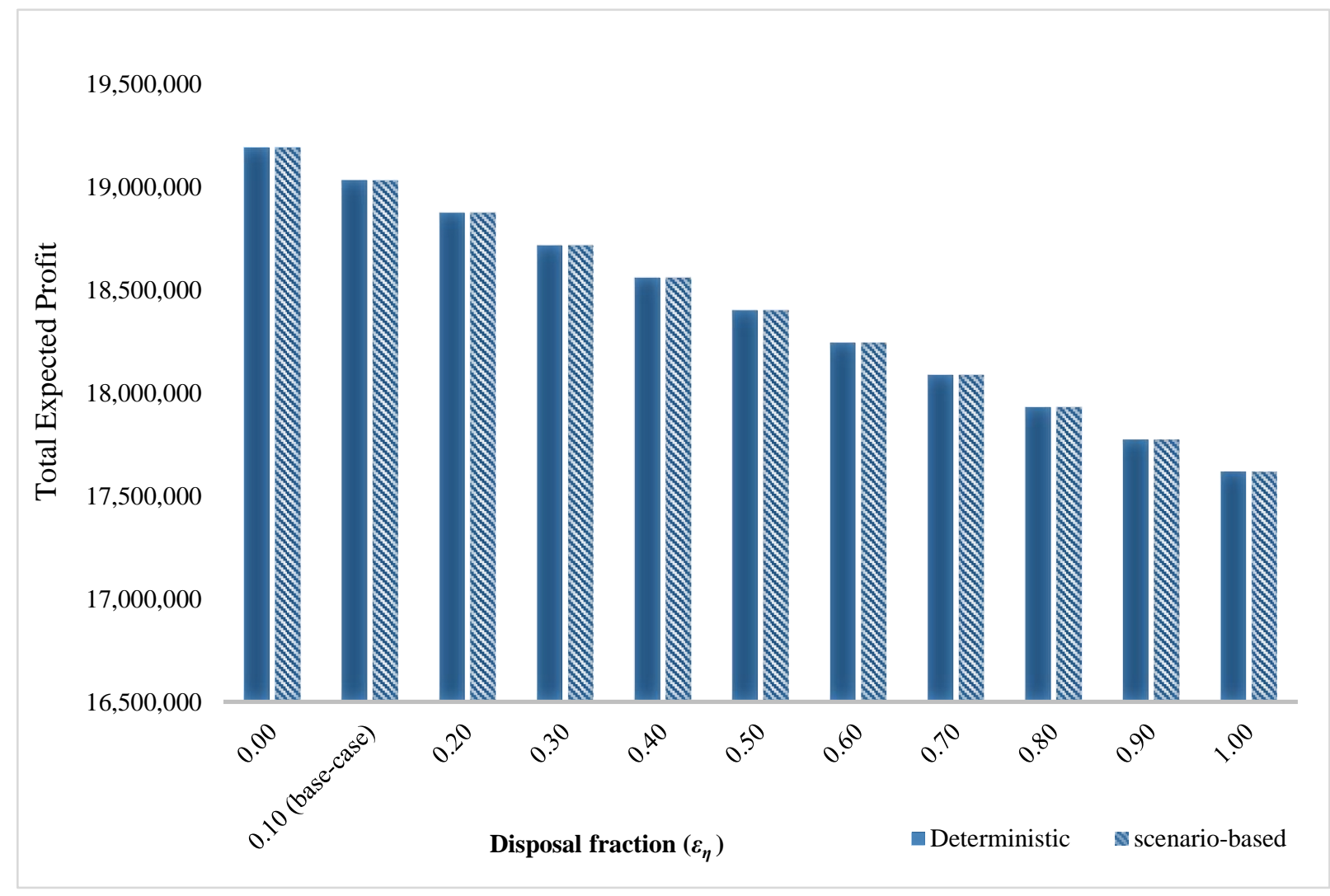

Fig. 3.4. Sensitivity analysis of disposal fraction $\left(\varepsilon_{\eta}\right)$

\subsection{Conclusions}

In this chapter, a deterministic model for a battery CLSC has been introduced. The proposed model has considered multi-echelon, multi-component, multi-product CLSC in multiple periods. To display the application of the proposed model, a realistic network has been applied. According to the assumptions, 5 suppliers, 6 locations for plants, 7 retailers, and 10 locations for battery recovery centers were considered. The distance between echelons located in Vancouver was estimated through the google map. The solution for the proposed deterministic model indicated the objective optimal values, and decision variables with regard to multiple periods. 
Furthermore, the optimal binary variables included 2 suppliers, 1 location for plant, 5 retailers, and 2 locations for battery recovery centers. The introduced model has been evaluated for different scenarios of unexpected changes in demand and return through utilizing scenario-based analysis.

The sensitivity analysis has indicated that how efficiency (lower disposal fraction) can have impact on the battery CLSC profit. In other words, if the battery recovery centers recycle more components, plants can produce more batteries with recycled materials leading to reduce the cost of purchasing raw material from suppliers. Therefore, reverse flow consisting of collecting and recycling returned products can enhance CLSC profit, and reduce the environmental issues.

There are some potential complementary research areas. In this chapter, scenario-based analysis has been utilized to evaluate the proposed model under uncertain circumstances. In this method, the possibility of occurrence of each scenario can be determined by the probability function of each scenario $(\Phi \omega)$ which can be obtained based on judgment of decision makers. However, in some cases, there is not adequate information to estimate the probability of each scenario. Hence, other types of methods such as fuzzy programming and robust optimization are suggested to be applied as the supplement of scenario-based analysis to address uncertainty. 


\section{CHAPTER 4. APPLICATION OF FUZZY ANP TO RANK PLANTS AND BATTERY RECOVERY CENTERS BASED ON GREEN PERFORMANCE}

\subsection{Introduction}

Nowadays, green practices are an essential part of company's affairs due to environmental regulatory compliance. Hence, green closed-loop supply chain management (GCLSC) can be defined as the integration of environmental management with CLSC including eco-product design, utilization of eco-intelligent technology, green purchasing, sustainable packaging, environmental practice, and recycling to fulfill customer's demand by sustainable products and services with less environmental impacts. In addition, there are a variety of green performance indicators which are considered thoroughly in the part of review of related studies. In order to evaluate the effectiveness of GCLSC, companies are usually required to apply decision making techniques. In this way, utilization of fuzzy sets theory for the purpose of combination with decision making techniques may be beneficial in the case of existing ambiguity in the expert preferences. Therefore, in order to pay adequate attention to green operational strategy in GCLSC, fuzzy ANP method is utilized to rank plants and battery recovery centers based on green performance in this study.

Section 4.2 includes review of related studies to evaluate GSCM and green performance indicators. Section 4.3 provides some necessary information about fuzzy ANP and Chang's method. In Section 4.4, a framework consisting of four criteria and eleven sub-criteria is introduced to rank six plants based on green performance, and then related analyses are provided. In Section 4.5, three criteria and seven sub-criteria are identified to rank battery recovery centers. Finally, Section 4.6 is devoted to conclusions.

\subsection{Review of some related studies to identify the green performance indicators}

Uygun and Dede (2016) proposed a model to evaluate green supply chain management (GSCM) through an integrated fuzzy multi-criteria decision making (MCDM) technique. The proposed model included five criteria and 17 sub-criteria comprised of regulations, environmental performance and economic performance as the sub-criteria of green design; supplier-customer collaboration, enforcement of stakeholders and quality regulation as the subcriteria of green purchasing; green manufacturing, green packaging and green stock politics as the sub-criteria of green transformation; organization of green logistic network, quality of 
service, and quality of technology as the sub-criteria of green logistic; reducing activities, recycling, remanufacturing, reusing, and disposal as the sub-criteria of reverse logistic.

Kusi-sarpong et al. (2016) introduced a framework to evaluate the impact of GSCM on organizational sustainable performance in mining industry. The proposed GSCM factors included green information technology and system (GITS), strategic supplier's partnership (SSP) operations and logistic integration (OLI), internal environmental management (IEM), ecoinnovation practice (EOL), and end-of-life practices (EOL). Entezaminia et al. (2016) investigated the relationship between green principals and economic performance. In the proposed model recyclability, biodegradability, energy consumption, and product risk were determined as the environmental factors.

Miroshnychenko et al. (2017) investigated the impact of green practices comprised of ISO 14001, pollution prevention, and green product development on financial performance. They determined nitrogen dioxide, emission reduction, waste reduction, water and energy efficiency, and toxic chemical reduction as the factors to measure pollution prevention index, while environmental products and eco-product design were considered as the indicators of green product index. Sharma et al. (2017) utilized AHP method to rank 13 green performance factors and 79 sub-factors for GSCM. According to their findings, environmental management and design, regulatory pressure, and green purchasing were determined as the most effective green performance indicators.

Vanalle et al. (2017) indicated that environmental practice and economic performance have a positive relationship by application of partial least squares structural equation modeling (PLSSEM). Internal environmental issues (IEM), eco-design, green purchasing, collaboration with customers regarding environmental issues and investment recovery were determined as the indicators for GSCM practice in their study. Sari (2017) introduced a framework to evaluate GSCM by utilizing Monte Carlo simulation and AHP method. The green practices in inbound operation, production operation, outbound operation and reverse logistic were considered to assess the performance of GSCM. For such evaluation, designing recyclable products and utilization of cleaner technology were assigned as the sub-factors for green production operation. Choosing suppliers based on environmental criteria, green purchasing, and cooperation with suppliers to develop environmental practices were determined as the indicators for green inbound operation. Carvalho et al. (2017) proposed a model to determine the best set of green 
performance and lean supply chain management practices with the aim of promoting ecoefficiency in automotive industry. In the proposed framework, ISO 14001 and environmentally friendly packaging were considered as the indicators for green performance. Zhao et al. (2107) proposed a multi-objective model for the optimization of an GSCM network. They minimized the risk arising from hazardous materials, and carbon emission.

Tramarico et al. (2017) utilized AHP method to evaluate GSCM through four top-level criteria including plan, source, make, and deliver. In the proposed framework, sub-criteria of plan were considered as the planning for demand based on long-term basis, and planning for material with the best use of resource. Sub-criteria of source were identified as the usage of recycled raw material, and merchandizing based on renewable energy. Besides, sub-criteria of make were comprised of reducing the scrap rate, reducing the greenhouse gas emission, recycling and reusing water, and sub-criteria of deliver were chosen as the application of full truckload for distribution, and reducing the environmental impacts through the transportation management.

Scur and Barbosa (2017) examined the application of green practices in the home appliance industry. The proposed framework for green practices consisted of internal environmental management, green purchasing and manufacturing, eco-design, and waste management. According to their findings, waste management was the most widely applied practice between research participants.

\subsection{Fuzzy ANP}

Saaty (1996) introduced analytic network process (ANP) as the modified form of analytic hierarchy process (AHP) to deal with interrelationship among factors affecting in making decision. ANP was developed by synthesizing with fuzzy sets theory with the aim of dealing with ambiguity in expert preferences. Hence, fuzzy ANP and triangular fuzzy numbers (TFNs) have become integrated on account of coping with uncertainty. In this study, Chang's method (1996) is utilized to rank the green performance of plants and battery recovery centers.

As illustrated in Fig. 4.1, TFNs can be indicated by membership function which is between 0 and 1 . 


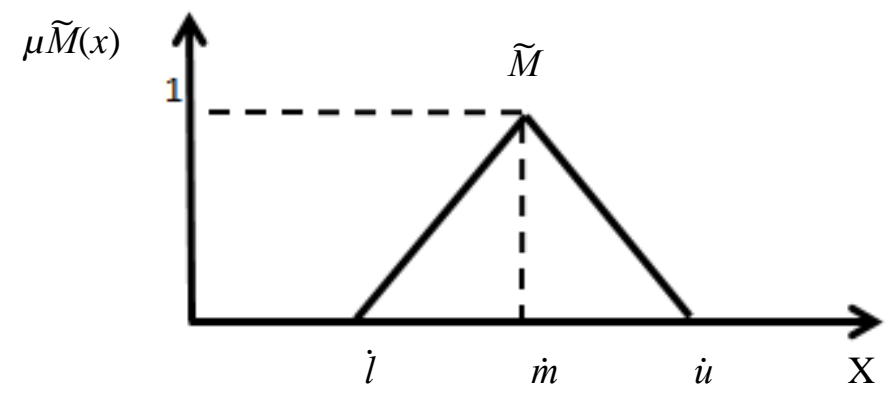

Fig. 4.1. A triangular fuzzy number $\widetilde{M}$.

If $\widetilde{M}$ is assumed as an TFN by three components such as $\widetilde{M}=(\dot{l}, \dot{m}, \dot{u})$, the associated membership function is written by Eq. (4.1).

$\mu M(x)=\left\{\begin{array}{l}0, x<\dot{l}, \\ \frac{x-\dot{l}}{\dot{m}-\dot{l}}, \dot{l} \leq x \leq \dot{m}, \\ \frac{\dot{u}-x}{\dot{u}-\dot{m}}, \dot{m} \leq x \leq \dot{u}, \\ 0, x>\dot{u},\end{array}\right.$

To apply the pairwise comparisons through the fuzzy ANP method, the Chang's extent examination is utilized.

Step 1: Eq. (4.2) indicates the value of fuzzy synthetic extent considering the $i^{\text {th }}$ object. In this way, the value of $\sum_{j} \tilde{M}_{g i}^{j}$ can be obtained from Eq. (4.3).

$$
\begin{aligned}
& \dot{S}_{i}=\sum_{j} \tilde{M}_{g i}^{j} \otimes\left[\sum_{i} \sum_{j} \tilde{M}_{g i}^{j}\right]^{-1} \\
& \sum_{j} \tilde{M}_{g i}^{j}=\left(\sum_{j} i_{j}, \sum_{j} \dot{m}_{j}, \sum_{j} \dot{u}_{j}\right)
\end{aligned}
$$

Where all the $\tilde{M}_{g i}^{j}$ are assumed triangular fuzzy numbers.

Step 2: to compare the fuzzy numbers, it is required to calculate the degree of possibility for $\widetilde{M}_{1} \geq \widetilde{M}_{2}$, which can be defined by Eq. (4.4).

$$
V\left(\widetilde{M}_{1} \geq \widetilde{M}_{2}\right)=\sup _{x \geq y}\left[\min \left(\mu \widetilde{M}_{1}(x), \mu \widetilde{M}_{2}(y)\right)\right]
$$


According to assumptions, if there is a pair of $(x, y)$ and $x \geq y$, while $\mu \widetilde{M}_{1}(x)=\mu \widetilde{M}_{2}(y)=1$, then $V$ $\left(\widetilde{M}_{1} \geq \widetilde{M}_{2}\right)=1$. It is assumed that $\widetilde{M}_{1}=\left(i_{1}, \dot{m}_{1}, \dot{u}_{1}\right)$ and $\widetilde{M}_{2}=\left(\dot{l}_{2}, \dot{m}_{2}, \dot{u}_{2}\right)$ are convex fuzzy numbers.. Therefore Eq. (4.5) can be written as follows.

$V\left(\widetilde{M}_{1} \geq \widetilde{M}_{2}\right)=1 \quad$ if $\dot{m}_{1} \geq \dot{m}_{2}$,

$V\left(\widetilde{M}_{2} \geq \widetilde{M}_{1}\right)=\operatorname{hgt}\left(\widetilde{M}_{1} \cap \widetilde{M}_{2}\right)=\mu \widetilde{M}_{1}(d)$

As illustrated by Fig. $4.2, \dot{d}$ is the ordinate of the highest intersection point $D$ between $\mu \widetilde{M}_{1}$ and $\mu \widetilde{M}_{2}$, which can be obtained from Eq. (4.6).

$V\left(\widetilde{M}_{2} \geq \widetilde{M}_{1}\right)=\operatorname{hgt}\left(\widetilde{M}_{1} \cap \widetilde{M}_{2}\right)=\frac{\dot{l}_{1}-\dot{u}_{2}}{\left(\dot{m}_{2}-\dot{u}_{2}\right)-\left(\dot{m}_{1}-\dot{l}_{1}\right)}$

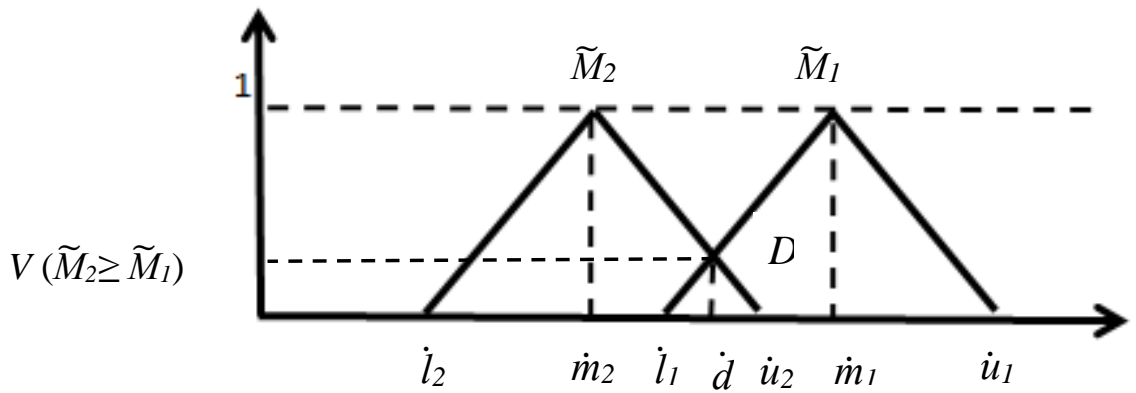

Fig. 4.2. The intersection between $\widetilde{M}_{1}$ and $\widetilde{M}_{2}$.

In order to apply the comparisons between $\widetilde{M}_{1}$ and $\widetilde{M}_{2}$, it is required to have the both values of $V$ $\left(\widetilde{M}_{1} \geq \widetilde{M}_{2}\right)$ and $V\left(\widetilde{M}_{2} \geq \widetilde{M}_{1}\right)$. Generally, if there are $k$ TFNs, the degree of possibility can be estimated as follows:

$V\left(\widetilde{M} \geq \widetilde{M}_{1}, \widetilde{M}_{2}, \ldots, \widetilde{M}_{k}\right)=V\left[\left(\widetilde{M} \geq \widetilde{M}_{1}\right)\right.$ and $\left(\widetilde{M} \geq \widetilde{M}_{2}\right)$ and $\ldots$ and, $\left.\left(\widetilde{M} \geq \widetilde{M}_{k}\right)\right]$

$=\min V\left(\widetilde{M} \geq \widetilde{M}_{i}\right), i=1,2, \ldots, k$

$d^{\prime}\left(\dot{A}_{i}\right)=\min V\left(\dot{S}_{i} \geq \dot{S}_{k}\right)$,

The weight vector can be written by Eq. (4.9) for $k=1,2, \ldots, n$ and $k \neq i$

$W^{\prime}=\left(d^{\prime}\left(\dot{A}_{1}\right), d^{\prime}\left(\dot{A}_{2}\right), \ldots, d^{\prime}\left(\dot{A}_{n}\right)\right)^{\mathrm{T}}$,

Where $\dot{A}_{i}(i=1,2, \ldots, n)$ are $n$ elements. Thereafter, Eq. (4.9) is replaced by Eq. (4.10) after normalization.

$W=\left(d\left(\dot{A}_{1}\right), d\left(\dot{A}_{2}\right), \ldots, d\left(\dot{A}_{n}\right)\right)^{\mathrm{T}}$, 


\subsection{ANP model to determine plants priority based on green performance}

In this section, it is aimed to prioritize potential plants based on green performance through the fuzzy ANP method. As indicated by Fig. 4.3, some associated criteria and sub-criteria are identified based on the related literatures and websites of battery plants and recovery centers (Sorting and processing, 2017; how to recycle battery, 2012). 


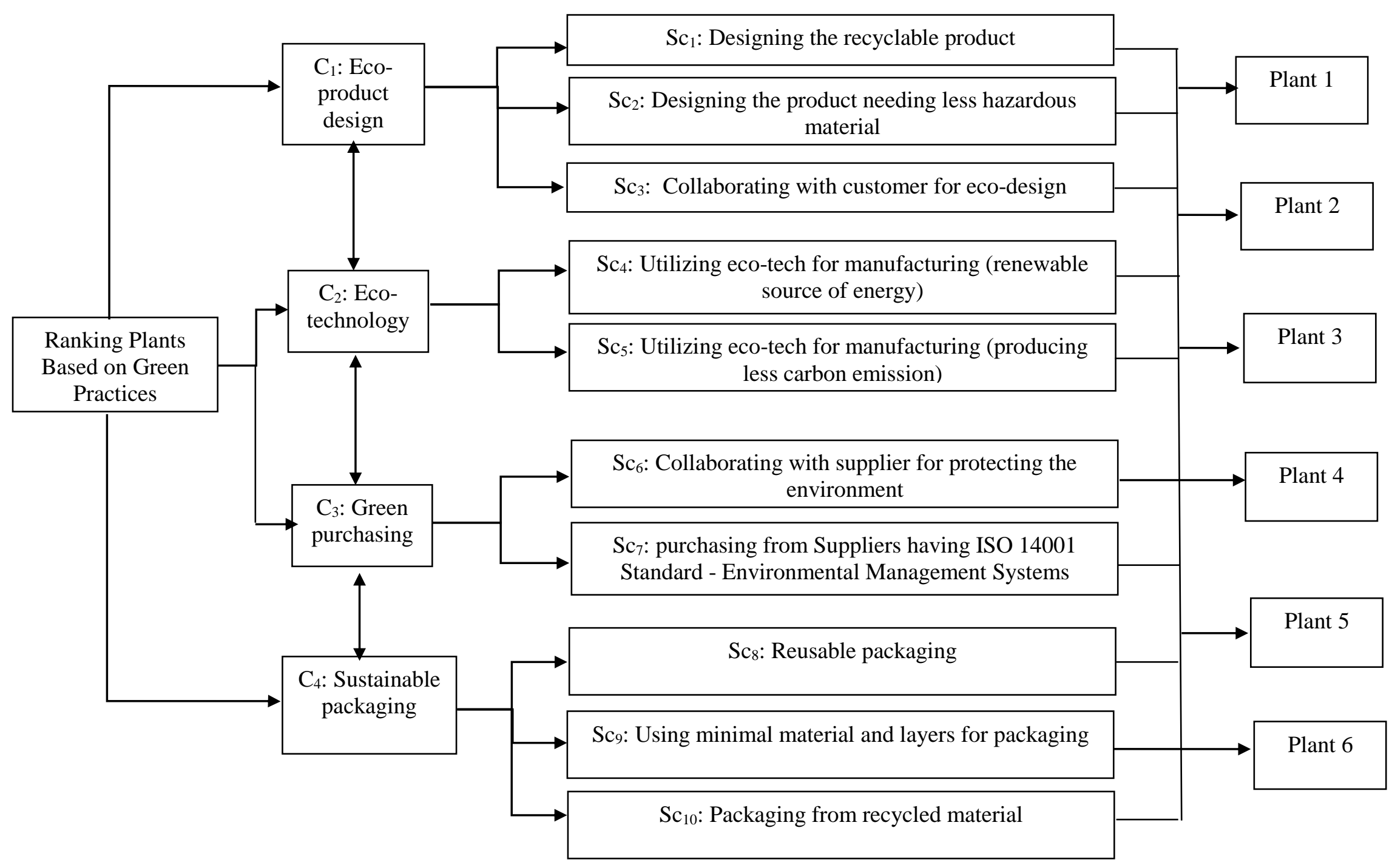

Fig. 4.3. The ANP model for prioritizing plants based on their green performance 


\subsubsection{Criterion 1: Eco-product design}

The advantages of eco-product design have been realized in CLSC. In addition, market demand is the other factor to stimulate manufacturers to utilize eco-design in production. In this study, it is intended to consider three sub-factors for eco-design as follows:

\subsubsection{Sub- criterion 1: Designing the recyclable product}

According to many studies, recyclable products can increase the profits of CLSCs. Amin and Zhang (2013), Rao and Holt (2005) indicated that there is a relationship between the rate of returned product, and improving the economic performance of supply chains.

\subsubsection{Sub- criterion 2: Designing the product needing less hazardous material}

According to various regulations, manufacturers have been prohibited to design the products containing toxic materials for humans and environment. For instance, production of mercury batteries has been significantly reduced due to the legislation of Mercury-Containing and Rechargeable Battery Management Act in 1996.

\subsubsection{Sub- criterion 3: Collaborating with customers for eco-design}

There is no doubt that customer's needs and expectations should be always prioritized. For such reasons, collaborating with customers in eco-design may develop the relationships between customers and companies leading to emerge the customer loyalty.

\subsubsection{Criterion 2: Utilizing eco-technology}

Application of eco-technology has been more popular on account of benefit, and preventing environmental issues. It is aimed to consider two sub-criteria for the factors of eco-technology to rank plants based on green performance.

\subsubsection{Sub- criterion 4: Utilizing eco- technology in production (renewable source of energy)}

Nowadays, companies are encouraged to utilize renewable energy in production such as wind and water power or solar energy. The renewable energy can be applied in production (in case of producing electricity), heating and cooling (for the process), and in transportation sector.

\subsubsection{Sub- criterion 5: Utilizing eco-tech for manufacturing (producing less carbon emission)}

Carbon emission or greenhouse gasses including carbon dioxide and carbon monoxide are released to environment mostly from plants and transportation sector. Accumulated carbon emission in the atmosphere reflect the heat to the ground surface which contributes to the global 
warming. To prevent the environmental impacts of using technology, it is recommended to replace old technology using inefficient fossil fuel by modern eco-technology releasing less carbon emission.

\subsubsection{Criterion 3: Green purchasing}

Green purchasing is defined as the collaboration with suppliers to produce and develop the products which are environmentally sustainable. In this step, two sub-criteria are categorized under green purchasing as follows:

\subsubsection{Sub- criterion 6: Collaborating with supplier for protecting the environment}

Process of purchasing products from supplier can be supplemented with environmental design which may facilitate recycling process and decreasing the scrap rate of returned products. In this way, providing material specifications to the suppliers based on environmental concerns can decrease waste material and benefit environment.

\subsubsection{Sub- criterion 7: Purchasing from suppliers having ISO 14001 standard - environmental management systems}

Nowadays, environmental concerns such as climate changes and contamination of soil and groundwater by hazardous industrial septic are growing as the mutual global concerns. ISO 14001 provided by International standards organization aims to help all types of businesses to have more sustainable operations. It provides comprehensive instruction in various aspects of businesses including procurement, manufacturing, transportation, and storage to have less impacts on environment.

\subsubsection{Criterion 4: Sustainable packaging}

Sustainable or eco-friendly packaging can be defined as the utilization of materials in packaging which are recyclable and reusable. Three sub-criteria are determined for sustainable packaging in this study.

\subsubsection{Sub- criterion 8: Reusable packaging}

Reusable packaging is a type of packaging which can be reused many times. This type of packaging is intentionally designed in terms of durability, reparability, and cleanability for multiple usages.

\subsubsection{Sub- criterion 9: Using minimal material and layers for packaging}

Application of minimal materials and layers in packaging is the most prominent factor in ecofriendly packaging which can diminish the waste materials significantly. 


\subsubsection{Sub- criterion 10: Packaging from recycled material}

Some types of materials such as glasses, papers, metals, and cardboard can be recycled and go back to the same types of packaging for many times.

The steps (guidelines) to prioritise plants based on green performance are as follows:

Step 1: As illustrated in Fig. 4.3, the problem is converted to three levels. First, criteria (ecoproduct design, eco-technology, green purchasing, sustainable packaging), then sub-criteria ( $S c_{l}$, ..., $S c_{10}$ ), and finally alternatives (Plants 1 to 6 ) are defined.

Step 2: Pairwise comparisons are applied for the problem. The fuzzy linguistic scale written in Table 4.1 and Fig. 4.4 is utilized for the pairwise comparisons. Initially, it is assumed that there is no dependency among the criteria. The results of the pairwise comparisons by the given fuzzy scales for the criteria $\left(\mathrm{We}_{1}\right)$, are indicated in Table 4.2.

Table 4.1

The linguistic scale

\begin{tabular}{lcc}
\hline Linguistic scale & TFNs & Reciprocal TFNs \\
\hline $\begin{array}{l}\text { Absolutely more } \\
\text { important (AMI) }\end{array}$ & $(5 / 2,3,7 / 2)$ & $(2 / 7,1 / 3,2 / 5)$ \\
$\begin{array}{l}\text { Very strongly more } \\
\text { important (VSMI) }\end{array}$ & $(2,5 / 2,3)$ & $(1 / 3,2 / 5,1 / 2)$ \\
Strongly more & $(3 / 2,2,5 / 2)$ & $(2 / 5,1 / 2,2 / 3)$ \\
important (SMI) & $(1,3 / 2,2)$ & $(1 / 2,2 / 3,1)$ \\
$\begin{array}{l}\text { Weakly more } \\
\text { important (WMI) }\end{array}$ & $(1 / 2,1,3 / 2)$ & $(2 / 3,1,2)$ \\
Equally important (EI) & $(1,1,1)$ & $(1,1,1)$ \\
Just equal & & \\
\hline
\end{tabular}

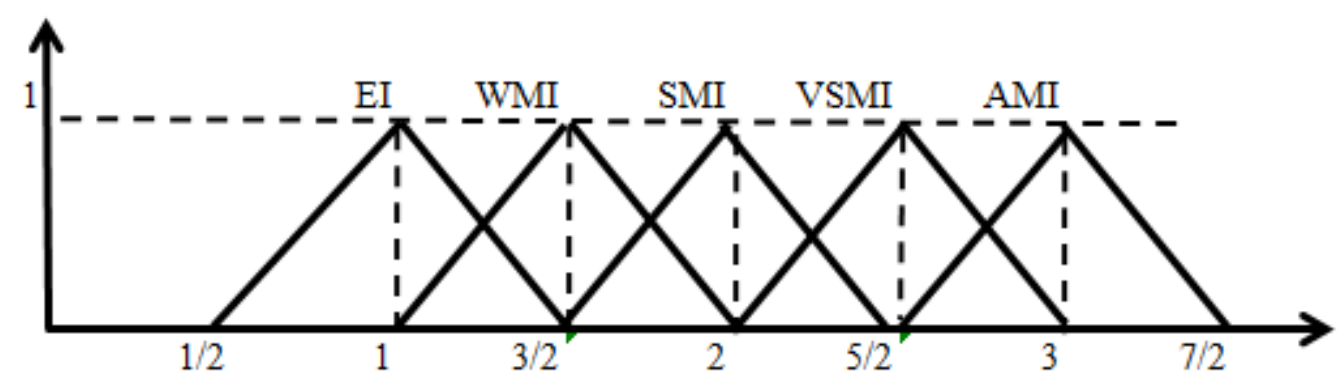

Fig. 4.4. Linguistic scale for relative importance 
Table 4.2

Pairwise comparisons among criteria

\begin{tabular}{|c|c|c|c|c|c|c|c|c|c|c|c|c|c|}
\hline$W e_{1}$ & & $C_{I}$ & & & $C_{2}$ & & & $C_{3}$ & & & $C_{4}$ & & Local weights \\
\hline$C_{l}$ & $(1$ & 1 & 1) & $(0.5$ & 1 & $1.5)$ & $(1$ & 1.5 & 2) & $(1.5$ & 2 & $2.5)$ & 0.337 \\
\hline$C_{2}$ & $(0.67$ & 1 & 2) & $(1$ & 1 & 1) & $(1$ & 1.5 & 2) & $(2.5$ & 3 & $3.5)$ & 0.402 \\
\hline$C_{3}$ & $(0.5$ & 0.67 & 1) & $(0.5$ & 0.67 & 1) & $(1$ & 1 & 1) & $(0.5$ & 1 & $1.5)$ & 0.152 \\
\hline$C_{4}$ & $(0.4$ & 0.5 & $0.67)$ & $(0.29$ & 0.33 & $0.4)$ & $(0.67$ & 1 & 2) & $(1$ & 1 & 1) & 0.109 \\
\hline
\end{tabular}

Step 3: As indicated in Fig. 4.5, there may be inner dependence between the factors. In this situation, the inner dependency among criteria can be measured by considering the effect of every criterion on every other through the pairwise comparisons. In this way, the following question may be asked: To what extend eco-technology could be more important compared to eco-product design with respect to sustainable packaging (see Tables $4.3-4.6$ ). The results of the pairwise comparisons are presented in Table 4.7 which is related to the inner dependence matrix of green performance criteria $\left(W e_{2}\right)$.

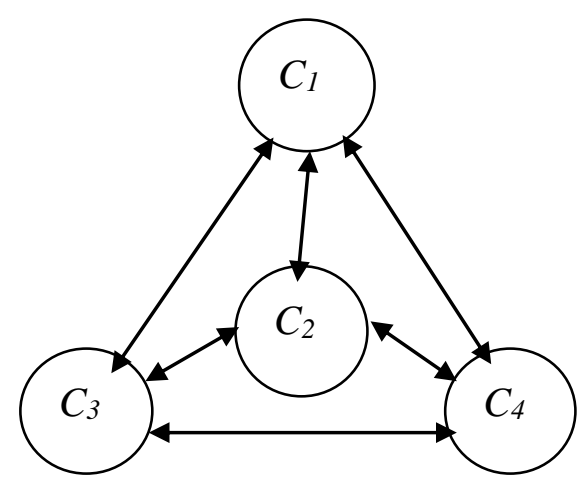

Fig. 4.5. Inner dependence between green performance criteria

Table 4.3

The inner dependence matrix and relative importance weight with respect to Eco-product design

\begin{tabular}{|c|c|c|c|c|c|c|c|c|c|}
\hline Eco-product design & \multicolumn{3}{|c|}{ Eco-technology } & \multicolumn{3}{|c|}{ Green purchasing } & \multicolumn{2}{|c|}{$\begin{array}{c}\text { Sustainable } \\
\text { packaging }\end{array}$} & \multirow{2}{*}{$\begin{array}{c}\begin{array}{c}\text { Local } \\
\text { weights }\end{array} \\
0.293\end{array}$} \\
\hline Eco-technology & $(1$ & 1 & 1) & $\begin{array}{ll}1 & 1.5\end{array}$ & 2) & $(0.4$ & 0.5 & $0.67)$ & \\
\hline Green purchasing & $(0.5$ & 0.67 & 1) & (1 11 & 1) & $(0.5$ & 0.67 & 1) & 0.161 \\
\hline $\begin{array}{l}\text { Sustainable } \\
\text { packaging }\end{array}$ & $(1.5$ & 2 & $2.5)$ & (1 1.5 & 2) & $(1$ & 1 & 1) & 0.546 \\
\hline
\end{tabular}


Table 4.4

The inner dependence matrix and relative importance weight with respect to Eco-technology

\begin{tabular}{|c|c|c|c|c|c|c|c|c|c|c|}
\hline \multirow{2}{*}{$\begin{array}{l}\text { Eco-technology } \\
\text { Eco-product design }\end{array}$} & \multicolumn{3}{|c|}{ Eco-product design } & \multicolumn{3}{|c|}{ Green purchasing } & \multicolumn{3}{|c|}{ Sustainable packaging } & \multirow{2}{*}{$\begin{array}{l}\begin{array}{l}\text { Local } \\
\text { weights }\end{array} \\
0.602\end{array}$} \\
\hline & $(1$ & 1 & 1) & $(2$ & 2.5 & 3) & $(1$ & 1.5 & 2) & \\
\hline Green purchasing & $(0.33$ & 0.4 & $0.5)$ & $(1$ & 1 & 1) & $(0.5$ & 1 & 1.5) & 0.125 \\
\hline $\begin{array}{l}\text { Sustainable } \\
\text { packaging }\end{array}$ & $(0.5$ & 0.67 & 1) & $(0.67$ & 1 & 2) & $(1$ & 1 & 1) & 0.273 \\
\hline
\end{tabular}

Table 4.5

The inner dependence matrix and relative importance weight with respect to Green purchasing

\begin{tabular}{|c|c|c|c|c|c|c|c|c|c|c|}
\hline Green purchasing & Eco- & broduct & design & & -techi & $\log y$ & $\begin{array}{l}\text { Sus } \\
\text { pac }\end{array}$ & $\begin{array}{l}\text { inable } \\
\text { aging }\end{array}$ & & $\begin{array}{l}\text { Local } \\
\text { weights }\end{array}$ \\
\hline Eco-product design & $(1$ & 1 & 1) & $(1$ & 1.5 & 2) & $(1.5$ & 2 & 2.5) & 0.547 \\
\hline Eco-technology & $(0.5$ & 0.67 & 1) & $(1$ & 1 & 1) & $(0.4$ & 0.5 & $0.67)$ & 0.077 \\
\hline Sustainable packaging & $(0.4$ & 0.5 & $0.67)$ & $(1.5$ & 2 & 2.5) & $(1$ & 1 & 1) & 0.377 \\
\hline
\end{tabular}

Table 4.6

The inner dependence matrix and relative importance weight with respect to Sustainable packaging

\begin{tabular}{|c|c|c|c|c|c|c|c|c|c|c|}
\hline $\begin{array}{l}\text { Sustainable } \\
\text { packaging }\end{array}$ & \multicolumn{3}{|c|}{ Eco-product design } & \multicolumn{3}{|c|}{ Eco-technology } & \multicolumn{3}{|c|}{ Green purchasing } & $\begin{array}{l}\text { Local } \\
\text { weights }\end{array}$ \\
\hline Eco-product design & $(1$ & 1 & 1) & $(1.5$ & 2 & $2.5)$ & $(1.5$ & 2 & $2.5)$ & 0.614 \\
\hline Eco-technology & $(0.4$ & 0.5 & $0.67)$ & $(1$ & 1 & 1) & $(0.5$ & 1 & 1.5) & 0.157 \\
\hline Green purchasing & $(0.4$ & 0.5 & $0.67)$ & $(0.67$ & 1 & 2) & $(1$ & 1 & 1) & 0.229 \\
\hline
\end{tabular}

Table 4.7

The inner dependence matrix of green performance criteria

\begin{tabular}{lcccc}
\hline$W e_{2}$ & $\begin{array}{c}\text { Eco-product } \\
\text { design }\end{array}$ & $\begin{array}{c}\text { Eco- } \\
\text { technology }\end{array}$ & $\begin{array}{c}\text { Green } \\
\text { purchasing }\end{array}$ & $\begin{array}{c}\text { Sustainable } \\
\text { packaging }\end{array}$ \\
\hline Eco-product design & 1 & 0.602 & 0.547 & 0.614 \\
Eco-technology & 0.293 & 1 & 0.077 & 0.157 \\
Green purchasing & 0.161 & 0.125 & 1 & 0.229 \\
Sustainable packaging & 0.546 & 0.273 & 0.377 & 1 \\
\hline
\end{tabular}

Step 4: In this step, We criteria is calculated based on the inner dependence matrices $W e_{1}$ and $W e_{2}$. The results are provided in Table 4.8 .

Table 4.8

The related priorities of the green performance criteria

\begin{tabular}{lcccc|c|c}
\hline$W e_{2}$ & $C_{1}$ & $C_{2}$ & $C_{3}$ & $C_{4}$ & $W e_{1}$ & $W e_{\text {criteria }}=W e_{2}^{*} W e_{1}$ \\
\hline$C_{1}$ & 1 & 0.602 & 0.547 & 0.614 & 0.337 & 0.365 \\
$C_{2}$ & 0.293 & 1 & 0.077 & 0.157 & 0.402 & 0.265 \\
$C_{3}$ & 0.161 & 0.125 & 1 & 0.229 & 0.152 & 0.141 \\
$C_{4}$ & 0.546 & 0.273 & 0.377 & 1 & 0.109 & 0.230 \\
\hline
\end{tabular}


Step 5: The priorities of the green performance sub-criteria are obtained based on pairwise comparisons. The local weights of sub-criteria are provided in Tables 4.9 - 4.12.

Table 4.9

Pairwise comparisons among sub-criteria of Eco-product design

\begin{tabular}{|c|c|c|c|c|c|c|c|c|c|c|}
\hline $\begin{array}{l}\text { Eco-product } \\
\text { design }\end{array}$ & & $S c_{1}$ & & & $c_{2}$ & & & $S c_{3}$ & & $\begin{array}{l}\text { Local } \\
\text { weights }\end{array}$ \\
\hline$S c_{l}$ & $(1$ & 1 & 1) & $(2$ & 2.5 & 3) & $(1.5$ & 2 & 2.5) & 0.771 \\
\hline$S c_{2}$ & (0.33 & 0.4 & $0.5)$ & $(1$ & 1 & 1) & $(0.5$ & 1 & 1.5) & 0.038 \\
\hline$S c_{3}$ & $(0.4$ & 0.5 & $0.67)$ & (0.67 & 1.0 & 2) & (1 & 1 & 1) & 0.191 \\
\hline
\end{tabular}

Table 4.10

Pairwise comparisons among sub-criteria of Eco-technology

\begin{tabular}{|c|c|c|c|c|c|c|c|}
\hline $\begin{array}{l}\text { Eco- } \\
\text { technology }\end{array}$ & \multicolumn{3}{|c|}{$\mathrm{Sc}_{4}$} & \multicolumn{3}{|c|}{$S c_{5}$} & $\begin{array}{l}\text { Local } \\
\text { weights }\end{array}$ \\
\hline $\mathrm{Sc}_{4}$ & $(1$ & 1 & 1) & $(0.5$ & 0.67 & 1) & 0.316 \\
\hline$S c_{5}$ & (1 & 1.5 & 2) & (1 & 1 & 1) & 0.684 \\
\hline
\end{tabular}

Table 4.11

Pairwise comparisons among sub-criteria of Green purchasing

\begin{tabular}{llllllll}
\hline $\begin{array}{l}\text { Green } \\
\text { purchasing }\end{array}$ & & \multicolumn{3}{c}{$S c_{6}$} & & \multicolumn{3}{c}{$S c_{7}$} & $\begin{array}{l}\text { Local } \\
\text { weights }\end{array}$ \\
\hline$S c_{6}$ & $(1$ & 1 & $1)$ & $(1$ & 1.5 & $2)$ & 0.684 \\
$S c_{7}$ & $(0.5$ & 0.67 & $1)$ & $(1$ & 1 & $1)$ & 0.316 \\
\hline
\end{tabular}

Table 4.12

Pairwise comparisons among sub-criteria of Sustainable packaging

\begin{tabular}{llllllllllll}
\hline $\begin{array}{l}\text { Sustainable } \\
\text { packaging }\end{array}$ & \multicolumn{3}{c}{$S c_{8}$} & \multicolumn{3}{c}{$S c_{9}$} & & & $S c_{10}$ & & $\begin{array}{l}\text { Local } \\
\text { weights }\end{array}$ \\
\hline$S c_{8}$ & $(1$ & 1 & $1)$ & $(0.5$ & 0.67 & $1)$ & $(1.5$ & 2 & $2.5)$ & 0.405 \\
$S c_{9}$ & $(1$ & 1.5 & $2)$ & $(1$ & 1 & $1)$ & $(1$ & 1.5 & $2)$ & 0.448 \\
$S c_{10}$ & $(0.4$ & 0.5 & $0.67)$ & $(0.5$ & 0.67 & $1)$ & $(1$ & 1 & $1)$ & 0.147 \\
\hline
\end{tabular}

Step 6: The overall priorities related to the green performance sub-criteria are computed by multiplying $W e_{\text {criteria }}$ (interdependent priorities of green performance criteria) obtained in Step 4, and the local weights of sub-criteria obtained in Step 5. The results are illustrated in Table 4.13. 
Table 4.13

Overall priority of the sub-criteria of green performance for potential plants

\begin{tabular}{|c|c|c|c|c|}
\hline Fuzzy ANP & $\begin{array}{c}\text { We criteria } \\
\text { obtained in } \\
\text { Step } 4\end{array}$ & Sub-criteria & $\begin{array}{l}\text { We } e_{\text {sub-criteria }} \\
\text { obtained in } \\
\text { Step } 5\end{array}$ & $\begin{array}{c}\text { We } \text { sub-criteria } \\
\quad \text { (overall) }\end{array}$ \\
\hline \multirow{3}{*}{$C_{l}$ : Eco-product design } & \multirow{3}{*}{0.365} & $S c_{1}$ & 0.771 & 0.281 \\
\hline & & $S c_{2}$ & 0.038 & 0.014 \\
\hline & & $S c_{3}$ & 0.191 & 0.070 \\
\hline \multirow{2}{*}{$C_{2}:$ Eco-technology } & \multirow[b]{2}{*}{0.265} & $\mathrm{Sc}_{4}$ & 0.316 & 0.084 \\
\hline & & $S c_{5}$ & 0.684 & 0.181 \\
\hline \multirow{2}{*}{$C_{3}$ : Green purchasing } & \multirow[b]{2}{*}{0.141} & $S c_{6}$ & 0.684 & 0.096 \\
\hline & & $S c_{7}$ & 0.316 & 0.044 \\
\hline \multirow{3}{*}{$C_{4}$ : Sustainable packaging } & \multirow{3}{*}{0.230} & $S c_{8}$ & 0.405 & 0.093 \\
\hline & & $S c_{9}$ & 0.448 & 0.103 \\
\hline & & $S c_{10}$ & 0.147 & 0.034 \\
\hline
\end{tabular}

Step 7: The priorities of the potential plants with regard to each sub-criterion are computed by pairwise comparisons. The results are indicated in Table $4.14\left(\mathrm{We}_{4}\right)$, and the details of calculations are provided in Appendix A.

Table 4.14

Overall priority of each plant associated with each sub-criterion

\begin{tabular}{lcccccccccc}
\hline$W e_{4}$ & $S c_{1}$ & $S c_{2}$ & $S c_{3}$ & $S c_{4}$ & $S c_{5}$ & $S c_{6}$ & $S c_{7}$ & $S c_{8}$ & $S c_{9}$ & $S c_{10}$ \\
\hline Plant 1 & 0.211 & 0.232 & 0.262 & 0.262 & 0.312 & 0.198 & 0.270 & 0.214 & 0.235 & 0.225 \\
Plant 2 & 0.183 & 0.219 & 0.206 & 0.169 & 0.156 & 0.212 & 0.184 & 0.229 & 0.181 & 0.184 \\
Plant 3 & 0.186 & 0.177 & 0.157 & 0.168 & 0.155 & 0.151 & 0.145 & 0.135 & 0.179 & 0.187 \\
Plant 4 & 0.149 & 0.111 & 0.185 & 0.153 & 0.185 & 0.180 & 0.126 & 0.145 & 0.127 & 0.148 \\
Plant 5 & 0.158 & 0.142 & 0.112 & 0.142 & 0.133 & 0.134 & 0.157 & 0.175 & 0.156 & 0.157 \\
Plant 6 & 0.111 & 0.121 & 0.078 & 0.106 & 0.058 & 0.124 & 0.118 & 0.102 & 0.122 & 0.099 \\
\hline
\end{tabular}

Step 8: The overall priority of the potential plants based on green practices are measured by multiplying $\mathrm{We}_{4}$ found in Step 7, and Wesub-criteria (overall) obtained in Step 6. The results are provided in Table 4.15. 
Table 4.15

Results of the fuzzy ANP method for the plants

\begin{tabular}{lll}
\hline Plants & ANP & $\begin{array}{l}\text { ANP } \\
\text { priority }\end{array}$ \\
\hline 1 & 0.242 & 1 \\
2 & 0.186 & 2 \\
3 & 0.166 & 3 \\
4 & 0.157 & 4 \\
5 & 0.148 & 5 \\
6 & 0.100 & 6 \\
\hline
\end{tabular}

\subsection{ANP model to determine priority of battery recovery centers based on green performance}

The overall priorities of the potential battery recovery centers in aspect of green performance are measured based on the same method utilized for ranking the potential plants. As illustrated in Fig. 4.6, 3 criteria and 7 sub-criteria have been identified in this part. 


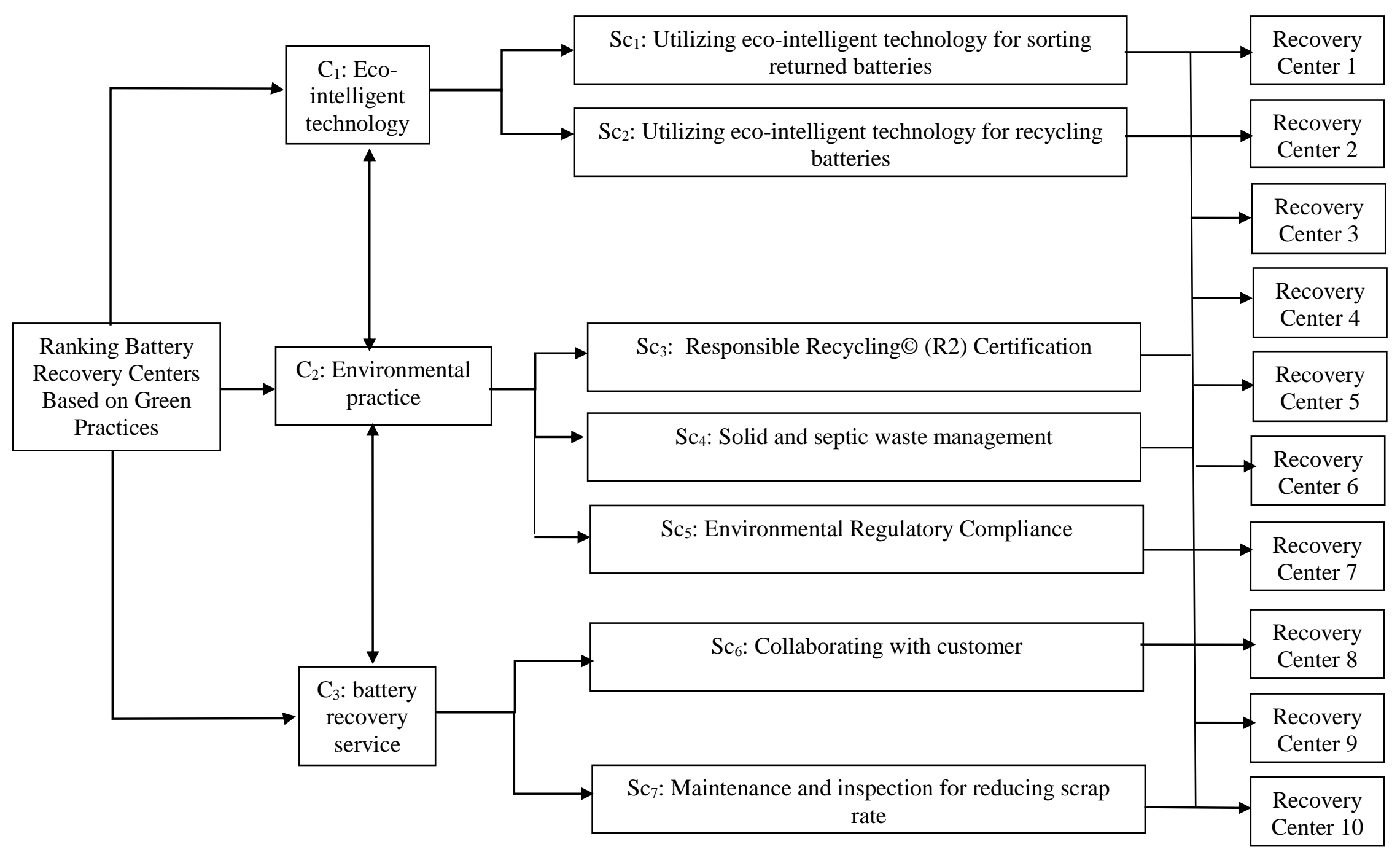

Fig. 4.6. The ANP model for prioritizing recovery centers based on their green performance 


\subsubsection{Criterion 1: Eco-intelligent technology}

Process of battery recycling can be complicated on account of safety reasons and environmental impacts. In this way, eco-intelligent technology can be utilized to overcome these issues.

\subsubsection{Sub- criterion 1: Utilizing eco-intelligent technology for sorting returned batteries}

Sorting the returned batteries for the purpose of recycling needs broad knowledge and expertise. For instance, mixing the Alkaline batteries and mercury containing batteries is hazardous because of reusing recycled materials, or mixing Lithium batteries with Alkaline batteries may lead to fire occurrence. For such reasons, utilizing eco-intelligent technology is the significant help in the sorting section (www.batterysolutions.com).

\subsubsection{Sub- criterion 2: Utilizing eco-intelligent technology for recycling batteries}

Application of eco-intelligent technology allows recovery centers to recycle the returned batteries intelligently with less environmental impacts due to the usage of renewable source of energy.

\subsubsection{Criterion 2: Environmental practice}

Transparency and compliance of the recovery centers with the rules legislated to protect the environment can be an overriding factor for ranking them.

\subsubsection{Sub- criterion 3: Responsible Recycling@ (R2) Certification}

The Responsible Recycling $\odot$ (R2) Certification provided by the environmental protection agency (EPA) includes a variety of guidelines and principals to evaluate green performance of recyclers. It is necessary for battery recovery centers to show their commitments towards protecting environment. Obtaining such certification makes the battery recovery centers equipped to do the recycling process with less impact on environment.

\subsubsection{Sub- criterion 4: Solid and septic waste management}

Solid and septic waste management include all activities such as collecting, transporting, treating, and disposal of waste with regard to ratified regulation. Therefore, considering waste management is a critical subject due to the usage of chemical materials for the purpose of recycling in battery recovery centers. 


\subsubsection{Sub- criterion 5: Environmental Regulatory Compliance}

Environmental compliance is defined as the obedience to ratified laws and regulations to protect environment. Battery recovery centers are supposed to comply with environmental regulations such as chemical use policy, mercury statement, and carbon footprint.

\subsubsection{Criterion 3: Battery recovery service}

Some of the battery recovery centers provide some services including preventive maintenance and free battery handling. In this category, two sub-factors such as collaborating with customers and maintenance for reduction of scrap rate are utilized for ranking the recovery centers.

\subsubsection{Sub- criterion 6: Collaborating with customer}

There are some services offered by recovery centers which can help customers such as installation of valve regulated battery, de-installation of lead battery, handling and removal of battery. All mentioned services can be the prominent factors to reduce discarded battery in environment.

\subsubsection{Sub- criterion 7: Maintenance and inspection for reducing scrap rate}

Preventive maintenance along with comprehensive inspection reports are offered by some of the battery recovery centers which may prolong life of the battery.

In order to rank the battery recovery centers, Step 1 to Step 8 were applied for green performance framework (Fig. 4.6). The details of the calculations are provided in Appendix B, and the results are indicated in Table 4.16.

Table 4.16.

Results of the fuzzy ANP method for the recovery centers

\begin{tabular}{lcc}
\hline Result & ANP & $\begin{array}{c}\text { ANP } \\
\text { priority }\end{array}$ \\
\hline Recovery center 1 & 0.148 & 1 \\
Recovery center 2 & 0.120 & 2 \\
Recovery center 3 & 0.102 & 5 \\
Recovery center 4 & 0.109 & 4 \\
Recovery center 5 & 0.116 & 3 \\
Recovery center 6 & 0.098 & 6 \\
Recovery center 7 & 0.071 & 9 \\
Recovery center 8 & 0.087 & 8 \\
Recovery center 9 & 0.092 & 7 \\
Recovery center 10 & 0.057 & 10 \\
\hline
\end{tabular}




\subsection{Conclusions}

In this chapter, some related literatures to find green performance indicators for evaluating GSCM have been provided. Thereafter, some necessary concepts about fuzzy ANP and Chang's method have been described comprehensively. Since, it is intended to consider the green practices of plants and battery recovery centers in the next chapters, two frameworks have been introduced. Firstly, a framework included four criteria and eleven sub-criteria has been proposed to rank the six plants based on green performance. Subsequently, three criteria and seven subcriteria have been identified to rank battery recovery centers. In this way, fuzzy ANP has been utilized based on Chang's method. The necessary linguistic scale of relative importance along with related guidelines for doing pairwise comparison were provided. According to the instructions, all criteria were supposed to compare without considering the probable inner dependency. However, there could be relationship among criteria led to have impacts on final results. Therefore, pairwise comparisons were applied by considering the inner dependency among criteria. Thereafter, all sub-criteria were compared, and then all plants and battery recovery centers were prioritized based on each sub-criterion. Other details of calculations along with analyses related to the battery recovery centers are provided in Appendices A and B. 


\section{CHAPTER 5. A POSSIBILISTIC SOLUTION TO CONFIGURE A BATTERY CLOSED-LOOP SUPPLY CHAIN: MULTI-OBJECTIVE APPROACH}

\subsection{Introduction}

Nowadays, decision makers encounter challenges about imprecise information in design an optimization of supply chain models. Those ambiguities stem from either internal or external factors affecting model's profit or cost. In other words, most of information is not deterministic, and decision makers are supposed to reconcile their decisions with such uncertainties. In this sense, fuzzy programming plays a prominent role in optimization problems. If it is assumed that all parameters and decision variables are imprecise, the fuzzy programming can be extended to fully fuzzy programming (FFP) case. In this thesis, it is aimed to develop and apply FFP to address the probable uncertainty in the introduced battery CLSC network.

The structure of this chapter is arranged as follows: First, some literatures of fuzzy programming method are reviewed in Section 5.2. Subsequently, some necessary concepts and background of fuzzy arithmetic are provided in Section 5.3. Thereafter, FFP method is applied for the proposed battery CLSC network in Section 5.4. The values of parameters and solutions are provided in Section 5.5. To address uncertainty thoroughly, combination of scenario-based analysis and FFP is employed to consider different scenarios in Section 5.6. An extension to multi-objective is described in Section 5.7. The definition and application of distance method along with the results are provided in Section 5.8. The E-constraint method is also utilized for comparison the results with distance method in Section 5.9. Finally, Section 5.10 is devoted to conclusions.

\subsection{Review of some related studies to fuzzy programming method}

Kabak and Ülengin. (2011) applied possibilistic linear programming (PLP) in order to deal with uncertainties in their proposed model. For such purposes, a fuzzy sets theory-based model was used with the view of making strategic plan for utilizing resources under uncertainties. According to their assumption, some parameters of their proposed model were fuzzy, and the others were crisp. Ebrahimnejad et al. (2014) proposed a method in which parameters of the objective function and the values of the right-hand side related to constraints are complied with symmetric trapezoidal fuzzy numbers, while the other parameters are indicated by real numbers. 
They also mentioned that their model needs less arithmetic operations. Furthermore, they retrieved a fuzzy solution from the converted crisp problem without adding constraints and variables to the original problems. Wan et al. (2014) proposed a fuzzy linear programming model consisting of trapezoidal fuzzy numbers (TrFNs). They used TrFNs to consider uncertainties for the imprecise parameters and decision variables existing in the objective functions, and the constraints. They applied auxiliary multi-objective linear programming (MOLP) in order to solve the possibilistic problems. Weighted-sum method, optimistic, and pessimistic approaches were utilised to solve the auxiliary MOLP. Azadeh et al. (2015) developed a multi-objective multiperiod fuzzy programming model to consider different objectives under uncertain circumstances. Hence, a two-phase approach was introduced to solve the problem. First, a multi-objective possibilistic method was converted into the equivalent crisp version, and secondly, interactive method was applied to convert the multi-objective model into a single objective one. They applied a possibilistic programming approach to verify and validate their model.

Ezzati et al. (2015) proposed a new algorithm to solve the FFP problem with regard to new lexicographic ordering on triangular fuzzy numbers (TFNS). According to their novel algorithm, FFP was converted to its equivalent MOLP problem, and then it was solved by complying with lexicographic method. Dai et al. (2016) developed an interval fuzzy possibilistic programming (IFPP) by combining interval parameters programming (IPP), fuzzy possibilistic programming (FPP), and a fuzzy expected value equation. They claimed that the proposed method could deal with uncertainties and improve the conventional fuzzy mathematical programming.

\subsection{An overview of triangular fuzzy number operations}

In this part, some necessary concepts and backgrounds of fuzzy arithmetic are provided.

Definition 5.1. As indicated in Fig. 5.1, $\tilde{u}=(j, k, l)$ is a triangular fuzzy number, if its membership function is given as follows:

$$
\mu_{u}(x)= \begin{cases}0, & x<i \\ (x-i) /(k-i) & i \leq x \leq k \\ (l-x) /(l-k) & k \leq x \leq l \\ 0, & x>l\end{cases}
$$

Definition 5.2. A triangular fuzzy set $\tilde{u}=(i, k, l)$ is assumed to be non-negative triangular fuzzy set, if and only if $i \geq 0$. 


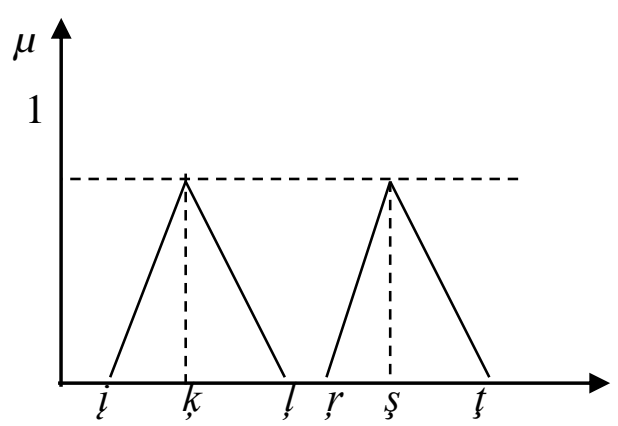

Fig. 5.1. A triangle fuzzy number

Definition 5.3. The arithmetic operations between two triangular fuzzy set $\tilde{u}=(i, k, l)$ and $\tilde{v}=(r$, $s, t)$ are indicated as follows

i. $n \geq 0, n \tilde{u}=(n i, n k, n l)$,

ii. $\quad n \leq 0, n \tilde{u}=(n l, n k, n i)$,

iii. $\tilde{u}+\tilde{v}=(i+r, k,+s ̧, l+t)$,

iv. $\quad \tilde{v}-\tilde{u}=(r-l,, s\}-k, t,-i)$,

I. If $\tilde{u}=(i, k, l)$ is defined as a triangular fuzzy set, and $\tilde{v}=(r, s, t \underline{t})$ is assumed a nonnegative triangular fuzzy set, then

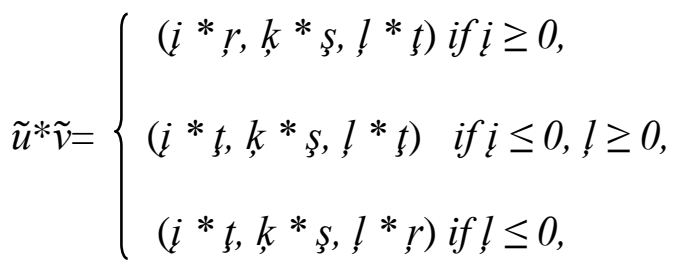

Definition 5.4. it can be assumed that $\tilde{u} \leq \tilde{v}$, if and only if:

i. $\quad k<s ̧$, or

ii. $\quad k=s$, and $(l-i)>(t-r)$ or

iii. $\quad k=s ̧,(l-i)=(t-r)$ and $(i+l)<(r+t)$

\subsection{FFP model in closed-loop supply chain}

Fuzzy programming is a prominent technique in optimization. Although all parameters and variables are assumed to be precise in general mathematical models, there is often imprecise information in real life particularly in CLSCs. Therefore, fuzzy numbers and variables should be 
applied in modeling CLSCs. It is aimed to develop and apply a solution approach according to the algorithm proposed by Ezzati et al., (2015), to solve the FFP model in the introduced CLSC. Problem 5.8 is considered as the typical arrangement of FFP.

$\operatorname{Max}(\operatorname{Min}) \stackrel{\mathscr{C}}{C}^{T} \widetilde{X}$

s.t. $\tilde{\mathscr{A}} \widetilde{X}=\tilde{b}$

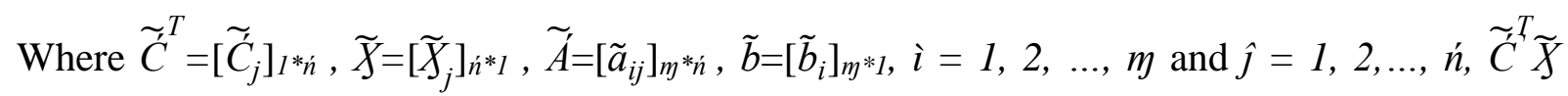
$=\left(\left(\dot{C}^{T} X\right)^{l},\left(\dot{C}^{T} X\right)^{c},\left(\dot{C}^{T} X\right)^{u}\right), \tilde{A} \tilde{X}=\left((A X)^{l},(A X)^{c},(A X)^{u}\right), \tilde{b}=\left((b)^{l},(b)^{c},(b)^{u}\right), \tilde{X}=\left((X)^{l},(X)^{c},(X)^{u}\right)$, $(X)^{l} \geq 0$, therefore Problem (5.8) is indicated as follows:

$\operatorname{Max}(\operatorname{Min})\left(\left(\dot{C}^{T} X\right)^{l},\left(\dot{C}^{T} X\right)^{c},\left(\dot{C}^{T} X\right)^{u}\right)$

s.t. $\left((A X)^{l},(\dot{A} X)^{c},(\dot{A} X)^{u}\right)=\left((b)^{l},(b)^{c},(b)^{u}\right)$

The steps to find the solution of the problem are mentioned in this section.

Step 1: To solve Problem (5.9), the problem is written as follows:

$\operatorname{Max}(\operatorname{Min})\left(\left(\dot{C}^{T} X\right)^{l},\left(\dot{C}^{T} X\right)^{c},\left(\dot{C}^{T} X\right)^{u}\right)$

s.t. $\left(A^{\prime} X\right)^{l}=(b)^{l},\left(A^{\prime} X\right)^{c}=(b)^{c},\left(A^{\prime} X\right)^{u}=(b)^{u}$

$(X)^{c}-(X)^{l} \geq 0,(X)^{u}-(X)^{c} \geq 0,(X)^{l} \geq 0$

Step 2: Problem (5.10) is divided to the three following crisp objectives:

$\operatorname{Max}(\operatorname{Min})\left(C^{T} X\right)^{c}$

$\operatorname{Min}(\operatorname{Max})\left(\left(\dot{C}^{T} X\right)^{u}-\left(\dot{C}^{T} X\right)^{l}\right)$

$\operatorname{Max}(\operatorname{Min})\left(\left(\dot{C}^{T} X\right)^{l}+\left(\dot{C}^{T} X\right)^{u}\right)$,

s.t. $\left(A^{\prime} X\right)^{l}=(b)^{l},\left(A^{\prime} X\right)^{c}=(b)^{c},\left(A^{\prime} X\right)^{u}=(b)^{u}$

$(X)^{c}-(X)^{l} \geq 0,(X)^{u}-(X)^{c} \geq 0,(X)^{l} \geq 0$

Step 3: In this step, the first objective function of Problem (5.11) is considered regarding to the defined constraints.

$\operatorname{Max}(\operatorname{Min})\left(C^{T} X\right)^{c}$

s.t. $\left(A^{\prime} X\right)^{l}=(b)^{l},\left(A^{\prime} X\right)^{c}=(b)^{c},\left(A^{\prime} X\right)^{u}=(b)^{u}$

$(X)^{c}-(X)^{l} \geq 0,(X)^{u}-(X)^{c} \geq 0,(X)^{l} \geq 0$

Thereafter, if a unique optimal solution was obtained explicitly for $\widetilde{X}^{*}=\left(\left(X^{*}\right)^{l},\left(X^{*}\right)^{c},\left(X^{*}\right)^{u}\right)$ in Step 3, we stop; otherwise we go to the next step. 
$\left(\widetilde{X}^{*}=\left(X^{*}\right)^{l},\left(X^{*}\right)^{c},\left(X^{*}\right)^{u}\right)$ is considered as a unique optimal solution, if the following conditions are fulfilled:

(i) $\widetilde{X}^{*}=\left[\widetilde{X}_{j}^{*}\right]_{n^{*} l}$, where $\widetilde{X}_{j}^{*} \in T F(\mathrm{R})^{+} j=1,2, \ldots, n$,

(ii) $A X^{*}=b$,

(iii) $\quad \forall \widetilde{X}=\left((X)^{l},(X)^{c},(X)^{u}\right) \in \tilde{S}=\left\{\widetilde{X} \mid \widetilde{A} \widetilde{X}=\tilde{b}, \widetilde{X}=\left[\widetilde{X}_{j}\right]_{n^{* l}}\right.$ where $\left.\widetilde{X}_{j} \in T F(\mathrm{R})^{+}\right\}, \widetilde{C}^{T} \widetilde{X} \leq \widetilde{C}^{T} \widetilde{X}^{*}$ (in case of minimization $\widetilde{C}^{T} \widetilde{X} \geq \widetilde{C}^{T} \widetilde{X}^{*}$ ).

Step 4: Problem (5.13) is solved regarding the solution $\left(p^{*}\right)$ obtained in Step 3. If the unique optimal solution is obtained for $\widetilde{X}^{*}=\left(\left(X^{*}\right)^{l},\left(X^{*}\right)^{c},\left(X^{*}\right)^{u}\right)$, we stop, otherwise we go to Step 5 .

$$
\begin{aligned}
& \text { Min }(\operatorname{Max})\left(\left(\dot{C}^{T} X\right)^{u}-\left(\dot{C}^{T} X\right)^{l}\right) \\
& \text { s.t. }\left(\dot{C}^{T} X\right)^{c}=p^{*} \\
& (A X)^{l}=(b)^{l},(A X)^{c}=(b)^{c},(A X)^{u}=(b)^{u} \\
& (X)^{c}-(X)^{l} \geq 0,(X)^{u}-(X)^{c} \geq 0,(X)^{l} \geq 0
\end{aligned}
$$

Step 5: Problem (5.14) is solved according to the solutions ( $p^{*}$ and $q^{*}$ ) obtained in Steps 3 and 4.

$$
\begin{aligned}
& \text { Max (Min) }\left(\left(\dot{C}^{T} X\right)^{l}+\left(\dot{C}^{T} X\right)^{u}\right), \\
& \text { s.t. }\left(\left(\dot{C}^{T} X\right)^{u}-\left(\dot{C}^{T} X\right)^{l}\right)=q^{*} \\
& \left(\dot{C}^{T} X\right)^{c}=p^{*} \\
& (\dot{A} X)^{l}=(b)^{l},(\dot{A} X)^{c}=(b)^{c},(A X)^{u}=(b)^{u} \\
& (X)^{c}-(X)^{l} \geq 0,(X)^{u}-(X)^{c} \geq 0,(X)^{l} \geq 0
\end{aligned}
$$

As indicated by the algorithm, it is supposed to define the lower, middle, and upper ranges for the objective at the beginning of the solution approach. Since the objective function of the introduced algorithm included vector $X$ in the same direction, all lower, middle, and upper ranges were defined based on Eq. (5.9) $\left(z^{l}=\left(\dot{C}^{T} X\right)^{l}, z^{c}=\left(\dot{C}^{T} X\right)^{c}, z^{u}=\left(\dot{C}^{T} X\right)^{u}\right)$. However, in the proposed FFP model, the objective function consists of two parts; the first part is about the revenue of selling products, and the second part is about all imposed costs associated with production, transportation, disposal, and inventory costs (as the variable costs), and costs of opening the plants, retailers, and battery recovery centers (as the fixed costs). Therefore, the upper range of the objective can be obtained when all parameters and decision variables contributing to achieve the revenue are in the upper range, and all parameters and decision variables causing imposed 
cost are in the lower range. By the reverse approach, the lower range of the objective can be reached. To define the middle range, the same instruction with regard to Eq. (5.9) $\left(z^{c}=\left(C^{T} X\right)^{c}\right)$ is followed up. Therefore, our proposed FFP model for the battery CLSC network can be written as Eqs. (5.15) - (5.67). Then, the solution will be calculated based on the defined steps.

$$
\begin{aligned}
& \operatorname{Max}\left(\begin{array}{l}
z^{l}=\sum_{r} \sum_{k} \sum_{j} \sum_{t}\left(\delta_{j}^{l}-H_{j}^{u} E_{r k}\right) S_{r k j t}^{l}-\left(\sum_{s} \sum_{i} \sum_{\eta} \sum_{t}\left(N_{s \eta}^{u}+F_{\eta}^{u} E_{s i}\right) Q_{s i \eta t}^{u}+\sum_{i} \sum_{r} \sum_{j} \sum_{t}\left(P_{j}^{u}+G_{j}^{u} E_{i r}\right) R_{i r j t}^{u}\right. \\
+\sum_{r} \sum_{j} \sum_{t} \alpha_{j}^{u} I_{r j t}^{u}+\sum_{k} \sum_{l} \sum_{j} \sum_{t} M_{j}^{u} E_{k l} T_{k l j t}^{u}+\sum_{l} \sum_{i} \sum_{\eta} \sum_{t}\left(-a_{\eta}^{l}+O_{\eta}^{u} E_{l i}\right) U_{l i \eta t}^{l}+\sum_{l} \sum_{\eta} \sum_{t}\left(f_{\eta}^{u}+\theta_{\eta}^{u} E_{l}\right) \lambda_{l \eta t}^{u} \\
\left.+\sum_{s} A_{s}^{u} Y_{s}+\sum_{i} B_{i}^{u} V_{i}+\sum_{r} R_{r}^{u} W_{r}+\sum_{l} C_{l}^{u} X_{l}\right)
\end{array}\right), \\
& \left(\begin{array}{l}
z^{c}=\sum_{r} \sum_{k} \sum_{j} \sum_{t}\left(\delta_{j}^{c}-H_{j}^{c} E_{r k}\right) S_{r k j t}^{c}-\left(\sum_{s} \sum_{i} \sum_{\eta} \sum_{t}\left(N_{s \eta}^{c}+F_{\eta}^{c} E_{s i}\right) Q_{s i \eta t}^{c}+\sum_{i} \sum_{r} \sum_{j} \sum_{t}\left(P_{j}^{c}+G_{j}^{c} E_{i r}\right) R_{i r j t}^{c}\right. \\
+\sum_{r} \sum_{j} \sum_{t} \alpha_{j}^{c} I_{r j t}^{c}+\sum_{k} \sum_{l} \sum_{j} \sum_{t} M_{j}^{c} E_{k l} T_{k l j t}^{c}+\sum_{l} \sum_{i} \sum_{\eta} \sum_{t}\left(-a_{\eta}^{c}+O_{\eta}^{c} E_{l i}\right) U_{l i \eta t}^{c}+\sum_{l} \sum_{\eta} \sum_{t}\left(f_{\eta}^{c}+\theta_{\eta}^{c} E_{l}\right) \lambda_{l \eta t}^{c} \\
\left.+\sum_{s} A_{s}^{c} Y_{s}+\sum_{i} B_{i}^{c} V_{i}+\sum_{r} R_{r}^{c} W_{r}+\sum_{l} C_{l}^{c} X_{l}\right)
\end{array}\right), \\
& \left(z^{u}=\sum_{r} \sum_{k} \sum_{j} \sum_{t}\left(\delta_{j}^{u}-H_{j}^{l} E_{r k}\right) S_{r k j t}^{u}-\left(\sum_{s} \sum_{i} \sum_{\eta} \sum_{t}\left(N_{s \eta}^{l}+F_{\eta}^{l} E_{s i}\right) Q_{s i \eta t}^{l}+\sum_{i} \sum_{r} \sum_{j} \sum_{t}\left(P_{j}^{l}+G_{j}^{l} E_{i r}\right) R_{i r j t}^{l}\right.\right. \\
& +\sum_{r} \sum_{j} \sum_{t} \alpha_{j}^{l} I_{r j t}^{l}+\sum_{k} \sum_{l} \sum_{j} \sum_{t} M_{j}^{l} E_{k l} T_{k l j t}^{l}+\sum_{l} \sum_{i} \sum_{\eta} \sum_{t}\left(-a_{\eta}^{u}+O_{\eta}^{l} E_{l i}\right) U_{l i \eta t}^{u}+\sum_{l} \sum_{\eta} \sum_{t}\left(f_{\eta}^{1}+\theta_{\eta}^{l} E_{l}\right) \lambda_{l \eta t}^{l} \\
& \left.+\sum_{s} A_{s}^{l} Y_{s}+\sum_{i} B_{i}^{l} V_{i}+\sum_{r} R_{r}^{l} W_{r}+\sum_{l} C_{l}^{l} X_{l}\right)
\end{aligned}
$$

s.t.

$$
\begin{array}{ll}
I_{r j t}^{l}=I_{r j t-1}^{l}+\sum_{i} R_{i r j t}^{l}-\sum_{k} S_{r k j t}^{l} & \forall r, j, t \\
I_{r j t}^{c}=I_{r j t-1}^{c}+\sum_{i} R_{i r j t}^{c}-\sum_{k} S_{r k j t}^{c} & \forall r, j, t \\
I_{r j t}^{u}=I_{r j t-1}^{u}+\sum_{i} R_{i r j t}^{u}-\sum_{k} S_{r k j t}^{u} & \forall r, j, t \\
\sum_{s} Q_{s i \eta t}^{l}+\sum_{l} U_{l i \eta t}^{l}=\sum_{r} \sum_{j}\left(R_{i r j t}^{l}\right) v_{j n} & \forall i, \eta, t \\
\sum_{s} Q_{s i \eta t}^{c}+\sum_{l} U_{l i \eta t}^{c}=\sum_{r} \sum_{j}\left(R_{i r j t}^{c}\right) v_{j n} & \forall i, \eta, t \\
\sum_{s} Q_{s i \eta t}^{u}+\sum_{l} U_{l i \eta t}^{u}=\sum_{r} \sum_{j}\left(R_{i r j t}^{u}\right) v_{j n} & \forall i, \eta, t
\end{array}
$$




$$
\begin{aligned}
& \sum_{i} R_{i r j t}^{l}+I_{r j t}^{l} \geq \sum_{k} S_{r k j t}^{l} \quad \forall r, j, t \\
& \sum_{i} R_{i j j t}^{c}+I_{r j t}^{c} \geq \sum_{k} S_{r k j t}^{c} \quad \forall r, j, t \\
& \sum_{i} R_{i j j t}^{u}+I_{r j t}^{u} \geq \sum_{k} S_{r k j t}^{u} \quad \forall r, j, t \\
& \sum_{r} S_{r k j t}^{l} \leq d_{k j t}^{l} \quad \forall k, j, t \\
& \sum_{r} S_{r k j t}^{c} \leq d_{k j t}^{c} \quad \forall k, j, t \\
& \sum_{r} S_{r k j t}^{u} \leq d_{k j t}^{u} \quad \forall k, j, t \\
& \sum_{r} S_{r k j t}^{l} \geq \sum_{l} T_{k j j t}^{l} \quad \forall k, j, t \\
& \sum_{r} S_{r k j t}^{c} \geq \sum_{l} T_{k j j t}^{c} \quad \forall k, j, t \\
& \sum_{r} S_{r k j t}^{u} \geq \sum_{l} T_{k l j t}^{u} \quad \forall k, j, t \\
& \sum_{l} T_{k j t}^{l}=z_{k j t}^{l} \quad \forall k, j, t \\
& \sum_{l} T_{k j j}^{c}=z_{k j t}^{c} \quad \forall k, j, t \\
& \sum_{l} T_{k j t}^{u}=z_{k j t}^{u} \quad \forall k, j, t \\
& \varepsilon_{\eta}^{l} \sum_{k} \sum_{j}\left(T_{k l j t}^{l}\right) v_{j \eta} \leq \lambda_{l \eta t}^{l} \quad \forall l, \eta, t \\
& \varepsilon_{\eta}^{c} \sum_{k} \sum_{j}\left(T_{k l j t}^{c}\right) v_{j \eta} \leq \lambda_{l \eta t}^{c} \quad \forall l, \eta, t \\
& \varepsilon_{\eta}^{u} \sum_{k} \sum_{j}\left(T_{k j l t}^{u}\right) v_{j \eta} \leq \lambda_{l \eta \eta}^{u} \quad \forall l, \eta, t \\
& \sum_{k} \sum_{j}\left(T_{k j t}^{l}\right) \nu_{j \eta}=\sum_{i} U_{l i \eta t}^{l}+\lambda_{l \eta t}^{l} \quad \forall l, \eta, t
\end{aligned}
$$


$\begin{array}{ll}\sum_{k} \sum_{j}\left(T_{k j t}^{c}\right) v_{j \eta}=\sum_{i} U_{l i \eta t}^{c}+\lambda_{l \eta \eta t}^{c} & \forall l, \eta, t \\ \sum_{k} \sum_{j}\left(T_{k j j t}^{u}\right) v_{j \eta}=\sum_{i} U_{l i \eta t}^{u}+\lambda_{l \eta t}^{u} & \forall l, \eta, t\end{array}$

$\sum_{s} \sum_{\eta} Q_{s i \eta t}^{l}+\sum_{l} \sum_{\eta} U_{l i \eta t}^{l} \leq V_{i} \sum_{\eta} g_{i \eta} \quad \forall i, t$

$\sum_{s} \sum_{\eta} Q_{s i \eta t}^{c}+\sum_{l} \sum_{\eta} U_{l i \eta t}^{c} \leq V_{i} \sum_{\eta} g_{i \eta} \quad \forall i, t$

$\sum_{s} \sum_{\eta} Q_{s i \eta t}^{u}+\sum_{l} \sum_{\eta} U_{l i \eta t}^{u} \leq V_{i} \sum_{\eta} g_{i \eta} \quad \forall i, t$

$\sum_{i} \sum_{j} R_{i r j t}^{l}+\sum_{j} I_{r j t}^{l} \leq W_{r} \sum_{j} h_{r j} \quad \forall r, t$

$\sum_{i} \sum_{j} R_{i j i t}^{c}+\sum_{j} I_{r j t}^{c} \leq W_{r} \sum_{j} h_{r j} \quad \forall r, t$

$\sum_{i} \sum_{j} R_{i r j t}^{u}+\sum_{j} I_{r j t}^{u} \leq W_{r} \sum_{j} h_{r j} \quad \forall r, t$

$\sum_{k} \sum_{j} T_{k l j t}^{l} \leq X_{l} \sum_{j} n_{l j} \quad \forall l, t$

$\sum_{k} \sum_{j} T_{k j t}^{c} \leq X_{l} \sum_{j} n_{l j} \quad \forall l, t$

$\sum_{k} \sum_{j} T_{k l j t}^{u} \leq X_{l} \sum_{j} n_{l j} \quad \forall l, t$

$\sum_{i} \sum_{\eta} Q_{s i \eta t}^{l} \leq Y_{s} \sum_{\eta} u_{s \eta} \quad \forall s, t$

$\sum_{i} \sum_{\eta} Q_{s i \eta t}^{c} \leq Y_{s} \sum_{\eta} u_{s \eta} \quad \forall s, t$

$\sum_{i} \sum_{\eta} Q_{s i \eta t}^{u} \leq Y_{s} \sum_{\eta} u_{s \eta} \quad \forall s, t$

$Q_{\text {sint }}^{c}-Q_{\text {sint }}^{l} \geq 0 \quad \forall s, i, \eta, t$

$Q_{s i \eta t}^{u}-Q_{s i n t}^{c} \geq 0 \quad \forall s, i, \eta, t$

$R_{i r j t}^{c}-R_{i r j t}^{l} \geq 0 \quad \forall i, r, j, t$ 


$$
\begin{aligned}
& R_{i j j t}^{u}-R_{i r j t}^{c} \geq 0 \quad \forall i, r, j, t \\
& S_{r k j t}^{c}-S_{r k j t}^{l} \geq 0 \quad \forall r, k, j, t \\
& S_{r k j t}^{u}-S_{r k j t}^{c} \geq 0 \quad \forall r, k, j, t \\
& T_{k l j t}^{c}-T_{k l t}^{l} \geq 0 \quad \forall k, l, j, t \\
& \begin{array}{l}
T_{k j t}^{u}-T_{k j t}^{c} \geq 0 \quad \forall k, l, j, t
\end{array} \\
& U_{\text {lint }}^{c}-U_{\text {lint }}^{l} \geq 0 \quad \forall l, i, \eta, t \\
& U_{\text {lint }}^{u}-U_{\text {lint }}^{c} \geq 0 \quad \forall l, i, \eta, t \\
& \begin{array}{l}
I_{r j t}^{c}-I_{r j t}^{l} \geq 0 \quad \forall r, j, t
\end{array} \\
& I_{r j t}^{u}-I_{r j t}^{c} \geq 0 \quad \forall r, j, t \\
& \lambda_{l \eta t}^{c}-\lambda_{l \eta t}^{l} \geq 0 \quad \forall l, \eta, t \\
& \lambda_{l \eta t}^{u}-\lambda_{l \eta t}^{c} \geq 0 \quad \forall l, \eta, t \\
& V_{i}, W_{r}, X_{l}, Y_{s} \in\{0,1\} \quad \forall i, r, l, s \\
& Q_{s i \eta t}^{l}, R_{i r j t}^{l}, S_{r k j t}^{l}, T_{k j j t}^{l}, U_{l i \eta t}^{l}, \lambda_{l \eta t}^{l}, I_{r j t}^{l} \geq 0 \quad \forall s, i, \eta, t, r, j, k, l
\end{aligned}
$$

\subsection{Values of the parameters and solution}

As mentioned in Chapter 3, the model has been designed for a battery CLSC network in Vancouver, Canada. The middle triangular fuzzy values for all parameters are assumed to be equal to the parameters values of the deterministic model, while the lower and upper triangular fuzzy values of parameters are assumed to be equal to the lower and upper ranges of each value. For further elaboration, the lower retail price of fuel was 1.06 in Vancouver during the last year. According to the fuel consumption guide, each truck almost needs 8.15 litre per 100 kilometers. Therefore, the lower range transportation cost is approximately estimated by $(8.15 / 100) * 1.06=$ 
0.087. The values of the fuzzy parameters applied to solve the proposed FFP model are provided in Table 5.1.

Table 5.1

Values of some parameters applied to solve the proposed FFP model

\begin{tabular}{lll}
\hline$J=3$ & $\widetilde{A}_{s}=(900,1,000,1,100)$ & $\widetilde{P}_{j}=(14,15,16)$ \\
$N=5$ & $\widetilde{B}_{i}=(900,000,1,000,000,1,100,000)$ & $\tilde{f}_{\eta}=(0.9,1,1.1)$ \\
$S=5$ & $\widetilde{R}_{r}=(1,400,1,500,1,600)$ & $\tilde{a}_{\eta}=(9,10,11)$ \\
$I=6$ & $\widetilde{C}_{l}=(1,400,1,500,1,600)$ & $g_{i \eta}=(2,500,000)_{6 * 5}$ \\
$R=7$ & $\widetilde{\delta}_{j}=(145,150,155)$ & $h_{r j}=(10,000)_{7 * 3}$ \\
$K=22$ & $\widetilde{G}_{j}=\widetilde{H}_{j}=\widetilde{M}_{j}=(0.087,0.097,0.107)$ & $n_{l j}=(10,000)_{10 * 3}$ \\
$L=10$ & $\widetilde{F}_{\eta}=\widetilde{O}_{\eta}=\widetilde{\theta}_{\eta}=(0.0174,0.0194,0.0214)$ & $u_{s \eta}=(30,000)_{5 * 5}$ \\
$T=3$ & $\widetilde{\varepsilon}_{\eta}=(0.09,0.10,0.11)$ & $\tilde{\alpha}_{j}=(38,40,42)$ \\
\hline
\end{tabular}

IBM ILOG CPLEX 12.7.1.0 is used for solving the mathematical model based on the defined steps. In the last step, the FFP model is solved in 32 seconds. 10,469 constraints, 10,680 single variables, 28 binary variables, and 107,415 non-zero coefficients exist. The results of FFP model are illustrated in Table 5.2.

\subsection{Comparison between the solution of deterministic and FFP model}

In order to compare the solutions obtained from deterministic and FFP model, the values parameters using in these methods should be considered at first. In FFP model, TFNs were employed to define each parameter, and solution was calculated for lower value (pessimistic approach), middle value (most likely approach), and upper value (optimistic approach). It is supposed to be notified that the value of binary variables estimated by both methods were exactly equal. Existence of lower and upper optimal value for objective function and decision variables are the privilege of FFP compared to deterministic model.

The configuration of CLSC is usually applied to make strategic decision which is impossible to change in a short time. Therefore, all possible range of parameters, decision variables, and objective function should be considered for making a comprehensive decision. The FFP was applied to find the range of possible results for objective function and decision variables in uncertain situation. 
Table 5.2

Solution of the FFP model

\begin{tabular}{|c|c|c|c|c|c|c|c|}
\hline & \multicolumn{2}{|c|}{ Lower value } & \multicolumn{2}{|r|}{ Middle value } & \multicolumn{2}{|r|}{ Upper value } & $\begin{array}{l}\text { Binary variables }\left(Y_{s}, V_{i} \text {, }\right. \\
\left.W_{r}, X_{l}\right)\end{array}$ \\
\hline Objective & \multicolumn{2}{|c|}{$15,865,536.69$} & \multicolumn{2}{|r|}{$19,031,814.21$} & \multicolumn{2}{|c|}{$20,751,305.19$} & \multirow{3}{*}{$\begin{array}{l}\text { Supplier Location }\left(Y_{S}\right) \text { : } \\
Y_{l} \text { (Downtown), } Y_{5} \\
\text { (Downtown) }\end{array}$} \\
\hline \multirow{2}{*}{$\widetilde{Q}_{s i \eta t}$} & $2064668 ?$ & Period 1: & \multirow{2}{*}{$206,466.82$} & Period 1: & \multirow{2}{*}{$206,466.82$} & Period 1: & \\
\hline & & Period 2: $206,466.82$ & & Period 2: $206,466.82$ & & Period 2: 206,466.82 & \\
\hline \multirow{2}{*}{$\widetilde{R}_{i r j t}$} & \multirow{2}{*}{$52,022.81$} & Period 1: 5,364.72 & \multirow{2}{*}{$57,655.90$} & Period 1: $8,181.27$ & \multirow{2}{*}{$57,655.90$} & Period 1: $8,181.27$ & \multirow{2}{*}{$\begin{array}{l}\text { Plant Location }\left(V_{i}\right): V_{2} \\
\text { (Downtown) }\end{array}$} \\
\hline & & Period 2: 46,658.09 & & Period 2: $49,474.635$ & & Period 2: $49,474.635$ & \\
\hline \multirow{2}{*}{$\tilde{S}_{r k j t}$} & \multirow{2}{*}{$172,872.74$} & Period 1: $85,404.74$ & \multirow{2}{*}{181,536} & Period 1: 90,768 & \multirow{2}{*}{181,536} & Period 1: 90,768 & \multirow{4}{*}{$\begin{array}{l}\text { Retailer Location }\left(W_{r}\right) \text { : } \\
W_{l} \text { (Strathcona) } W_{2} \\
\text { (Strathcona), } W_{3} \\
\text { (Grandview Woodland), } \\
W_{4}(\text { Grandview }\end{array}$} \\
\hline & & Period 2: 87,468 & & Period 2: 90,768 & & Period 2: 90,768 & \\
\hline \multirow{2}{*}{$\widetilde{T}_{k l j t}$} & \multirow{2}{*}{$11,790.60$} & Period 1: 5,895.3 & \multirow{2}{*}{$18,180.60$} & Period 1: $9,090.3$ & \multirow{2}{*}{$24,780.60$} & Period 1: $12,390.3$ & \\
\hline & & Period 2: 5,895.3 & & Period 2: $9,090.3$ & & Period 2: $12,390.3$ & \\
\hline \multirow{2}{*}{$\widetilde{U}_{l i \eta t}$} & \multirow{2}{*}{$53,647.23$} & Period $1: 26,823.62$ & \multirow{2}{*}{$81,812.70$} & Period 1: $40,906.35$ & \multirow{2}{*}{$81,812.70$} & Period 1: $40,906.35$ & \multirow{7}{*}{$\begin{array}{l}\text { Woodland), } W_{7} \\
\text { (Downtown) } \\
\text { Battery recovery center } \\
\text { location }\left(X_{l}\right): \quad X_{5} \\
\text { (Strathcona), } \\
\text { (Renfrew- Collinwood) }\end{array}$} \\
\hline & & Period 2: 26,823.62 & & Period 2: $40,906.35$ & & Period 2: $40,906.35$ & \\
\hline \multirow{3}{*}{$\tilde{I}_{r j t}$} & \multirow{3}{*}{$285,539.9$} & Period 0: $162,143.30$ & \multirow{3}{*}{$289,053.55$} & Period 0: $165,173.46$ & \multirow{3}{*}{$289,053.55$} & Period 0: $165,173.46$ & \\
\hline & & Period 1: $82,103.28$ & & Period 1: $82,586.73$ & & Period 1: 82,586.73 & \\
\hline & & Period 2: 41,293.37 & & Period 2: $41,293.365$ & & Period 2: 41,293.365 & \\
\hline \multirow{2}{*}{$\tilde{\lambda}_{l \eta t}$} & \multirow{2}{*}{$5,305.77$} & Period 1: $2,652.88$ & \multirow{2}{*}{$9,090.3$} & Period 1: $4,545.15$ & & Period 1: $21,045.15$ & \\
\hline & & Period 2: 2,652.88 & & Period 2: $4,545.15$ & & Period 2: 21,045.15 & \\
\hline
\end{tabular}




\subsection{Application of FFP with regard to scenario-based analysis to address uncertainty}

In FFP method, it is intended to find lower range, middle range, and upper range for the objective function with regard to lower range, middle range, and upper range of parameters and non-negative variables. However, this question may arise for decision makers; what if there is more than one alternative for lower range, middle range, and upper range for one of the parameters such as demand or return. In this case, scenario-based analysis can be employed to consider different cases for each lower range, or middle range, or upper range of demand and return. The proposed FFP model for battery CLSC network with regard to different scenarios can be written as follows:

$$
\begin{aligned}
& \operatorname{Max}\left(\begin{array}{l}
z^{l}=\sum_{\omega} \sum_{r} \sum_{k} \sum_{j} \sum_{t} \Phi_{\omega}\left(\delta_{j}^{l}-H_{j}^{u} E_{r k}\right) S_{r k j t \omega}^{l}-\left(\sum_{\omega} \sum_{s} \sum_{i} \sum_{\eta} \sum_{t} \Phi_{\omega}\left(N_{s \eta}^{u}+F_{\eta}^{u} E_{s i}\right) Q_{s i \eta t \omega}^{u}+\right. \\
\sum_{\omega} \sum_{i} \sum_{r} \sum_{j} \sum_{t} \Phi_{\omega}\left(P_{j}^{u}+G_{j}^{u} E_{i r}\right) R_{i j i t \omega}^{u}+\sum_{\omega} \sum_{r} \sum_{t} \sum_{j} \Phi_{\omega} \alpha_{j}^{u} I_{r i j \omega}^{u}+\sum_{\omega} \sum_{k} \sum_{l} \sum_{j} \sum_{t} \Phi_{\omega} M_{j}^{u} E_{k l} T_{k j l t o s}^{u}+ \\
\left.\sum_{\omega} \sum_{l} \sum_{i} \sum_{\eta} \sum_{t} \Phi_{\omega}\left(-a_{\eta}^{l}+O_{\eta}^{u} E_{l j}\right) U_{l i \eta t \omega}^{l}+\sum_{\omega} \sum_{l} \sum_{\eta} \sum_{t} \Phi_{\omega}\left(f_{\eta}^{u}+\theta_{\eta}^{u} E_{l}\right)\right)_{l \eta t \omega}^{u} \\
\left.+\sum_{s} A_{s}^{u} Y_{s}+\sum_{i} B_{i}^{u} V_{i}+\sum_{r} R_{r}^{u} W_{r}+\sum_{l} C_{l}^{u} X_{l}\right)
\end{array}\right) \\
& \left(\begin{array}{l}
z^{c}=\sum_{\omega} \sum_{r} \sum_{k} \sum_{j} \sum_{t} \Phi_{\omega}\left(\delta_{j}^{c}-H_{j}^{c} E_{r k}\right) S_{r k j t \omega}^{c}-\left(\sum_{\omega} \sum_{s} \sum_{i} \sum_{\eta} \sum_{t} \Phi_{\omega}\left(N_{s \eta}^{c}+F_{\eta}^{c} E_{s i}\right) Q_{s i \eta t \omega}^{c}+\right. \\
\sum_{\omega} \sum_{i} \sum_{r} \sum_{j} \sum_{t} \Phi_{\omega}\left(P_{j}^{c}+G_{j}^{c} E_{i r}\right) R_{i j i t \omega}^{c}+\sum_{\omega} \sum_{r} \sum_{t} \sum_{j} \Phi_{\omega} \alpha_{j}^{c} I_{r j i \omega}^{c}+\sum_{\omega} \sum_{k} \sum_{l} \sum_{j} \sum_{t} \Phi_{\omega} M_{j}^{c} E_{k l} T_{k j i t \omega}^{c}+ \\
\sum_{\omega} \sum_{l} \sum_{i} \sum_{\eta} \sum_{t} \Phi_{\omega}\left(-a_{\eta}^{c}+O_{\eta}^{c} E_{l j}\right) U_{l i \eta t \omega}^{c}+\sum_{\omega} \sum_{l} \sum_{\eta} \sum_{t} \Phi_{\omega}\left(f_{\eta}^{c}+\theta_{\eta}^{c} E_{l}\right) \lambda_{l \eta t \omega}^{c} \\
\left.+\sum_{s} A_{s}^{c} Y_{s}+\sum_{i} B_{i}^{c} V_{i}+\sum_{r} R_{r}^{c} W_{r}+\sum_{l} C_{l}^{c} X_{l}\right)
\end{array}\right), \\
& \left(z^{u}=\sum_{\omega} \sum_{r} \sum_{k} \sum_{j} \sum_{t} \Phi_{\omega}\left(\delta_{j}^{u}-H_{j}^{l} E_{r k}\right) S_{r k j t o}^{u}-\left(\sum_{\omega} \sum_{s} \sum_{i} \sum_{\eta} \sum_{t} \Phi_{\omega}\left(N_{s \eta}^{l}+F_{\eta}^{l} E_{s i}\right) Q_{s i \eta t \omega}^{l}+\right.\right. \\
& \sum_{\omega} \sum_{i} \sum_{r} \sum_{j} \sum_{t} \Phi_{\omega}\left(P_{j}^{l}+G_{j}^{l} E_{i r}\right) R_{i r j t \omega}^{l}+\sum_{\omega} \sum_{r} \sum_{t} \sum_{j} \Phi_{\omega} \alpha_{j}^{l} I_{r t j \omega}^{l}+\sum_{\omega} \sum_{k} \sum_{l} \sum_{j} \sum_{t} \Phi_{\omega} M_{j}^{l} E_{k l} T_{k l j t \omega}^{l}+ \\
& \sum_{\omega} \sum_{l} \sum_{i} \sum_{\eta} \sum_{t} \Phi_{\omega}\left(-a_{\eta}^{u}+O_{\eta}^{l} E_{l j}\right) U_{l i \eta t \omega}^{u}+\sum_{\omega} \sum_{l} \sum_{\eta} \sum_{t} \Phi_{\omega}\left(f_{\eta}^{l}+\theta_{\eta}^{l} E_{l}\right) \lambda_{l \eta t \omega}^{l} \\
& \left.+\sum_{s} A_{s}^{l} Y_{s}+\sum_{i} B_{i}^{l} V_{i}+\sum_{r} R_{r}^{l} W_{r}+\sum_{l} C_{l}^{l} X_{l}\right)
\end{aligned}
$$

s.t.

Eqs. (5.16) - (5.67)

Scenario-based analysis is performed to consider the impacts of different possible alternatives of uncertain demand and return on the total expected profit. It is assumed that the value of market's demand and returned product in Scenario 3 is defined similarly to the proposed FFP 
model. Each scenario is indicated the 0.5 percent alteration in demand or return. As a matter of fact, all possible combinations of 0.5 percent changes in market's demand and returned product are examined. As indicated by Table 5.3, the values of objective functions are compared with Scenario 3 (e.g. change\% in Scenario 1 for middle range total expected profit: $(19,118,799.79-$ $19,031,814.217) / 19,031,814.217=0.4571 \%)$. Furthermore, the FFP with regard to scenario-based model (comprising of 52,324 constraints, 53,388 non-negative variables, 28 binary variables) is applied and the results are indicated in Table 5.3 as well. The scenario-based model is assumed to include all possible 5 scenarios with probability of $(0.15,0.2,0.3,0.2,0.15)$. The total expected profit of FFP with regard to scenario-based analysis have been depicted in Fig. 5.2.

Table 5.3

Solution of FFP with regard to scenario-based analysis

\begin{tabular}{lllcccc}
\hline Scenarios & $\begin{array}{l}\text { Demand } \\
\text { change } \%\end{array}$ & $\begin{array}{l}\text { Return } \\
\text { change } \%\end{array}$ & $\begin{array}{c}\text { Lower total } \\
\text { expected profit }\end{array}$ & $\begin{array}{c}\text { Middle total } \\
\text { expected profit }\end{array}$ & $\begin{array}{c}\text { Upper total } \\
\text { expected profit }\end{array}$ & $\begin{array}{c}\text { change } \% \\
\text { (Middle range) }\end{array}$ \\
\hline 1 & $0.5 \%$ increase & $0.5 \%$ decrease & $15,944,815.99$ & $19,118,799.79$ & $20,846,087.70$ & $0.4571 \%$ \\
2 & $0.5 \%$ decrease & $0.5 \%$ increase & $15,786,142.04$ & $18,944,828.64$ & $20,656,522.63$ & $-0.4571 \%$ \\
3 (base-case) & No change & No change & $15,865,479.04$ & $19,031,814.21$ & $20,751,305.19$ \\
4 & $0.5 \%$ increase & $0.5 \%$ increase & $16,200,565.09$ & $19,131,543.40$ & $20,859,178.07$ & $0.5240 \%$ \\
5 & $0.5 \%$ decrease & $0.5 \%$ decrease & $15,780,691.62$ & $18,931784.48$ & $20,643,162.71$ & $-0.5256 \%$ \\
6 (scenario- & Combination of five scenarios & $15,865,758.57$ & $19,032,452.08$ & $20,751,955.06$ & $0.0034 \%$ \\
based) & & & & & &
\end{tabular}

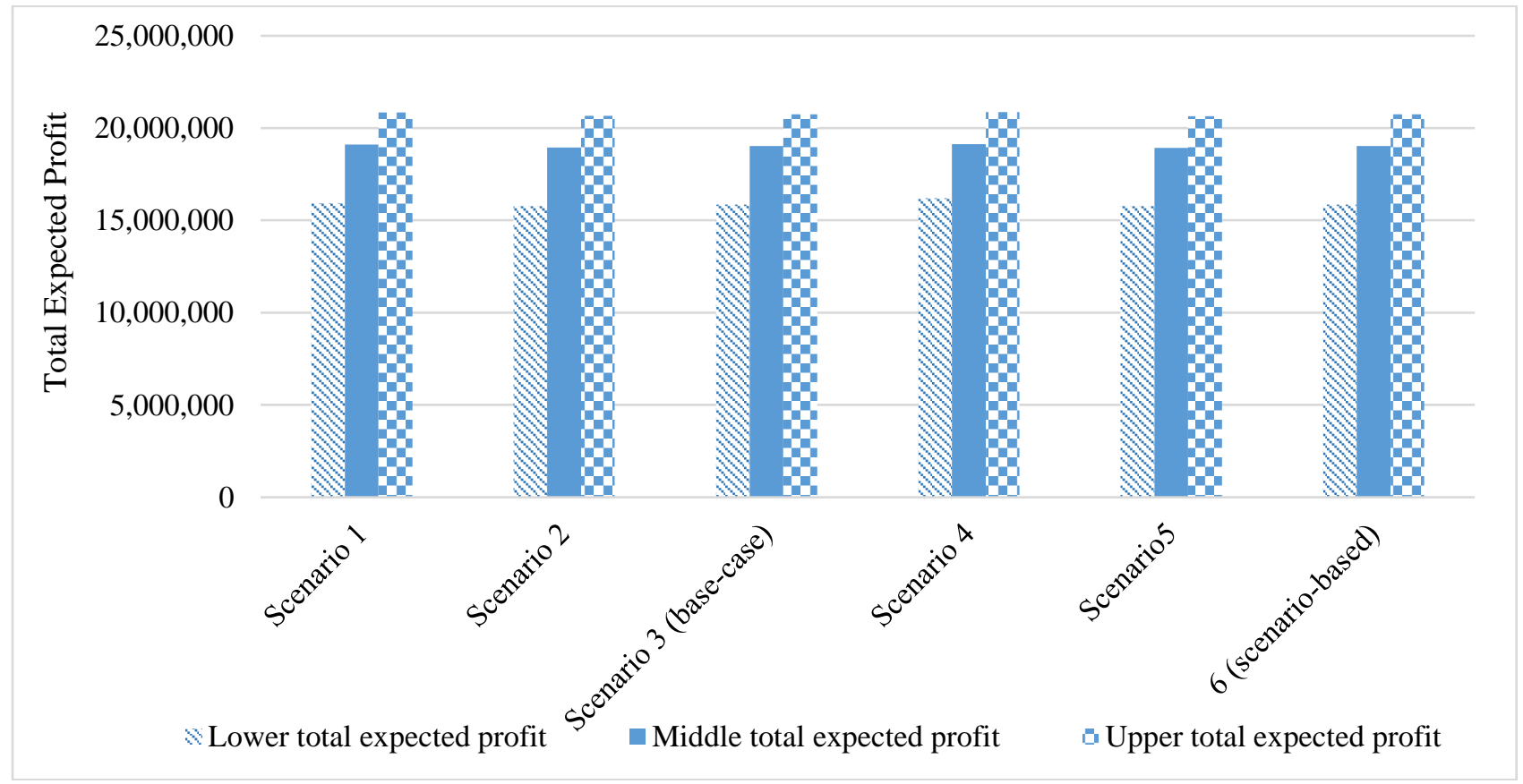

Fig. 5.2. Total expected profit of FFP with regard to scenario-based analysis 


\subsection{An extension to multi-objective}

Since the proposed FFP model has been defined for the battery CLSC network, it is commonsensical to maximize the green factors as well. To this aim, two qualitative parameters are considered including $M_{i \eta}^{\prime}$ and $N_{l \eta}^{\prime}$ as the measurement of the green factors for the potential plants, and the recovery centers, respectively. In this stage, it is assumed that some potential plants and recovery centers exist, and it is intended to select the best ones. $M_{i \eta}^{\prime}$ is defined as the parameter of green performance allocating to potential plant $i$ to produce the products via assembling of $\eta$ components. Besides, $N_{l \eta}^{\prime}$ is shown as the parameter of green performance allocating to the potential battery recovery center $l$ to recycle $\eta$ components via disassembling the products. The second objective function is defined as follows:

$$
\begin{aligned}
& \operatorname{Max} z_{2}=\sum_{i} \sum_{\eta} M_{i \eta}^{\prime}\left(\sum_{s} \sum_{t} \tilde{Q}_{\text {sint }}+\sum_{l} \sum_{t} \tilde{U}_{l i \eta t}+\sum_{r} \sum_{j} \sum_{t}\left(\tilde{R}_{i r j t}\right) v_{j \eta}\right)+ \\
& \sum_{l} \sum_{\eta} N_{l \eta}^{\prime}\left(\sum_{k} \sum_{j} \sum_{t}\left(\tilde{T}_{k l j t}\right) v_{j \eta}+\sum_{i} \sum_{t} \tilde{U}_{l i \eta t}+\sum_{t} \tilde{\lambda}_{l \eta t}\right)
\end{aligned}
$$

$M_{i \eta}^{\prime}$ and $N_{l \eta}^{\prime}$ are qualitative factors. According to Chapter 4, fuzzy ANP method was applied for determining the values of those parameters. On the other hand, the problem is multi-objective. Two methods (distance and E-constraint methods) are developed and applied to solve the multiobjective problem.

\subsection{Distance method and the solution}

To reach a solution close to the ideal values, the distance method is utilized for the proposed multi-objective CLSC network. In this method, ideal solution is the best value which can be obtained for each function disregarding other functions. As illustrated by Eq. (5.69), $w_{i}$ is used as the distance metric. In this chapter, there are two objective functions including the total expected profit and the green performance which are maximized. Therefore, the objective function for the proposed model can be written as Eq. (5.70).

$$
z=\left(\sum_{i} w_{i}^{\tau}\left(\frac{z_{i}-z_{i}^{*}}{z_{i}^{*}}\right)^{\tau}\right)^{\frac{1}{\tau}} \quad \forall i=1,2 \ldots, \infty
$$




$$
\operatorname{Max} z=\left(w_{1}^{\tau}\left(\frac{z_{1}-z_{1}^{*}}{z_{1}^{*}}\right)^{\tau}+w_{2}^{\tau}\left(\frac{z_{2}-z_{2}^{*}}{z_{2}^{*}}\right)^{\tau}\right)^{\frac{1}{\tau}}
$$

s.t. $\quad$ Eqs. (5.16) $-(5.67)$

In this section, an algorithm based on Ezzati et al., (2015) is developed and applied to solve each fuzzy objective as discussed previously. The results are provided in Table 5.4. Then, the distance method is applied to find the solutions of the multi-objective model.

Table 5.4

Optimal value of each fuzzy objective obtained separately subject to the defined constraints

\begin{tabular}{llll} 
& Lower value & Middle value & Upper value \\
\hline First objective & $15,865,479.04$ & $19,031,814.21$ & $20,751,305.19$ \\
Second objective & $657,201.28$ & $682,630.48$ & $686,392.48$ \\
\hline
\end{tabular}

To find the trade-off solution between the two mentioned fuzzy objectives, different pairs of $w_{i}$ are utilized under the $\sum_{i} w_{i}=1$ condition. The ideal solution for the lower range of the total expected profit and the lower range of green performance are 15,865,479.04 and 109,140, individually. Similarly, the distance method can explore one ideal solution of 20,751,000 and 133,410 for the upper range of the proposed multi-objective model. Table 5.5 illustrates the solutions for the middle values. As shown in Fig. 5.3, an ideal solution of one objective cannot be improved, unless the other objective value is sacrificed.

Table 5.5

Solutions for the $1^{\text {st }}$ and $2^{\text {nd }}$ objectives (middle values, distance method)

\begin{tabular}{lllllllll}
\hline$w_{l}$ & 0 & 0.1 & 0.2 & 0.3 & 0.6 & 0.7 & 0.8 & 1 \\
\hline $\begin{array}{l}\text { First } \\
\text { objective }\end{array}$ & 662,950 & $2,935,800$ & $3,411,600$ & $9,034,600$ & $15,558,000$ & $17,439,000$ & $18,928,000$ & $18,999,000$ \\
$\begin{array}{l}\begin{array}{l}\text { Second } \\
\text { objective }\end{array} \\
6\end{array}$ & 663,190 & 661,190 & 657,790 & 585,650 & 441,380 & 279,160 & 143,350 & 30,666 \\
\hline
\end{tabular}




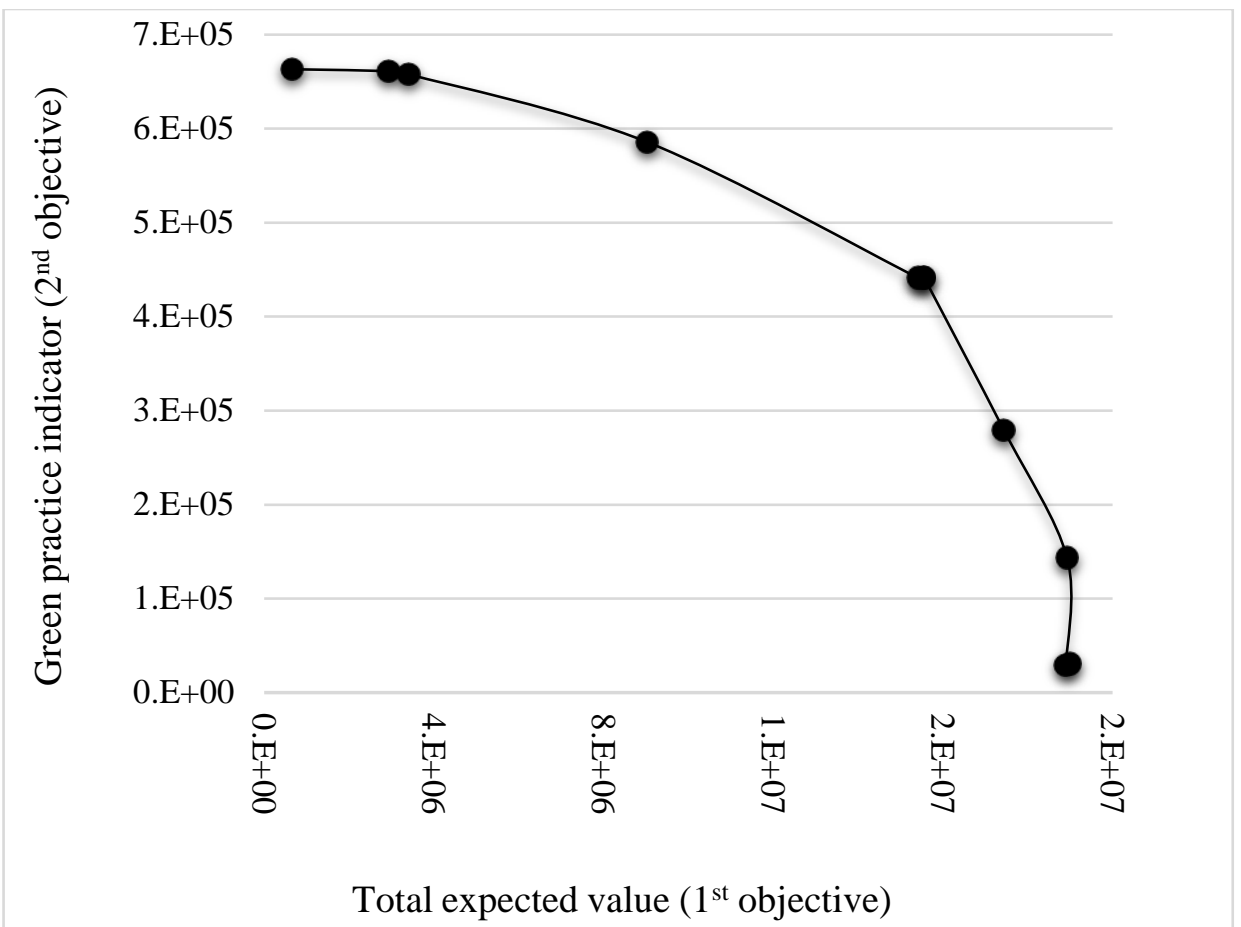

Fig. 5.3. Trade-off surface for the middle values of the $1^{\text {st }}$ and $2^{\text {nd }}$ objectives

\subsection{E-constraint method and the solution}

E-constraint can be employed to convert the multi-objective problem to a mono-objective optimization. It is aimed to apply E-constraint method to verify the answer of the proposed multiobjective FFP obtained from the distance method. In this technique, the objective with higher priority is chosen as the main objective function, and the other objective is assumed as a constraint. The converted problem can be written as:

$\operatorname{Max} z=z_{1}$

s.t.

$z_{2} \geq \mathcal{E}$

Eqs. (5.16) - (5.67)

To achieve the trade-off solution through the $\mathcal{E}$-constraint method, different values of $\mathcal{E}$ are considered. Hence, $\varepsilon$ was employed from 50,000 to 109,140 for the lower range multi-objective problem. For every $\mathcal{E}$ under 109,140 , the value of the first objective was equal to $15,865,479.04$, while the solution for $\mathcal{E}$ upper than 109,140 became infeasible or unbounded. Similarly, converted FFP model was solved for $\varepsilon$ between 50,000 to 133,410 for the upper range multiobjective, and the obtained objective was 20,751,305.19. However, the objective value of the 
converted FFP for $\varepsilon$ with higher than 133,410 became infeasible or unbounded for the upper range case. The middle values of the converted FFP are indicated in Table 5.6.

Table 5.6.

Solutions of the problem (middle values, E-constraint method)

\begin{tabular}{lcccccccc}
\hline $\mathcal{E}$ & 663,190 & 661,190 & 657,790 & 585,650 & 441,380 & 279,160 & 143,350 & 30,666 \\
$\begin{array}{l}\text { Converted } \\
\text { FFP }\end{array}$ & $2,416,993.30$ & $2,936,387.19$ & $3,411,788.11$ & $9,040,077.07$ & $15,559,741.54$ & $17,440,316.9$ & $18,938,805.16$ & $19,031,814.21$ \\
\hline
\end{tabular}

\subsection{Conclusions}

The proposed FFP model was applied for multi-echelon (multiple suppliers, plants, retailers, demand markets, battery recovery centers, and disposal center), multi-components, multiproducts CLSC in multiple periods. The solution included the optimal range of objective function and decision variables with regard to period 1 and 2. In the proposed FFP model, each parameter was defined based on TFNs to cover all possible range of values. The advantage of FFP compared to other types of programming is assumption of fuzziness for decision variables. In nondeterministic programming, information is assumed to be imprecise. Therefore, existence of fuzzy decision variables led to have more flexibility for making strategic decision.

In order to extend possible alternatives, scenario-based analysis has been integrated with FFP method to consider different cases for each lower range, or middle range, or upper range of demand and return. The results indicated changes in demand have more impacts on total expected profit of battery CLSC in comparison with return. Furthermore, the FFP model has been developed to the multi-objective with the aim of considering green practices in plants and battery recovery centers. To solve the proposed multi-objective model, each fuzzy problem has been solved separately, then the distance method has been applied to address the multi-objective feature. In addition, $\varepsilon$-constraint method has been utilized for comparison the results with the distance method. According to the findings, distance and $E$-constraint method indicated similar results for lower, middle, and upper ranges of the multi-objective FFP model. 


\section{CHAPTER 6. CONCLUSIONS AND FUTURE RESEARCH}

\subsection{Research contributions}

The research contributions of this thesis were introduced as follows:

- Designing and examining CLSC network of battery in Vancouver with regard to the related organizations in Canada.

- Application of scenario-based analysis to develop the proposed model under the risk of unexpected changes in demand and return.

- Employing Fuzzy ANP to convert the qualitative factors as the measurement of the green performance of plants and battery recovery centers to the quantitative parameters.

- Application of FFP method to evaluate the impacts of uncertainty on CLSC network. Since, the configuration of battery CLSC may be applied for making strategic decision and it is impossible to change in a short-term, it is necessary to consider all possible optimal range of decision variables and objective function.

- Employing the combination of possibilistic (fuzzy) and scenario-based analysis to involve more one alternative for lower, middle, and upper range of demand and return.

- Utilization of distance technique and E-constraint method to determine the tradeoff surface of solution.

- Assuming real distances in the proposed multi-echelon CLSC through Google Maps for estimating real transportation cost.

\subsection{Conclusions}

It was intended to develop a hybrid method to configure a battery CLSC network. The proposed model was extended to investigate the impact of uncertainty with respect to the environmental practices. Hence, some analyses were utilized and related solution approaches along with optimization models were developed.

A variety of concerns associated with manufacturing and remanufacturing of battery were described. As a matter of fact, discarded battery in landfills will become hazardous on account of spreading out the chemical materials into the soil and groundwater. Furthermore, some regulations urge the decision makers to emphasize the battery recycling, and also avoid using 
toxic materials such as mercury in production (Mercury-Containing and Rechargeable Battery Management Act in 1996). Therefore, such mentioned concerns and regulations engage battery producers to contribute to the battery recovery and recycling.

Some methodologies related to RL and CLSC were reviewed to cover decision making in all possible categories such as certain, uncertain, and risky situations in Chapter 2. Applications of MILP, stochastic (scenario-based analysis), and fuzzy programming were chosen as the main fields of this study.

Initially, a deterministic model for a multi-echelon, multi-components, multi-product, multiperiod battery CLSC in a realistic network was proposed in Chapter 3. The solution for the proposed deterministic model indicated the objective optimal values, and decision variables with regard to multiple periods. Furthermore, the optimal binary variables included 2 suppliers, 1 location for plant, 5 retailers, and 2 locations for battery recovery centers. Scenario-based analysis was utilized to evaluate the response of proposed model under the risks of unexpected changes in demand and return. Since, the possibility of occurrence of each scenario can be identified based on experts' judgment, all possible combinations of 10 percent changes in market's demand and returned product were investigated. Then, comparing the objective values of the provided scenarios proved that the expected profit of the battery CLSC is very sensitive to the unexpected changes in demand and returned. To figure out the importance of efficiency in CLSC, sensitivity analysis was conducted on disposal fraction. According to the findings, disposal fraction had major reverse impact on profit of battery CLSC. In other words, efficiency in recycling of used battery can enhance CLSC profit and reduce the environmental issues significantly.

Some related studies were considered to determine the green performance indicators in a battery CLSC in Chapter 4. The fuzzy ANP method was utilized based on Chang's method. The overall priorities of plants and battery recovery centers were measured with regard to the proposed green practice frameworks. According to linguistic scale of relative importance, all criteria were compared. Thereafter, pairwise comparisons were applied to all sub-criteria, and then all plants and battery recovery centers were prioritized based on green performance.

The preliminary concepts of using arithmetic operations for triangular fuzzy numbers were discussed in Chapter 5. The application of FFP approach was explained for the proposed battery CLSC. The solution included the optimal range of objective function and decision variables. To 
develop the possible alternatives, scenario-based analysis was integrated with FFP method to consider different cases for lower range, middle range, and upper range of demand and return. The results indicated changes in demand have more impacts on total expected profit of battery CLSC in comparison with return. To consider the green performance of plants and battery recovery centres under uncertainty, the fuzzy multi-objective approach was employed. Hence, each fuzzy problem was solved separately, and then distance technique and $\mathcal{E}$-constraint method were utilized to find the trade-off solution of multi-objective FFP model.

\subsection{Recommendations for future research}

There are some potential complementary research areas for this study in aspects of environmental issues, different transportation strategies, financial and economic indicators, robust optimization, and metaheuristic optimization as follows:

\section{- Developing mathematical models to consider environmental issues}

In Chapter 4, a fuzzy ANP method was utilized to convert the qualitative indicators of green performance to the quantitative parameters for plants and battery recovery centres. Furthermore, it will be commonsensical, if the proposed battery CLSC is developed to the multi-objective optimization model with more environmental factors. New environmental objectives can be defined for the CLSC such as minimization of carbon emission, fuel and energy consumption, solid and septic waste in addition to the maximization of total profit.

\section{- Developing mathematical models to consider different transportation strategies}

One of the main strategies to reduce the environmental impacts of CLSC is associated with transportation sectors. Hence, role of transportation strategies can be considered in the optimization model. For further clarification, the proposed CLSC model can be developed by the following scenarios; the finished products can be delivered to the retailers in a single shipment after manufacturing of all markets' demand, or the finished products can be delivered to the retailers separately (in multiple shipments) upon after manufacturing of each markets' demand.

\section{- Developing mathematical models to consider financial and economic indicators}

The total profit of CLSCs are dependent to the variety of financial and economic factors such as inflation rate, interest rate, exchange rate, cost of energy and labor force along with depreciation cost of all assets and machines belonging to the CLSCs. All mentioned factors can 
contribute to the optimization of CLSC network through the maximization of net present value (NPV) of discounted cash flows related to each period.

\section{- Developing solution approaches to consider robust optimization}

There are some potential complementary research areas to address uncertainty. In this thesis, fuzzy and scenario-based analysis were utilized to solve the proposed model. To deal with imprecise information, robust optimization can be applied as well. Contrary to the scenario-based analysis, probability of each scenario is unknown in robust optimization. For different types of uncertainties, robust optimization can be utilized due to its computational flexibility.

\section{- Developing solution approaches to consider metaheuristic optimization}

In real optimization problems, it is highly probable to confront multi-objective, non-linear mathematical models with regard to complicated constraints. Hence, different objectives may have conflict with each other leading to difficult optimization problems. In such cases, metaheuristic algorithms can be applied to reach good solutions, but there is not any guarantee to reach optimal solutions. 


\section{APPENDIX A. FUZZY ANP ANALYSES TO RANK THE PLANTS BASED ON THE GREEN PERFORMANCE}

Table A.1

Priority of each plant with respect to $S c_{1}$

\begin{tabular}{llllllllllllllllllllll}
\hline$S c_{1}$ & \multicolumn{3}{c}{ Plant 1 } & \multicolumn{4}{c}{ Plant 2 } & \multicolumn{4}{c}{ Plant 3 } & \multicolumn{4}{c}{ Plant 4 } & \multicolumn{3}{c}{ Plant 5 } & \multicolumn{1}{c}{ Plant 6 } \\
\hline Plant 1 & 1.00 & 1.00 & 1.00 & 1.00 & 1.50 & 2.00 & 1.00 & 1.50 & 2.00 & 1.50 & 2.00 & 2.50 & 0.50 & 1.00 & 1.50 & 1.00 & 1.50 & 2.00 & 0.211 \\
Plant 2 & 0.50 & 0.67 & 1.00 & 1.00 & 1.00 & 1.00 & 1.00 & 1.50 & 2.00 & 1.00 & 1.50 & 2.00 & 1.00 & 1.50 & 2.00 & 0.50 & 1.00 & 1.50 & 0.183 \\
Plant 3 & 0.50 & 0.67 & 1.00 & 0.50 & 0.67 & 1.00 & 1.00 & 1.00 & 1.00 & 0.50 & 1.00 & 1.50 & 1.00 & 1.50 & 2.00 & 2.00 & 2.50 & 3.00 & 0.186 \\
Plant 4 & 0.40 & 0.50 & 0.67 & 0.50 & 0.67 & 1.00 & 0.67 & 1.00 & 2.00 & 1.00 & 1.00 & 1.00 & 0.50 & 1.00 & 1.50 & 1.00 & 1.50 & 2.00 & 0.149 \\
Plant 5 & 0.67 & 1.00 & 2.00 & 0.50 & 0.67 & 1.00 & 0.50 & 0.67 & 1.00 & 0.67 & 1.00 & 2.00 & 1.00 & 1.00 & 1.00 & 1.00 & 1.50 & 2.00 & 0.158 \\
Plant 6 & 0.50 & 0.67 & 1.00 & 0.67 & 1.00 & 2.00 & 0.33 & 0.40 & 0.50 & 0.50 & 0.67 & 1.00 & 0.50 & 0.67 & 1.00 & 1.00 & 1.00 & 1.00 & 0.111 \\
\hline
\end{tabular}

Table A.2

Priority of each plant with respect to $S c_{2}$

\begin{tabular}{lllllllllllllllllllll}
\hline$S c_{2}$ & \multicolumn{3}{c}{ Plant 1 } & \multicolumn{4}{c}{ Plant 2 } & \multicolumn{3}{c}{ Plant 3 } & \multicolumn{3}{c}{ Plant 4 } & \multicolumn{3}{c}{ Plant 5 } & \multicolumn{1}{c}{ Plant 6 } \\
\hline Plant 1 & 1.00 & 1.00 & 1.00 & 2.00 & 2.50 & 3.00 & 1.00 & 1.50 & 2.00 & 1.50 & 2.00 & 2.50 & 0.50 & 1.00 & 1.50 & 1.00 & 1.50 & 2.00 & 0.232 \\
Plant 2 & 0.33 & 0.40 & 0.50 & 1.00 & 1.00 & 1.00 & 1.50 & 2.00 & 2.50 & 1.00 & 1.50 & 2.00 & 1.00 & 1.50 & 2.00 & 2.00 & 2.50 & 3.00 & 0.219 \\
Plant 3 & 0.50 & 0.67 & 1.00 & 0.40 & 0.50 & 0.67 & 1.00 & 1.00 & 1.00 & 2.00 & 2.50 & 3.00 & 1.00 & 1.50 & 2.00 & 0.50 & 1.00 & 1.50 & 0.177 \\
Plant 4 & 0.40 & 0.50 & 0.67 & 0.50 & 0.67 & 1.00 & 0.33 & 0.40 & 0.50 & 1.00 & 1.00 & 1.00 & 0.50 & 1.00 & 1.50 & 1.00 & 1.50 & 2.00 & 0.111 \\
Plant 5 & 0.67 & 1.00 & 2.00 & 0.50 & 0.67 & 1.00 & 0.50 & 0.67 & 1.00 & 0.67 & 1.00 & 2.00 & 1.00 & 1.00 & 1.00 & 0.50 & 1.00 & 1.50 & 0.142 \\
Plant 6 & 0.50 & 0.67 & 1.00 & 0.33 & 0.40 & 0.50 & 0.67 & 1.00 & 2.00 & 0.50 & 0.67 & 1.00 & 0.67 & 1.00 & 2.00 & 1.00 & 1.00 & 1.00 & 0.121 \\
\hline
\end{tabular}

Table A.3

Priority of each plant with respect to $S c_{3}$

\begin{tabular}{lllllllllllllllllllll}
\hline$S c_{3}$ & \multicolumn{3}{c}{ Plant 1 } & \multicolumn{4}{c}{ Plant 2 } & \multicolumn{3}{c}{ Plant 3 } & \multicolumn{3}{c}{ Plant 4 } & \multicolumn{3}{c}{ Plant 5 } & \multicolumn{3}{c}{ Plant 6 } \\
\hline Plant 1 & 1.00 & 1.00 & 1.00 & 1.00 & 1.50 & 2.00 & 2.00 & 2.50 & 3.00 & 1.50 & 2.00 & 2.50 & 0.50 & 1.00 & 1.50 & 2.00 & 2.50 & 3.00 & 0.262 \\
Plant 2 & 0.50 & 0.67 & 1.00 & 1.00 & 1.00 & 1.00 & 1.00 & 1.50 & 2.00 & 2.00 & 2.50 & 3.00 & 1.00 & 1.50 & 2.00 & 0.50 & 1.00 & 1.50 & 0.206 \\
Plant 3 & 0.33 & 0.40 & 0.50 & 0.50 & 0.67 & 1.00 & 1.00 & 1.00 & 1.00 & 0.50 & 1.00 & 1.50 & 1.50 & 2.00 & 2.50 & 1.00 & 1.50 & 2.00 & 0.157 \\
Plant 4 & 0.40 & 0.50 & 0.67 & 0.33 & 0.40 & 0.50 & 0.67 & 1.00 & 2.00 & 1.00 & 1.00 & 1.00 & 2.00 & 2.50 & 3.00 & 1.50 & 2.00 & 2.50 & 0.185 \\
Plant 5 & 0.67 & 1.00 & 2.00 & 0.50 & 0.67 & 1.00 & 0.40 & 0.50 & 0.67 & 0.33 & 0.40 & 0.50 & 1.00 & 1.00 & 1.00 & 1.00 & 1.50 & 2.00 & 0.112 \\
Plant 6 & 0.33 & 0.40 & 0.50 & 0.67 & 1.00 & 2.00 & 0.50 & 0.67 & 1.00 & 0.40 & 0.50 & 0.67 & 0.50 & 0.67 & 1.00 & 1.00 & 1.00 & 1.00 & 0.078 \\
\hline
\end{tabular}


Table A.4

Priority of each plant with respect to $\mathrm{Sc}_{4}$

\begin{tabular}{llllllllllllllllllllll}
\hline$S c_{4}$ & \multicolumn{3}{c}{ Plant 1 } & \multicolumn{4}{c}{ Plant 2 } & \multicolumn{4}{c}{ Plant 3 } & \multicolumn{3}{c}{ Plant 4 } & \multicolumn{3}{c}{ Plant 5 } & \multicolumn{1}{c}{ Plant 6 } \\
\hline Plant 1 & 1.00 & 1.00 & 1.00 & 2.00 & 2.50 & 3.00 & 1.00 & 1.50 & 2.00 & 1.50 & 2.00 & 2.50 & 0.50 & 1.00 & 1.50 & 2.00 & 2.50 & 3.00 & 0.262 \\
Plant 2 & 0.33 & 0.40 & 0.50 & 1.00 & 1.00 & 1.00 & 1.00 & 1.50 & 2.00 & 1.00 & 1.50 & 2.00 & 1.00 & 1.50 & 2.00 & 0.50 & 1.00 & 1.50 & 0.169 \\
Plant 3 & 0.50 & 0.67 & 1.00 & 0.50 & 0.67 & 1.00 & 1.00 & 1.00 & 1.00 & 0.50 & 1.00 & 1.50 & 2.00 & 2.50 & 3.00 & 0.50 & 1.00 & 1.50 & 0.168 \\
Plant 4 & 0.40 & 0.50 & 0.67 & 0.50 & 0.67 & 1.00 & 0.67 & 1.00 & 2.00 & 1.00 & 1.00 & 1.00 & 0.50 & 1.00 & 1.50 & 1.50 & 2.00 & 2.50 & 0.153 \\
Plant 5 & 0.67 & 1.00 & 2.00 & 0.50 & 0.67 & 1.00 & 0.33 & 0.40 & 0.50 & 0.67 & 1.00 & 2.00 & 1.00 & 1.00 & 1.00 & 1.00 & 1.50 & 2.00 & 0.142 \\
Plant 6 & 0.33 & 0.40 & 0.50 & 0.67 & 1.00 & 2.00 & 0.67 & 1.00 & 2.00 & 0.40 & 0.50 & 0.67 & 0.50 & 0.67 & 1.00 & 1.00 & 1.00 & 1.00 & 0.106 \\
\hline
\end{tabular}

Table A.5

Priority of each plant with respect to $S c_{5}$

\begin{tabular}{llllllllllllllllllllll}
\hline$S c_{5}$ & \multicolumn{3}{c}{ Plant 1 } & \multicolumn{3}{c}{ Plant 2 } & \multicolumn{3}{c}{ Plant 3 } & \multicolumn{3}{c}{ Plant 4 } & \multicolumn{3}{c}{ Plant 5 } & \multicolumn{1}{c}{ Plant 6} \\
\hline Plant 1 & 1.00 & 1.00 & 1.00 & 2.00 & 2.50 & 3.00 & 1.00 & 1.50 & 2.00 & 2.00 & 2.50 & 3.00 & 1.00 & 1.50 & 2.00 & 2.00 & 2.50 & 3.00 & 0.312 \\
Plant 2 & 0.33 & 0.40 & 0.50 & 1.00 & 1.00 & 1.00 & 1.00 & 1.50 & 2.00 & 1.00 & 1.50 & 2.00 & 0.50 & 1.00 & 1.50 & 0.50 & 1.00 & 1.50 & 0.156 \\
Plant 3 & 0.50 & 0.67 & 1.00 & 0.50 & 0.67 & 1.00 & 1.00 & 1.00 & 1.00 & 0.50 & 1.00 & 1.50 & 1.00 & 1.50 & 2.00 & 1.00 & 1.50 & 2.00 & 0.155 \\
Plant 4 & 0.33 & 0.40 & 0.50 & 0.50 & 0.67 & 1.00 & 0.67 & 1.00 & 2.00 & 1.00 & 1.00 & 1.00 & 1.00 & 1.50 & 2.00 & 2.00 & 2.50 & 3.00 & 0.185 \\
Plant 5 & 0.50 & 0.67 & 1.00 & 0.67 & 1.00 & 2.00 & 0.50 & 0.67 & 1.00 & 0.50 & 0.67 & 1.00 & 1.00 & 1.00 & 1.00 & 1.00 & 1.50 & 2.00 & 0.133 \\
Plant 6 & 0.33 & 0.40 & 0.50 & 0.67 & 1.00 & 2.00 & 0.50 & 0.67 & 1.00 & 0.33 & 0.40 & 0.50 & 0.50 & 0.67 & 1.00 & 1.00 & 1.00 & 1.00 & 0.058 \\
\hline
\end{tabular}

Table A.6

Priority of each plant with respect to $S c_{6}$

\begin{tabular}{|c|c|c|c|c|c|c|c|c|c|c|c|c|c|c|c|c|c|c|c|}
\hline \multirow{2}{*}{$\frac{S c_{6}}{\text { Plant } 1}$} & \multicolumn{3}{|c|}{ Plant 1} & \multicolumn{3}{|c|}{ Plant 2} & \multicolumn{3}{|c|}{ Plant 3} & \multicolumn{3}{|c|}{ Plant 4} & \multicolumn{3}{|c|}{ Plant 5} & \multicolumn{3}{|c|}{ Plant 6} & \multirow{2}{*}{$\begin{array}{c}W_{c} \\
0.198\end{array}$} \\
\hline & 1.00 & 1.00 & .00 & 1.00 & 1.50 & .00 & 50 & 1.00 & 1 & 1.50 & 2.00 & 2.50 & 50 & 1.00 & 1.50 & 1.00 & 1.50 & 2.00 & \\
\hline Plant 2 & 0.50 & 0.67 & 1.00 & 1.00 & 1.00 & 1.00 & 2.00 & 2.50 & 3.00 & 1.00 & 1.50 & 2.00 & 1.50 & 2.00 & 2.50 & 0.50 & 1.00 & 1.50 & 0.212 \\
\hline $\mathrm{Pl}$ & 0.67 & 1.00 & 2.00 & 0.33 & 0.40 & 0 & 0 & 1.00 & 1. & 0 & 1.00 & 1.50 & 1.00 & 1.50 & 2. & 0.50 & 1.00 & 1.50 & 0.151 \\
\hline Plant 4 & 0.40 & 0.50 & 0.67 & 0.50 & 0.67 & 1.00 & 0.67 & 1.00 & 2.00 & 1.00 & 1.00 & 1.00 & 1.00 & 1.50 & 2. & 2.00 & 2.50 & 3.00 & 0.180 \\
\hline Plant 5 & 0.67 & 1.00 & 2.00 & 0.40 & 0.50 & 0. & 50 & 0.67 & 1 & 0.50 & 0. & 1 & 0 & 1.00 & 1 & 1.00 & 0 & 2.00 & 0.13 \\
\hline Plant 6 & 0.50 & 0.67 & 1.00 & 0.67 & 1.00 & 2.00 & 0.67 & 1.00 & 2.00 & 0.33 & 0.40 & 0.50 & 0.50 & 0.67 & 1.00 & 1.00 & 1.00 & 1.00 & 0.124 \\
\hline
\end{tabular}


Table A.7

Priority of each plant with respect to $S c_{7}$

\begin{tabular}{llllllllllllllllllllll}
\hline$S c_{7}$ & \multicolumn{3}{c}{ Plant 1 } & \multicolumn{3}{c}{ Plant 2 } & \multicolumn{3}{c}{ Plant 3 } & \multicolumn{3}{c}{ Plant 4 } & \multicolumn{3}{c}{ Plant 5 } & \multicolumn{3}{c}{ Plant 6} \\
\hline Plant 1 & 1.00 & 1.00 & 1.00 & 1.00 & 1.50 & 2.00 & 2.00 & 2.50 & 3.00 & 1.50 & 2.00 & 2.50 & 0.50 & 1.00 & 1.50 & 2.00 & 2.50 & 3.00 & 0.270 \\
Plant 2 & 0.50 & 0.67 & 1.00 & 1.00 & 1.00 & 1.00 & 1.00 & 1.50 & 2.00 & 1.00 & 1.50 & 2.00 & 1.00 & 1.50 & 2.00 & 0.50 & 1.00 & 1.50 & 0.184 \\
Plant 3 & 0.33 & 0.40 & 0.50 & 0.50 & 0.67 & 1.00 & 1.00 & 1.00 & 1.00 & 0.50 & 1.00 & 1.50 & 1.00 & 1.50 & 2.00 & 1.00 & 1.50 & 2.00 & 0.145 \\
Plant 4 & 0.40 & 0.50 & 0.67 & 0.50 & 0.67 & 1.00 & 0.67 & 1.00 & 2.00 & 1.00 & 1.00 & 1.00 & 0.50 & 1.00 & 1.50 & 0.50 & 1.00 & 1.50 & 0.126 \\
Plant 5 & 0.67 & 1.00 & 2.00 & 0.50 & 0.67 & 1.00 & 0.50 & 0.67 & 1.00 & 0.67 & 1.00 & 2.00 & 1.00 & 1.00 & 1.00 & 1.00 & 1.50 & 2.00 & 0.157 \\
Plant 6 & 0.33 & 0.40 & 0.50 & 0.67 & 1.00 & 2.00 & 0.50 & 0.67 & 1.00 & 0.67 & 1.00 & 2.00 & 0.50 & 0.67 & 1.00 & 1.00 & 1.00 & 1.00 & 0.118 \\
\hline
\end{tabular}

Table A. 8

Priority of each plant with respect to $S c_{8}$

\begin{tabular}{llllllllllllllllllllll}
\hline$S c_{8}$ & \multicolumn{3}{c}{ Plant 1 } & \multicolumn{4}{c}{ Plant 2 } & \multicolumn{3}{c}{ Plant 3 } & \multicolumn{3}{c}{ Plant 4 } & \multicolumn{3}{c}{ Plant 5 } & \multicolumn{3}{c}{ Plant 6} \\
\hline Plant 1 & 1.00 & 1.00 & 1.00 & 1.00 & 1.50 & 2.00 & 1.00 & 1.50 & 2.00 & 1.50 & 2.00 & 2.50 & 0.50 & 1.00 & 1.50 & 1.00 & 1.50 & 2.00 & 0.214 \\
Plant 2 & 0.50 & 0.67 & 1.00 & 1.00 & 1.00 & 1.00 & 2.00 & 2.50 & 3.00 & 1.00 & 1.50 & 2.00 & 1.50 & 2.00 & 2.50 & 1.00 & 1.50 & 2.00 & 0.229 \\
Plant 3 & 0.50 & 0.67 & 1.00 & 0.33 & 0.40 & 0.50 & 1.00 & 1.00 & 1.00 & 0.50 & 1.00 & 1.50 & 1.00 & 1.50 & 2.00 & 0.50 & 1.00 & 1.50 & 0.135 \\
Plant 4 & 0.40 & 0.50 & 0.67 & 0.50 & 0.67 & 1.00 & 0.67 & 1.00 & 2.00 & 1.00 & 1.00 & 1.00 & 0.50 & 1.00 & 1.50 & 1.00 & 1.50 & 2.00 & 0.145 \\
Plant 5 & 0.67 & 1.00 & 2.00 & 0.40 & 0.50 & 0.67 & 0.50 & 0.67 & 1.00 & 0.67 & 1.00 & 2.00 & 1.00 & 1.00 & 1.00 & 2.00 & 2.50 & 3.00 & 0.175 \\
Plant 6 & 0.50 & 0.67 & 1.00 & 0.50 & 0.67 & 1.00 & 0.67 & 1.00 & 2.00 & 0.50 & 0.67 & 1.00 & 0.33 & 0.40 & 0.50 & 1.00 & 1.00 & 1.00 & 0.102 \\
\hline
\end{tabular}


Table A.9

Priority of each plant with respect to $S c_{9}$

\begin{tabular}{llllllllllllllllllllll}
\hline$S c_{9}$ & \multicolumn{3}{c}{ Plant 1 } & \multicolumn{3}{c}{ Plant 2 } & \multicolumn{3}{c}{ Plant 3 } & \multicolumn{3}{c}{ Plant 4 } & \multicolumn{3}{c}{ Plant 5 } & \multicolumn{1}{c}{ Plant 6} \\
\hline Plant 1 & 1.00 & 1.00 & 1.00 & 1.00 & 1.50 & 2.00 & 1.50 & 2.00 & 2.50 & 2.00 & 2.50 & 3.00 & 0.50 & 1.00 & 1.50 & 1.00 & 1.50 & 2.00 & 0.235 \\
Plant 2 & 0.50 & 0.67 & 1.00 & 1.00 & 1.00 & 1.00 & 1.00 & 1.50 & 2.00 & 1.00 & 1.50 & 2.00 & 1.00 & 1.50 & 2.00 & 0.50 & 1.00 & 1.50 & 0.181 \\
Plant 3 & 0.40 & 0.50 & 0.67 & 0.50 & 0.67 & 1.00 & 1.00 & 1.00 & 1.00 & 0.50 & 1.00 & 1.50 & 1.00 & 1.50 & 2.00 & 2.00 & 2.50 & 3.00 & 0.179 \\
Plant 4 & 0.33 & 0.40 & 0.50 & 0.50 & 0.67 & 1.00 & 0.67 & 1.00 & 2.00 & 1.00 & 1.00 & 1.00 & 0.50 & 1.00 & 1.50 & 0.50 & 1.00 & 1.50 & 0.127 \\
Plant 5 & 0.67 & 1.00 & 2.00 & 0.50 & 0.67 & 1.00 & 0.50 & 0.67 & 1.00 & 0.67 & 1.00 & 2.00 & 1.00 & 1.00 & 1.00 & 1.00 & 1.50 & 2.00 & 0.156 \\
Plant 6 & 0.50 & 0.67 & 1.00 & 0.67 & 1.00 & 2.00 & 0.33 & 0.40 & 0.50 & 0.67 & 1.00 & 2.00 & 0.50 & 0.67 & 1.00 & 1.00 & 1.00 & 1.00 & 0.122 \\
\hline
\end{tabular}

Table A.10

Priority of each plant with respect to $S c_{10}$

\begin{tabular}{lllllllllllllllllllll}
\hline$S c_{10}$ & \multicolumn{3}{c}{ Plant 1 } & \multicolumn{4}{c}{ Plant 2 } & \multicolumn{3}{c}{ Plant 3 } & \multicolumn{3}{c}{ Plant 4 } & \multicolumn{3}{c}{ Plant 5 } & \multicolumn{3}{c}{ Plant 6} \\
\hline Plant 1 & 1.00 & 1.00 & 1.00 & 1.00 & 1.50 & 2.00 & 1.00 & 1.50 & 2.00 & 1.50 & 2.00 & 2.50 & 1.00 & 1.50 & 2.00 & 1.00 & 1.50 & 2.00 & 0.225 \\
Plant 2 & 0.50 & 0.67 & 1.00 & 1.00 & 1.00 & 1.00 & 1.00 & 1.50 & 2.00 & 1.00 & 1.50 & 2.00 & 1.00 & 1.50 & 2.00 & 0.50 & 1.00 & 1.50 & 0.184 \\
Plant 3 & 0.50 & 0.67 & 1.00 & 0.50 & 0.67 & 1.00 & 1.00 & 1.00 & 1.00 & 0.50 & 1.00 & 1.50 & 1.00 & 1.50 & 2.00 & 2.00 & 2.50 & 3.00 & 0.187 \\
Plant 4 & 0.40 & 0.50 & 0.67 & 0.50 & 0.67 & 1.00 & 0.67 & 1.00 & 2.00 & 1.00 & 1.00 & 1.00 & 0.50 & 1.00 & 1.50 & 1.00 & 1.50 & 2.00 & 0.148 \\
Plant 5 & 0.50 & 0.67 & 1.00 & 0.50 & 0.67 & 1.00 & 0.50 & 0.67 & 1.00 & 0.67 & 1.00 & 2.00 & 1.00 & 1.00 & 1.00 & 1.50 & 2.00 & 2.50 & 0.157 \\
Plant 6 & 0.50 & 0.67 & 1.00 & 0.67 & 1.00 & 2.00 & 0.33 & 0.40 & 0.50 & 0.50 & 0.67 & 1.00 & 0.40 & 0.50 & 0.67 & 1.00 & 1.00 & 1.00 & 0.099 \\
\hline
\end{tabular}


APPENDIX B. FUZZY ANP ANALYSES TO RANK THE BATTERY RECOVERY CENTERS BASED ON THE GREEN PERFORMANCE

Table B.1

Pairwise comparisons among criteria

\begin{tabular}{lcclccccccc}
\hline$W e_{1}$ & & $C_{1}$ & \multicolumn{1}{c}{$C_{2}$} & & & $C_{3}$ & \\
\hline$C_{1}$ & 1 & 1 & 1 & 0.5 & 1 & 1.5 & 1 & 1.5 & 2 & 0.39 \\
$C_{2}$ & 0.67 & 1 & 2 & 1 & 1 & 1 & 1.5 & 2 & 2.5 & 0.45 \\
$C_{3}$ & 0.5 & 0.67 & 1 & 0.4 & 0.5 & 0.67 & 1 & 1. & 1 & 0.16 \\
\hline
\end{tabular}

Table B.2

The inner dependence matrix and relative importance weight with respect to $C_{l}$

\begin{tabular}{cccccccc}
\hline$C_{1}$ & & $C_{2}$ & & & $C_{3}$ & & $W_{c}$ \\
\hline$C_{2}$ & 1 & 1 & 1 & 1 & 1.5 & 2 & 0.68 \\
$C_{3}$ & 0.5 & 0.67 & 1 & 1 & 1 & 1 & 0.32 \\
\hline
\end{tabular}

Table B.3

The inner dependence matrix and relative importance weight with respect to $C_{2}$

\begin{tabular}{cccccccc}
\hline$C_{2}$ & & $C_{1}$ & & \multicolumn{3}{c}{$C_{3}$} & $W_{c}$ \\
\hline$C_{1}$ & 1 & 1 & 1 & 0.5 & 1 & 1.5 & 0.50 \\
$C_{3}$ & 0.67 & 1 & 2 & 1 & 1 & 1 & 0.50 \\
\hline
\end{tabular}

Table B.4

The inner dependence matrix and relative importance weight with respect to $C_{3}$

\begin{tabular}{cccccccc}
\hline$C_{3}$ & & $C_{1}$ & & & $C_{2}$ & & $W_{c}$ \\
\hline$C_{1}$ & 1 & 1 & 1 & 1 & 1.5 & 2 & 0.68 \\
$C_{2}$ & 0.5 & 0.67 & 1 & 1 & 1 & 1 & 0.32 \\
\hline
\end{tabular}


Table B.5

The related priorities of the green performance criteria for battery recovery centers

\begin{tabular}{lccccc}
\hline$W e_{2}$ & $C_{1}$ & $C_{2}$ & $C_{3}$ & $W e_{1}$ & $W e_{\text {criteria }}=W e_{2} * W e_{1}$ \\
\hline$C_{1}$ & 1 & 0.5 & 0.68 & 0.39 & 0.36 \\
$C_{2}$ & 0.68 & 1 & 0.32 & 0.45 & 0.38 \\
$C_{3}$ & 0.32 & 0.5 & 1 & 0.16 & 0.25 \\
\hline
\end{tabular}

Table B.6

Pairwise comparisons among sub-criteria of $C_{l}$

\begin{tabular}{cccccccc}
\hline$C_{1}$ & & $S c_{1}$ & & & $S c_{2}$ & & $W_{c}$ \\
\hline$S c_{1}$ & 1 & 1 & 1 & 0.5 & 0.67 & 1 & 0.32 \\
$S c_{2}$ & 1 & 1.5 & 2 & 1 & 1 & 1 & 0.68 \\
\hline
\end{tabular}

Table B.7

Pairwise comparisons among sub-criteria of $C_{2}$

\begin{tabular}{ccccccccccc}
\hline$C_{2}$ & \multicolumn{1}{c}{$S c_{3}$} & \multicolumn{1}{c}{$S c_{4}$} & & $S c_{5}$ & & $W_{c}$ \\
\hline$S c_{3}$ & 1 & 1 & 1 & 0.5 & 1 & 1.5 & 1.5 & 2 & 2.5 & 0.41 \\
$S c_{4}$ & 0.67 & 1 & 2 & 1 & 1 & 1 & 0.5 & 1 & 1.5 & 0.33 \\
$S c_{5}$ & 0.4 & 0.5 & 0.67 & 0.67 & 1 & 2 & 1 & 1 & 1 & 0.26 \\
\hline
\end{tabular}

Table B.8

Pairwise comparisons among sub-criteria of $C_{3}$

\begin{tabular}{cccccccc}
\hline$C_{3}$ & & $S c_{6}$ & & & $S c_{7}$ & & $W_{c}$ \\
\hline$S c_{6}$ & 1 & 1 & 1 & 1 & 1.5 & 2 & 0.68 \\
$S c_{7}$ & 0.5 & 0.67 & 1 & 1 & 1 & 1 & 0.32 \\
\hline
\end{tabular}


Table B.9

Overall priority of the sub-criteria of green performance for potential battery recovery centers

\begin{tabular}{|c|c|c|c|c|}
\hline Fuzzy ANP & $\begin{array}{l}W e_{\text {criteria }} \text { obtained } \\
\quad \text { in Step } 4\end{array}$ & Sub-criteria & $\begin{array}{c}\text { We } e_{\text {sub-criteria }} \\
\text { obtained in } \\
\text { Step } 5\end{array}$ & $\begin{array}{c}\left.\text { We } e_{\text {sub-criteria }} \text {, overall }\right) \\
\text { (a) }\end{array}$ \\
\hline \multirow{2}{*}{$\begin{array}{l}C_{l}: \text { Eco-intelligent } \\
\text { technology }\end{array}$} & \multirow{2}{*}{0.36} & $\begin{array}{l}\text { Sc1: Utilizing eco-intelligent technology for sorting } \\
\text { returned batteries }\end{array}$ & 0.32 & 0.11 \\
\hline & & $\begin{array}{l}\text { Sc2: Utilizing eco-intelligent technology for recycling } \\
\text { batteries }\end{array}$ & 0.68 & 0.25 \\
\hline \multirow{3}{*}{$C_{2}$ : Environmental practice } & \multirow{3}{*}{0.38} & Sc3: Responsible Recycling@ (R2) Certification & 0.41 & 0.16 \\
\hline & & Sc4: Solid and septic waste management & 0.33 & 0.12 \\
\hline & & Sc5: Environmental Regulatory Compliance & 0.26 & 0.10 \\
\hline \multirow{2}{*}{$C_{3}$ : battery recovery service } & \multirow{2}{*}{0.25} & Sc6: Collaborating with customer & 0.68 & 0.17 \\
\hline & & Sc7: Maintenance and inspection for reducing scrap rate & 0.32 & 0.08 \\
\hline
\end{tabular}


Table B.10

Priority of each battery recovery center with respect to $S c_{1}$

\begin{tabular}{|c|c|c|c|c|c|c|c|c|c|c|c|c|c|c|c|c|c|c|c|c|c|c|c|c|c|c|c|c|c|c|c|}
\hline \multirow{2}{*}{$\frac{S c_{1}}{\text { Rec. center } 1}$} & \multicolumn{3}{|c|}{ Rec. center 1} & \multicolumn{3}{|c|}{ Rec. center 2} & \multicolumn{3}{|c|}{ Rec. center 3} & \multicolumn{3}{|c|}{ Rec. center 4} & \multicolumn{3}{|c|}{ Rec. center 5} & \multicolumn{3}{|c|}{ Rec. center 6} & \multicolumn{3}{|c|}{ Rec. center 7} & \multicolumn{3}{|c|}{ Rec. center 8} & \multicolumn{3}{|c|}{ Rec. center 9} & \multicolumn{3}{|c|}{ Rec. center 10} & \multirow{2}{*}{$\frac{\mathrm{W}_{\mathrm{c}}}{0.14}$} \\
\hline & 1 & 1 & 1 & 1 & 1.5 & 2 & 1 & 1.5 & 2 & 1.5 & 2 & 2.5 & 0.5 & 1 & 1.5 & 1 & 1.5 & 2 & 1.5 & 2 & 2.5 & 0.5 & 1 & 1.5 & 2 & 2.5 & 3 & 2 & 2.5 & 3 & \\
\hline Rec. center 2 & 0.5 & 0.67 & 1 & 1 & 1 & 1 & 1 & 1.5 & 2 & 1 & 1.5 & 2 & 1 & 1.5 & 2 & 0.5 & 1 & 1.5 & 2 & 2.5 & 3 & 1 & 1.5 & 2 & 0.5 & 1 & 1.5 & 0.5 & 1 & 1.5 & 0.12 \\
\hline Rec. center 3 & 0.5 & 0.67 & 1 & 0.5 & 0.67 & 1 & 1 & 1 & 1 & 0.5 & 1 & 1.5 & 1 & 1.5 & 2 & 0.5 & 1 & 1.5 & 0.5 & 1 & 1.5 & 0.5 & 1 & 1.5 & 1 & 1.5 & 2 & 1 & 1.5 & 2 & 0.10 \\
\hline Rec. center 4 & 0.4 & 0.5 & 0.67 & 0.5 & 0.67 & 1 & 0.67 & 1 & 2 & 1 & 1 & 1 & 0.5 & 1 & 1.5 & 1 & 1.5 & 2 & 2 & 2.5 & 3 & 0.5 & 1 & 1.5 & 0.5 & 1 & 1.5 & 0.5 & 1. & 1.5 & 0.10 \\
\hline Rec. center 5 & 0.67 & 1 & 2 & 0.5 & 0.67 & 1 & 0.5 & 0.67 & 1 & 0.67 & 1 & 2 & 1 & 1 & 1 & 1 & 1.5 & 2 & 2 & 2.5 & 3 & 1.5 & 2 & 2.5 & 1 & 1.5 & 2 & 1.5 & 2 & 2.5 & 0.12 \\
\hline Rec. center 6 & 0.5 & 0.67 & 1 & 0.67 & 1 & 2 & 0.67 & 1 & 2 & 0.5 & 0.67 & 1 & 0.5 & 0.67 & 1 & 1 & 1 & 1 & 1 & 1.5 & 2 & 0.5 & 1 & 1.5 & 0.5 & 1 & 1.5 & 1 & 1.5 & 2 & 0.09 \\
\hline Rec. center 7 & 0.4 & 0.5 & 0.67 & 0.33 & 0.4 & 0.5 & 0.67 & 1 & 2 & 0.33 & 0.4 & 0.5 & 0.33 & 0.4 & 0.5 & 0.5 & 0.67 & 1 & 1 & 1 & 1 & 0.5 & 1 & 1.5 & 0.5 & 1 & 1.5 & 0.5 & 1 & 1.5 & 0.06 \\
\hline Rec. center 8 & 0.67 & 1 & 2 & 0.5 & 0.67 & 1 & 0.67 & 1 & 2 & 0.67 & 1 & 2 & 0.4 & 0.5 & 0.67 & 0.67 & 1 & 2 & 0.67 & 1 & 2 & 1 & 1 & 1 & 1.5 & 2 & 2.5 & 1 & 1.5 & 2 & 0.10 \\
\hline Rec. center 9 & 0.33 & 0.4 & 0.5 & 0.67 & 1 & 2 & 0.5 & 0.67 & 1 & 0.67 & 1 & 2 & 0.5 & 0.67 & 1 & 0.67 & 1 & 2 & 0.67 & 1 & 2 & 0.4 & 0.5 & 0.67 & 1 & 1 & 1 & 2 & 2.5 & 3 & 0.09 \\
\hline Rec. center 10 & 0.33 & 0.4 & 0.5 & 0.67 & 1 & 2 & 0.5 & 0.67 & 1 & 0.67 & 1 & 2 & 0.4 & 0.5 & 0.67 & 0.5 & 0.67 & 1 & 0.67 & 1 & 2 & 0.5 & 0.67 & 1 & 0.33 & 0.4 & 0.5 & 1 & 1 & 1 & 0.07 \\
\hline
\end{tabular}

Table B.11

Priority of each battery recovery center with respect to $\mathrm{Sc}_{2}$

\begin{tabular}{|c|c|c|c|c|c|c|c|c|c|c|c|c|c|c|c|c|c|c|c|c|c|c|c|c|c|c|c|c|c|c|c|}
\hline \multirow{2}{*}{$\begin{array}{l}S_{c_{2}} \\
\text { Rec. center } 1\end{array}$} & \multicolumn{3}{|c|}{ Rec. center 1} & \multicolumn{3}{|c|}{ Rec. center 2} & \multicolumn{3}{|c|}{ Rec. center 3} & \multicolumn{3}{|c|}{ Rec. center 4} & \multicolumn{3}{|c|}{ Rec. center 5} & \multicolumn{3}{|c|}{ Rec. center 6} & \multicolumn{3}{|c|}{ Rec. center 7} & \multicolumn{3}{|c|}{ Rec. center 8} & \multicolumn{3}{|c|}{ Rec. center 9} & \multicolumn{3}{|c|}{ Rec. center 10} & \multirow{2}{*}{$\frac{\mathrm{W}_{\mathrm{c}}}{0.16}$} \\
\hline & 1 & 1 & 1 & 1 & 1.5 & 2 & 1 & 1.5 & 2 & 1.5 & 2 & 2.5 & 2 & 2.5 & 3 & 1 & 1.5 & 2 & 1.5 & 2 & 2.5 & 2 & 2.5 & 3 & 0.5 & 1 & 1.5 & 2 & 2.5 & 3 & \\
\hline Rec. center 2 & 0.5 & 0.67 & 1 & 1 & 1 & 1 & 1 & 1.5 & 2 & 1 & 1.5 & 2 & 1 & 1.5 & 2 & 0.5 & 1 & 1.5 & 2 & 2.5 & 3 & 0.5 & 1 & 1.5 & 0.5 & 1 & 1.5 & 0.5 & 1 & 1.5 & 0.11 \\
\hline Rec. center 3 & 0.5 & 0.67 & 1 & 0.5 & 0.67 & 1 & 1 & 1 & 1 & 0.5 & 1 & 1.5 & 1 & 1.5 & 2 & 0.5 & 1 & 1.5 & 0.5 & 1 & 1.5 & 0.5 & 1 & 1.5 & 1 & 1.5 & 2 & 1 & 1.5 & 2 & 0.10 \\
\hline Rec. center 4 & 0.4 & 0.5 & 0.67 & 0.5 & 0.67 & 1 & 0.67 & 1 & 2 & 1 & 1 & 1 & 0.5 & 1 & 1.5 & 1 & 1.5 & 2 & 1 & 1.5 & 2 & 2 & 2.5 & 3 & 0.5 & 1 & 1.5 & 0.5 & 1 & 1.5 & 0.11 \\
\hline Rec. center 5 & 0.33 & 0.4 & 0.5 & 0.5 & 0.67 & 1 & 0.5 & 0.67 & 1 & 0.67 & 1 & 2 & 1 & 1 & 1 & 1 & 1.5 & 2 & 2 & 2.5 & 3 & 0.5 & 1 & 1.5 & 0.5 & 1 & 1.5 & 1.5 & 2 & 2.5 & 0.11 \\
\hline Rec. center 6 & 0.5 & 0.67 & 1 & 0.67 & 1 & 2 & 0.67 & 1 & 2 & 0.5 & 0.67 & 1 & 0.5 & 0.67 & 1 & 1 & 1 & 1 & 0.5 & 1 & 1.5 & 0.5 & 1 & 1.5 & 1 & 1.5 & 2 & 2 & 2.5 & 3 & 0.10 \\
\hline Rec. center 7 & 0.4 & 0.5 & 0.67 & 0.33 & 0.4 & 0.5 & 0.67 & 1 & 2 & 0.5 & 0.67 & 1 & 0.33 & 0.4 & 0.5 & 0.67 & 1 & 2 & 1 & 1 & 1 & 0.5 & 1 & 1.5 & 0.5 & 1 & 1.5 & 0.5 & 1 & 1.5 & 0.07 \\
\hline Rec. center 8 & 0.33 & 0.4 & 0.5 & 0.67 & 1 & 2 & 0.67 & 1 & 2 & 0.33 & 0.4 & 0.5 & 0.67 & 1 & 2 & 0.67 & 1 & 2 & 0.67 & 1 & 2 & 1 & 1 & 1 & 0.5 & 1 & 1.5 & 0.5 & 1 & 1.5 & 0.09 \\
\hline Rec. center 9 & 0.67 & 1 & 2 & 0.67 & 1 & 2 & 0.5 & 0.67 & 1 & 0.67 & 1 & 2 & 0.67 & 1 & 2 & 0.5 & 0.67 & 1 & 0.67 & 1 & 2 & 0.67 & 1 & 2 & 1 & 1 & 1 & 1 & 1.5 & 2 & 0.10 \\
\hline Rec. center 10 & 0.33 & 0.4 & 0.5 & 0.67 & 1 & 2 & 0.5 & 0.67 & 1 & 0.67 & 1 & 2 & 0.4 & 0.5 & 0.67 & 0.33 & 0.4 & 0.5 & 0.67 & 1 & 2 & 0.67 & 1 & 2 & 0.5 & 0.67 & 1 & 1 & 1 & 1 & 0.07 \\
\hline
\end{tabular}


Table B.12

Priority of each battery recovery center with respect to $S c_{3}$

\begin{tabular}{|c|c|c|c|c|c|c|c|c|c|c|c|c|c|c|c|c|c|c|c|c|c|c|c|c|c|c|c|c|c|c|c|}
\hline \multirow{2}{*}{$\begin{array}{l}S c 3 \\
\text { Rec. center } 1\end{array}$} & \multicolumn{3}{|c|}{ Rec. center 1} & \multicolumn{3}{|c|}{ Rec. center 2} & \multicolumn{4}{|c|}{ Rec. center 3} & \multicolumn{3}{|c|}{ Rec. center 4} & \multicolumn{3}{|c|}{ Rec. center 5} & \multicolumn{3}{|c|}{ Rec. center 6} & \multicolumn{3}{|c|}{ Rec. center 7} & \multicolumn{3}{|c|}{ Rec. center 8} & \multicolumn{3}{|c|}{ Rec. center 9} & \multicolumn{2}{|c|}{ Rec. center 10} & \multirow{2}{*}{$\frac{\mathrm{W}_{\mathrm{c}}}{0.16}$} \\
\hline & 1 & 1 & 1 & 2 & 2.5 & 3 & 1 & 1.5 & 2 & 1.5 & 2 & 2.5 & 2 & 2.5 & 3 & 1 & 1.5 & 2 & 2 & 2.5 & 3 & 1 & 1.5 & 2 & 0.5 & 1 & 1.5 & 2 & 2.5 & 3 & \\
\hline Rec. center 2 & 0.33 & 0.4 & 0.5 & 1 & 1 & 1 & 1 & 1.5 & 2 & 1 & 1.5 & 2 & 1 & 1.5 & 2 & 0.5 & 1 & 1.5 & 2 & 2.5 & 3 & 0.5 & 1 & 1.5 & 1.5 & 2 & 2.5 & 1.5 & 2 & 2.5 & 0.13 \\
\hline Rec. center 3 & 0.5 & 0.67 & 1 & 0.5 & 0.67 & 1 & 1 & 1 & 1 & 0.5 & 1 & 1.5 & 1 & 1.5 & 0 & 0.5 & 1 & 1.5 & 0.5 & 1 & 1.5 & 1.5 & 2 & 2.5 & 0.5 & 1 & 1.5 & 1 & 1.5 & 2 & 0.10 \\
\hline Rec. center 4 & 0.4 & 0.5 & 0.67 & 0.5 & 0.67 & 1 & 0.67 & 1 & 2 & 1 & 1 & 1 & 0.5 & 1 & 1.5 & 1 & 1.5 & 2 & 2 & 2.5 & 3 & 0.5 & 1 & 1.5 & 1 & 1.5 & 2 & 0.5 & 1 & 1.5 & 0.10 \\
\hline Rec. center 5 & 0.33 & 0.4 & 0.5 & 0.5 & 0.67 & 1 & 0.5 & 0.67 & 1 & 0.67 & 1 & 2 & 1 & 1 & 1 & 1 & 1.5 & 2 & 2 & 2.5 & 3 & 1 & 1.5 & 2 & 1.5 & 2 & 2.5 & 1.5 & 2 & 2.5 & 0.12 \\
\hline Rec. center 6 & 0.5 & 0.67 & 1 & 0.67 & 1 & 2 & 0.67 & 1 & 2 & 0.5 & 0.67 & 1 & 0.5 & 0.67 & 1 & 1 & 1 & 1 & 1 & 1.5 & 2 & 1.5 & 2 & 2.5 & 0.5 & 1 & 1.5 & 0.5 & 1 & 1.5 & 0.10 \\
\hline Rec. center 7 & 0.33 & 0.4 & 0.5 & 0.33 & 0.4 & 0.5 & 0.67 & 1 & 2 & 0.33 & 0.4 & 0.5 & 0.33 & 0.4 & 0.5 & 0.5 & 0.67 & 1 & 1 & 1 & 1 & 0.5 & 1 & 1.5 & 0.5 & 1 & 1.5 & 2 & 2.5 & 3 & 0.07 \\
\hline Rec. center 8 & 0.5 & 0.67 & 1 & 0.67 & 1.0 & 2 & 0.4 & 0.5 & 0.67 & 0.67 & 1 & 2 & 0.5 & 0.67 & 1 & 0.4 & 0.5 & 0.67 & 0.67 & 1 & 2 & 1 & 1 & 1 & 2 & 2.5 & 3 & 0.5 & 1 & 1.5 & 0.09 \\
\hline Rec. center 9 & 0.67 & 1.0 & 2 & 0.4 & 0.5 & 0.67 & 0.67 & 1 & 2. & 0.5 & 0.67 & 1 & 0.4 & 0.5 & 0.67 & 0.67 & 1 & 2 & 0.67 & 1 & 2 & 0.33 & 0.4 & 0.5 & 1 & 1 & 1 & 1.5 & 2 & 2.5 & 0.08 \\
\hline Rec. center 10 & 0.33 & 0.4 & 0.5 & 0.4 & 0.5 & 0.67 & 0.5 & 0.67 & 1 & 0.67 & 1 & 2 & 0.4 & 0.5 & 0.67 & 0.67 & 1 & 2 & 0.33 & 0.4 & 0.5 & 0.67 & 1 & 2 & 0.4 & 0.5 & 0.67 & 1 & 1 & 1 & 0.05 \\
\hline
\end{tabular}

Table B.13

Priority of each battery recovery center with respect to $S c_{4}$

\begin{tabular}{|c|c|c|c|c|c|c|c|c|c|c|c|c|c|c|c|c|c|c|c|c|c|c|c|c|c|c|c|c|c|c|c|}
\hline \multirow{2}{*}{$\begin{array}{l}S c_{4} \\
\text { Rec. center } 1\end{array}$} & \multicolumn{3}{|c|}{ Rec. center 1} & \multicolumn{3}{|c|}{ Rec. center 2} & \multicolumn{3}{|c|}{ Rec. center 3} & \multicolumn{3}{|c|}{ Rec. center 4} & \multicolumn{3}{|c|}{ Rec. center 5} & \multicolumn{3}{|c|}{ Rec. center 6} & \multicolumn{3}{|c|}{ Rec. center 7} & \multicolumn{3}{|c|}{ Rec. center 8} & \multicolumn{3}{|c|}{ Rec. center 9} & \multicolumn{3}{|c|}{ Rec. center 10} & \multirow{2}{*}{$\frac{\mathrm{W}_{\mathrm{c}}}{0.15}$} \\
\hline & 1 & 1 & 1 & 1 & 1.5 & 2 & 2 & 2.5 & 3 & 1.5 & 2 & 2.5 & 0.5 & 1 & 1.5 & 1.5 & 2 & 2.5 & 0.5 & 1 & 1.5 & 2 & 2.5 & 3 & 1 & 1.5 & 2 & 2 & 2.5 & 3 & \\
\hline Rec. center 2 & 0.5 & 0.67 & 1 & 1 & 1 & 1 & 1 & 1.5 & 2 & 1 & 1.5 & 2 & 1 & 1.5 & 2 & 0.5 & 1 & 1.5 & 2 & 2.5 & 3 & 0.5 & 1 & 1.5 & 0.5 & 1 & 1.5 & 0.5 & 1 & 1.5 & 0.11 \\
\hline Rec. center 3 & 0.33 & 0.4 & 0.5 & 0.5 & 0.67 & 1 & 1 & 1 & 1 & 0.5 & 1 & 1.5 & 1 & 1.5 & 2 & 0.5 & 1 & 1.5 & 1.5 & 2 & 2.5 & 0.5 & 1 & 1.5 & 1 & 1.5 & 2 & 2 & 2.5 & 3 & 0.11 \\
\hline Rec. center 4 & 0.4 & 0.5 & 0.67 & 0.5 & 0.67 & 1 & 0.67 & 1 & 2 & 1 & 1 & 1 & 0.5 & 1 & 1.5 & 1 & 1.5 & 2 & 0.5 & 1 & 1.5 & 1.5 & 2 & 2.5 & 0.5 & 1 & 1.5 & 0.5 & 1 & 1.5 & 0.10 \\
\hline Rec. center 5 & 0.67 & 1 & 2 & 0.5 & 0.67 & 1 & 0.5 & 0.67 & 1 & 0.67 & 1 & 2 & 1 & 1 & 1 & 1 & 1.5 & 2 & 2 & 2.5 & 3 & 0.5 & 1 & 1.5 & 2 & 2.5 & 3 & 1.5 & 2 & 2.5 & 0.12 \\
\hline Rec. center 6 & 0.4 & 0.5 & 0.67 & 0.67 & 1 & 2 & 0.67 & 1 & 2 & 0.5 & 0.67 & 1 & 0.5 & 0.67 & 1 & 1 & 1 & 1 & 1.5 & 2 & 2.5 & 1.5 & 2 & 2.5 & 0.5 & 1 & 1.5 & 1.5 & 2 & 2.5 & 0.11 \\
\hline Rec. center 7 & 0.67 & 1 & 2 & 0.33 & 0.4 & 0.5 & 0.4 & 0.5 & 0.67 & 0.67 & 1 & 2 & 0.33 & 0.4 & 0.5 & 0.4 & 0.5 & 0.67 & 1 & 1 & 1 & 0.5 & 1 & 1.5 & 1.5 & 2 & 2.5 & 0.5 & 1 & 1.5 & 0.08 \\
\hline Rec. center 8 & 0.33 & 0.4 & 0.5 & 0.67 & 1 & 2 & 0.67 & 1 & 2 & 0.4 & 0.5 & 0.67 & 0.67 & 1 & 2 & 0.4 & 0.5 & 0.67 & 0.67 & 1 & 2 & 1 & 1 & 1 & 0.5 & 1 & 1.5 & 1 & 1.5 & 2 & 0.08 \\
\hline Rec. center 9 & 0.5 & 0.67 & 1 & 0.67 & 1 & 2 & 0.5 & 0.67 & 1 & 0.67 & 1 & 2 & 0.33 & 0.4 & 0.5 & 0.67 & 1 & 2 & 0.4 & 0.5 & 0.67 & 0.67 & 1 & 2 & 1 & 1 & 1 & 2 & 2.5 & 3 & 0.09 \\
\hline Rec. center 10 & 0.33 & 0.4 & 0.5 & 0.67 & 1 & 2 & 0.33 & 0.4 & 0.5 & 0.67 & 1 & 2 & 0.4 & 0.5 & 0.67 & 0.4 & 0.5 & 0.67 & 0.67 & 1 & 2 & 0.50 & 0.67 & 1 & 0.33 & 0.4 & 0.5 & 1 & 1 & 1 & 0.05 \\
\hline
\end{tabular}


Table B.14

Priority of each battery recovery center with respect to $S c_{5}$

\begin{tabular}{|c|c|c|c|c|c|c|c|c|c|c|c|c|c|c|c|c|c|c|c|c|c|c|c|c|c|c|c|c|c|c|c|}
\hline \multirow{2}{*}{$\begin{array}{l}S c_{5} \\
\text { Rec. center } 1\end{array}$} & \multicolumn{3}{|c|}{ Rec. center 1} & \multicolumn{3}{|c|}{ Rec. center 2} & \multicolumn{3}{|c|}{ Rec. center 3} & \multicolumn{3}{|c|}{ Rec. center 4} & \multicolumn{3}{|c|}{ Rec. center 5} & \multicolumn{3}{|c|}{ Rec. center 6} & \multicolumn{3}{|c|}{ Rec. center 7} & \multicolumn{3}{|c|}{ Rec. center 8} & \multicolumn{3}{|c|}{ Rec. center 9} & \multicolumn{3}{|c|}{ Rec. center 10} & \multirow{2}{*}{$\begin{array}{r}\mathrm{W}_{\mathrm{c}} \\
0.13\end{array}$} \\
\hline & 1 & 1 & 1 & 1 & 1.5 & 2 & 1 & 1.5 & 2 & 1.5 & 2 & 2.5 & 0.5 & 1 & 1.5 & 1 & 1.5 & 2 & 1.5 & 2 & 2.5 & 0.5 & 1 & 1.5 & 1 & 1.5 & 2 & 2 & 2.5 & 3 & \\
\hline Rec. center 2 & 0.5 & 0.67 & 1 & 1 & 1 & 1 & 1 & 1.5 & 2 & 1 & 1.5 & 2 & 1 & 1.5 & 2 & 0.5 & 1 & 1.5 & 2 & 2.5 & 3 & 1.5 & 2 & 2.5 & 0.5 & 1 & 1.5 & 0.5 & 1 & 1.5 & 0.12 \\
\hline Rec. center 3 & 0.5 & 0.67 & 1 & 0.5 & 0.67 & 1 & 1 & 1 & 1 & 2 & 2.5 & 3 & 1 & 1.5 & 2 & 2 & 2.5 & 3 & 0.5 & 1 & 1.5 & 0.5 & 1 & 1.5 & 0.5 & 1 & 1.5 & 1 & 1.5 & 2 & 0.11 \\
\hline Rec. center 4 & 0.4 & 0.5 & 0.67 & 0.5 & 0.67 & 1 & 0.33 & 0.4 & 0.5 & 1 & 1 & 1 & 0.5 & 1 & 1.5 & 1 & 1.5 & 2 & 0.5 & 1 & 1.5 & 1 & 1.5 & 2 & 2 & 2.5 & 3 & 0.5 & 1 & 1.5 & 0.10 \\
\hline Rec. center 5 & 0.67 & 1 & 2 & 0.5 & 0.67 & 1 & 0.5 & 0.67 & 1 & 0.67 & 1 & 2 & 1 & 1 & 1 & 1 & 1.5 & 2 & 2 & 2.5 & 3 & 0.5 & 1 & 1.5 & 0.5 & 1 & 1.5 & 2 & 2.5 & 3 & 0.11 \\
\hline Rec. center 6 & 0.5 & 0.67 & 1 & 0.67 & 1 & 2 & 0.33 & 0.4 & 0.5 & 0.5 & 0.67 & 1 & 0.5 & 0.67 & 1 & 1 & 1 & 1 & 2 & 2.5 & 3 & 1.5 & 2 & 2.5 & 1 & 1.5 & 2 & 2 & 2.5 & 3 & 0.11 \\
\hline Rec. center 7 & 0.4 & 0.5 & 0.67 & 0.33 & 0.4 & 0.5 & 0.67 & 1 & 2 & 0.67 & 1 & 2 & 0.33 & 0.4 & 0.5 & 0.33 & 0.4 & 0.5 & 1 & 1 & 1 & 0.5 & 1 & 1.5 & 0.5 & 1 & 1.5 & 0.5 & 1 & 1.5 & 0.07 \\
\hline Rec. center 8 & 0.67 & 1 & 2 & 0.4 & 0.5 & 0.67 & 0.67 & 1 & 2 & 0.5 & 0.67 & 1 & 0.67 & 1 & 2 & 0.4 & 0.5 & 0.67 & 0.67 & 1 & 2 & 1 & 1 & 1 & 1.5 & 2 & 2.5 & 2 & 2.5 & 3 & 0.10 \\
\hline Rec. center 9 & 0.5 & 0.67 & 1 & 0.67 & 1 & 2 & 0.67 & 1 & 2 & 0.33 & 0.4 & 0.5 & 0.67 & 1 & 2 & 0.5 & 0.67 & 1 & 0.67 & 1 & 2 & 0.4 & 0.5 & 0.67 & 1 & 1 & 1 & 2 & 2.5 & 3 & 0.09 \\
\hline Rec. center 10 & 0.33 & 0.4 & 0.5 & 0.67 & 1 & 2 & 0.5 & 0.67 & 1 & 0.67 & 1 & 2 & 0.33 & 0.4 & 0.5 & 0.33 & 0.4 & 0.5 & 0.67 & 1 & 2 & 0.33 & 0.4 & 0.5 & 0.33 & 0.4 & 0.5 & 1 & 1 & 1 & 0.06 \\
\hline
\end{tabular}

Table B. 15

Priority of each battery recovery center with respect to $S c_{6}$

\begin{tabular}{|c|c|c|c|c|c|c|c|c|c|c|c|c|c|c|c|c|c|c|c|c|c|c|c|c|c|c|c|c|c|c|c|}
\hline \multirow{2}{*}{$\begin{array}{l}S c 6 \\
\text { Rec. center } 1\end{array}$} & \multicolumn{3}{|c|}{ Rec. center 1} & \multicolumn{3}{|c|}{ Rec. center 2} & \multicolumn{3}{|c|}{ Rec. center 3} & \multicolumn{3}{|c|}{ Rec. center 4} & \multicolumn{3}{|c|}{ Rec. center 5} & \multicolumn{3}{|c|}{ Rec. center 6} & \multicolumn{3}{|c|}{ Rec. center 7} & \multicolumn{3}{|c|}{ Rec. center 8} & \multicolumn{3}{|c|}{ Rec. center 9} & \multicolumn{3}{|c|}{ Rec. center 10} & \multirow{2}{*}{$\frac{\mathrm{W}_{\mathrm{c}}}{0.14}$} \\
\hline & 1 & 1 & 1 & 1 & 1.5 & 2 & 1 & 1.5 & 2 & 1.5 & 2 & 2.5 & 0.5 & 1 & 1.5 & 1 & 1.5 & 2 & 2 & 2.5 & 3 & 0.5 & 1 & 1.5 & 2 & 2.5 & 3 & 1.5 & 2 & 2.5 & \\
\hline Rec. center 2 & 0.5 & 0.67 & 1 & 1 & 1 & 1 & 1 & 1.5 & 2 & 1 & 1.5 & 2 & 1 & 1.5 & 2 & 0.5 & 1 & 1.5 & 2 & 2.5 & 3 & 1 & 1.5 & 2 & 1 & 1.5 & 2 & 2 & 2.5 & 3 & 0.13 \\
\hline Rec. center 3 & 0.5 & 0.67 & 1 & 0.5 & 0.67 & 1 & 1 & 1 & 1 & 0.5 & 1 & 1.5 & 2. & 2.5 & 3 & 0.5 & 1 & 1.5 & 0.5 & 1 & 1.5 & 0.5 & 1 & 1.5 & 0.5 & 1 & 1.5 & 1 & 1 & 2 & 0.10 \\
\hline Rec. center 4 & 0.4 & 0.5 & 0.67 & 0.5 & 0.67 & 1 & 0.67 & 1 & 2 & 1 & 1 & 1 & 2 & 2.5 & 3 & 1 & 1.5 & 2 & 0.5 & 1 & 1.5 & 2 & 2.5 & 3 & 2 & 2.5 & 3 & 1.5 & 2 & 2.5 & 0.13 \\
\hline Rec. center 5 & 0.67 & 1 & 2 & 0.5 & 0.67 & 1 & 0.33 & 0.4 & 0.5 & 0.33 & 0.4 & 0.5 & 1 & 1 & 1 & 2 & 2.5 & 3 & 1 & 1.5 & 2 & 2 & 2.5 & 3. & 0.5 & 1 & 1.5 & 2 & 2.5 & 3 & 0.12 \\
\hline Rec. center 6 & 0.5 & 0.67 & 1 & 0.67 & 1 & 2 & 0.67 & 1 & 2 & 0.5 & 0.67 & 1 & 0.33 & 0.4 & 0.5 & 1 & 1 & 1. & 0.5 & 1 & 1.5 & 0.5 & 1 & 1.5 & 1 & 1.5 & 2 & 0.5 & 1 & 1.5 & 0.08 \\
\hline Rec. center 7 & 0.33 & 0.4 & 0.5 & 0.33 & 0.4 & 0.5 & 0.67 & 1 & 2 & 0.67 & 1 & 2 & 0.5 & 0.67 & 1 & 0.67 & 1 & 2 & 1 & 1 & 1 & 1.5 & 2 & 2.5 & 0.5 & 1 & 1.5 & 1 & 1.5 & 2 & 0.09 \\
\hline Rec. center 8 & 0.67 & 1 & 2 & 0.5 & 0.67 & 1 & 0.67 & 1 & 2 & 0.33 & 0.4 & 0.5 & 0.33 & 0.4 & 0.5 & 0.67 & 1 & 2 & 0.4 & 0.5 & 0.67 & 1 & 1 & 1 & 0.5 & 1 & 1.5 & 0.5 & 1 & 1.5 & 0.07 \\
\hline Rec. center 9 & 0.33 & 0.4 & 0.5 & 0.5 & 0.67 & 1 & 0.67 & 1 & 2 & 0.33 & 0.4 & 0.5 & 0.67 & 1 & 2 & 0.5 & 0.67 & 1 & 0.67 & 1 & 2 & 0.67 & 1 & 2 & 1 & 1 & 1 & 2 & 2.5 & 3 & 0.09 \\
\hline Rec. center 10 & 0.4 & 0.5 & 0.67 & 0.33 & 0.4 & 0.5 & 0.5 & 0.67 & 1 & 0.4 & 0.5 & 0.67 & 0.33 & 0.4 & 0.5 & 0.67 & 1 & 2 & 0.5 & 0.67 & 1 & 0.67 & 1 & 2 & 0.33 & 0.4 & 0.5 & 1 & 1 & 1 & 0.05 \\
\hline
\end{tabular}


Table B.16

Priority of each battery recovery center with respect to $S_{7}$

\begin{tabular}{|c|c|c|c|c|c|c|c|c|c|c|c|c|c|c|c|c|c|c|c|c|c|c|c|c|c|c|c|c|c|c|c|}
\hline \multirow{2}{*}{$\begin{array}{l}S c_{7} \\
\text { Rec. center } 1\end{array}$} & \multicolumn{3}{|c|}{ Rec. center 1} & \multicolumn{3}{|c|}{ Rec. center 2} & \multicolumn{3}{|c|}{ Rec. center 3} & \multicolumn{3}{|c|}{ Rec. center 4} & \multicolumn{3}{|c|}{ Rec. center 5} & \multicolumn{3}{|c|}{ Rec. center 6} & \multicolumn{3}{|c|}{ Rec. center 7} & \multicolumn{3}{|c|}{ Rec. center 8} & \multicolumn{3}{|c|}{ Rec. center 9} & \multicolumn{3}{|c|}{ Rec. center 10} & \multirow{2}{*}{$\frac{\mathrm{W}_{\mathrm{c}}}{0.16}$} \\
\hline & 1 & 1 & 1 & 1 & 1.5 & 2 & 2 & 2.5 & 3 & 1.5 & 2 & 2.5 & 0.5 & 1 & 1.5 & 1 & 1.5 & 2 & 2 & 2.5 & 3 & 1 & 1.5 & 2 & 1.5 & 2 & 2.5 & 2 & 2.5 & 3 & \\
\hline Rec. center 2 & 0.5 & 0.67 & 1 & 1 & 1 & 1 & 1 & 1.5 & 2 & 1 & 1.5 & 2 & 2 & 2.5 & 3 & 0.5 & 1 & 1.5 & 1.5 & 2 & 2.5 & 1 & 1.5 & 2 & 1 & 1.5 & 2 & 0.5 & 1 & 1.5 & 0.13 \\
\hline Rec. center 3 & 0.33 & 0.4 & 0.5 & 0.5 & 0.67 & 1 & 1 & 1 & 1 & 0.5 & 1 & 1.5 & 1 & 1.5 & 2 & 0.5 & 1 & 1.5 & 1 & 1.5 & 2 & 0.5 & 1 & 1.5 & 0.5 & 1 & 1.5 & 2 & 2.5 & 3 & 0.10 \\
\hline Rec. center 4 & 0.4 & 0.5 & 0.67 & 0.5 & 0.67 & 1 & 0.67 & 1 & 2 & 1 & 1 & 1 & 2 & 2.5 & 3 & 1 & 1.5 & 2 & 2 & 2.5 & 3 & 1.5 & 2 & 2.5 & 0.5 & 1 & 1.5 & 2 & 2.5 & 3 & 0.13 \\
\hline Rec. center 5 & 0.67 & 1 & 2 & 0.33 & 0.4 & 0.5 & 0.5 & 0.67 & 1 & 0.33 & 0.4 & 0.5 & 1 & 1 & 1 & 1.5 & 2 & 2.5 & 2 & 2.5 & 3 & 1 & 1.5 & 2 & 2 & 2.5 & 3 & 1.5 & 2 & 2.5 & 0.12 \\
\hline Rec. center 6 & 0.5 & 0.67 & 1 & 0.67 & 1 & 2 & 0.67 & 1 & 2 & 0.5 & 0.67 & 1 & 0.4 & 0.5 & 0.67 & 1 & 1 & 1 & 1 & 1.5 & 2 & 0.5 & 1 & 1.5 & 0.5 & 1 & 1.5 & 1.5 & 2 & 2.5 & 0.09 \\
\hline Rec. center 7 & 0.33 & 0.4 & 0.5 & 0.4 & 0.5 & 0.67 & 0.5 & 0.67 & 1 & 0.33 & 0.4 & 0.5 & 0.33 & 0.4 & 0.5 & 0.5 & 0.67 & 1 & 1 & 1 & 1 & 1.5 & 2 & 2.5 & 1 & 1.5 & 2 & 0.5 & 1 & 1.5 & 0.06 \\
\hline Rec. center 8 & 0.5 & 0.67 & 1 & 0.5 & 0.67 & 1 & 0.67 & 1 & 2 & 0.4 & 0.5 & 0.67 & 0.5 & 0.67 & 1 & 0.67 & 1 & 2 & 0.4 & 0.5 & 0.67 & 1 & 1 & 1 & 0.5 & 1 & 1.5 & 1 & 1.5 & 2 & 0.07 \\
\hline Rec. center 9 & 0.4 & 0.5 & 0.67 & 0.5 & 0.67 & 1 & 0.67 & 1 & 2 & 0.67 & 1 & 2 & 0.33 & 0.4 & 0.5 & 0.67 & 1 & 2 & 0.5 & 0.67 & 1 & 0.67 & 1 & 2 & 1 & 1 & 1 & 2 & 2.5 & 3 & 0.09 \\
\hline Rec. center 10 & 0.33 & 0.4 & 0.5 & 0.67 & 1 & 2 & 0.33 & 0.4 & 0.5 & 0.33 & 0.4 & 0.5 & 0.4 & 0.5 & 0.67 & 0.4 & 0.5 & 0.67 & 0.67 & 1 & 2 & 0.5 & 0.67 & 1 & 0.33 & 0.4 & 0.5 & 1 & 1 & 1 & 0.04 \\
\hline
\end{tabular}

Table B. 17

Overall priority of each battery recovery center with respect to each sub-criterion

\begin{tabular}{llllllll}
\hline$W e_{4}$ & $S c_{1}$ & $S c_{2}$ & $S c_{3}$ & $S c_{4}$ & $S c_{5}$ & $S c_{6}$ & $S c_{7}$ \\
\hline Recovery center 1 & 0.14 & 0.16 & 0.16 & 0.15 & 0.13 & 0.14 & 0.16 \\
Recovery center 2 & 0.12 & 0.11 & 0.13 & 0.11 & 0.12 & 0.13 & 0.13 \\
Recovery center 3 & 0.10 & 0.10 & 0.10 & 0.11 & 0.11 & 0.10 & 0.10 \\
Recovery center 4 & 0.10 & 0.11 & 0.10 & 0.10 & 0.10 & 0.13 & 0.13 \\
Recovery center 5 & 0.12 & 0.11 & 0.12 & 0.12 & 0.11 & 0.12 & 0.12 \\
Recovery center 6 & 0.09 & 0.10 & 0.10 & 0.11 & 0.11 & 0.08 & 0.09 \\
Recovery center 7 & 0.06 & 0.07 & 0.07 & 0.08 & 0.07 & 0.09 & 0.06 \\
Recovery center 8 & 0.10 & 0.09 & 0.09 & 0.08 & 0.10 & 0.07 & 0.07 \\
Recovery center 9 & 0.09 & 0.10 & 0.08 & 0.09 & 0.09 & 0.09 & 0.09 \\
Recovery center 10 & 0.07 & 0.07 & 0.05 & 0.05 & 0.06 & 0.05 & 0.04 \\
\hline
\end{tabular}




\section{References}

Achillas, C., Vlachokostas, C., Aidonis, D., Moussiopoulos, N., Iakovou, E., \& Banias, G. (2010). Optimising reverse logistics network to support policy-making in the case of Electrical and Electronic Equipment. Waste Management, 30(12), 2592-2600.

Alimoradi, A., Yussuf, R. M., Ismail, N. B., \& Zulkifli, N. (2014). Developing a fuzzy linear programming model for locating recovery facility in a closed loop supply chain. International Journal of Sustainable Engineering, 8(2), 122-137.

Al-Othman, W. B., Lababidi, H. M., Alatiqi, I. M., \& Al-Shayji, K. (2008). Supply chain optimization of petroleum organization under uncertainty in market demands and prices. European Journal of Operational Research, 189(3), 822-840.

Al-Salem, M., Diabat, A., Dalalah, D., Alrefaei, M. (2016). A closed-loop supply chain management problem: Reformulation and piecewise linearization. Journal of Manufacturing Systems, 40, 1-8.

Amin, S. H., Zhang, G. (2012). An integrated model for closed-loop supply chain configuration and supplier selection: Multi-objective approach. Expert Systems with Applications, 39, 82-91.

Amin, S. H., \& Zhang, G. (2013). A multi-objective facility location model for closed-loop supply chain network under uncertain demand and return. Applied Mathematical Modelling, 37(6), 4165-4176.

Amin, S. H., \& Zhang, G. (2013). A three-stage model for closed-loop supply chain configuration under uncertainty. International Journal of Production Research, 51(5), 1405-1425.

Amin, S. H., Zhang, G., Akhtar, P. (2017). Effects of uncertainty on a tire closed-loop supply chain network. Expert Systems with Applications, 73, 82-91.

Amin, S. H., Baki, F. (2017). A facility location model for global closed-loop supply chain network design. Applied Mathematical Modelling, 41, 316-330.

Areas of the city. (2017). Retrieved from http://vancouver.ca/news-calendar/areas-of-thecity.aspx 
Azadeh, A., Raoofi, Z., \& Zarrin, M. (2015). A multi-objective fuzzy linear programming model for optimization of natural gas supply chain through a greenhouse gas reduction approach.

Journal of Natural Gas Science and Engineering, 26, 702-710.

Cardoso, S. R., Barbosa-Póvoa, A. P. F., \& Relvas, S. (2013). Design and planning of supply chains with integration of reverse logistics activities under demand uncertainty. European Journal of Operational Research, 226(3), 436-451.

Carvalho, H., Govindan, K., Azevedo, S. G., \& Cruz-Machado, V. (2017). Modelling green and lean supply chains: An eco-efficiency perspective. Resources, Conservation and Recycling, 120, $75-87$.

Cavinato, J. L. (1991). Identifying interfirm total cost advantages for supply chain competitiveness. Journal of Supply Chain Management, 27(4), 10.

Chang, D. Y. (1996). Applications of the extent analysis method on fuzzy AHP. European Journal of Operational Research, 95 (3), 649-655.

Chen, Y. W., Wang, L. C., Wang, A., Chen, T. L. (2017). A particle swarm approach for optimizing a multi-stage closed loop supply chain for the solar cell industry. Robotics and Computer-Integrated Manufacturing, 43, 111-123.

Cooper, M. C. (1993). International supply chain management: implications for the bottom line. Proceedings of the Society of Logistics Engineers, 57-60.

Costantino, N., Dotoli, M., Falagario, M., \& Sciancalepore, F. (2012). Fuzzy network design of sustainable supply chains. IFAC Proceedings Volumes, 45(6), 1284-1289.

Dai, Z., \& Zheng, X. (2015). Design of close-loop supply chain network under uncertainty using hybrid genetic algorithm: a fuzzy and chance-constrained programming model. Computers \& Industrial Engineering, 88, 444-457.

Dai, C., Cai, Y. P., Ren, W., Xie, Y. F., \& Guo, H. C. (2016). Identification of optimal placements of best management practices through an interval-fuzzy possibilistic programming model. Agricultural Water Management, 165, 108-121. 
Das, K., \& Posinasetti, N. R. (2015). Addressing environmental concerns in closed loop supply chain design and planning. International Journal of Production Economics, 163, 34-47.

Das, D., Dutta, P. (2016). Performance analysis of a closed-loop supply chain with incentive dependent demand and return, The International Journal of Advanced Manufacturing Technology, 86, 621-639.

Deb, K., \& Miettinen, K. (2008). Multiobjective optimization: interactive and evolutionary approaches (Vol. 5252). Springer Science \& Business Media.

Dutta, P., Das, D., Schultmann, F., Fröhling, M. (2016). Design and planning of a closed-loop supply chain with three-way recovery and buy-back offer. Journal of Cleaner Production, 135, 604-619.

Ebrahimnejad, A., \& Tavana, M. (2014). A novel method for solving linear programming problems with symmetric trapezoidal fuzzy numbers. Applied Mathematical Modelling, 38(17), 4388-4395.

Ellram, L. M. (1991). Supply-chain management: the industrial organisation perspective. International Journal of Physical Distribution \& Logistics Management, 21(1), 13-22.

Entezaminia, A., Heydari, M., \& Rahmani, D. (2016). A multi-objective model for multi-product multi-site aggregate production planning in a green supply chain: Considering collection and recycling centers. Journal of Manufacturing Systems, 40, 63-75.

Ezzati, R., Khorram, E., Enayati, R. (2015). A new algorithm to solve fully fuzzy linear programming problems using the MOLP problem. Applied Mathematical Modelling, 39 (12), 3183-3193.

Fallah-Tafti, A. L., Sahraeian, R., Tavakkoli-Moghaddam, R., \& Moeinipour, M. (2014). An interactive possibilistic programming approach for a multi-objective closed-loop supply chain network under uncertainty. International Journal of Systems Science, 45(3), 283-299.

Fahimnia, B., Sarkis, J., Dehghanian, F., Banihashemi, N., \& Rahman, S. (2013). The impact of carbon pricing on a closed-loop supply chain: an Australian case study. Journal of Cleaner Production, 59, 210-225. 
Feitó-Cespón, M., Sarache, W., Piedra-Jimenez, F., Cespón-Castro, R. (2017). Redesign of a sustainable reverse supply chain under uncertainty: A case study. Journal of Cleaner Production, $151,206-217$.

Fleischmann, M. (2001). Quantititative models for reverse logistics: Lecture Notes in Economics and Mathematical Systems.

Francie, K. A., Jean-Pierre, K., Pierre, D., Victor, S., \& Vladimir, P. (2015). Stochastic models and numerical solutions for manufacturing/remanufacturing systems with applications to the printer cartridge industry. Journal of Manufacturing Systems, 37, 662-671.

Fuel consumption guide. (2014). Natural Resources Canada’s Office of Energy Efficiency.

Govindan, K., Soleimani, H., \& Kannan, D. (2015). Reverse logistics and closed-loop supply chain: A comprehensive review to explore the future. European Journal of Operational Research, 240(3), 603-626.

Guide, V. D. R., Harrison, T. P., \& Van Wassenhove, L. N. (2003). The challenge of closed-loop supply chains. Interfaces, 33(6), 3-6.

Hashemi, V., Chen, M., \& Fang, L. (2014). Process planning for closed-loop aerospace manufacturing supply chain and environmental impact reduction. Computers \& Industrial Engineering, 75, 87-95.

Houlihan, J. B. (1985). International supply chain management. International Journal of Physical Distribution \& Materials Management, 15(1), 22-38.

How to recycle battery. (2012). Retrieved from http://battery.recycleplz.com/.

How are batteries recycled. (2017). Retrieved from https://www.batterysolutions.com/recyclinginformation/how-are-batteries-recycled/.

Hu, G., \& Bidanda, B. (2009). Modeling sustainable product lifecycle decision support systems. International Journal of Production Economics, 122(1), 366-375.

James A. Cooke. (1997) "In this Issue", supply chain management review, Vol.1,No1 spring 1997. 
Jayaraman, V., Guide Jr, V. D. R., \& Srivastava, R. (1999). A closed-loop logistics model for remanufacturing. Journal of the operational research society, 50(5), 497-508.

Jindal, A., \& Sangwan, K. S. (2014). Closed loop supply chain network design and optimisation using fuzzy mixed integer linear programming model. International Journal of Production Research, 52(14), 4156-4173.

Jeihoonian, M., Zanjani, M. K., Gendreau, M. (2017). Closed-loop supply chain network design under uncertain quality status: Case of durable products. International Journal of Production Economics, 183, 470-486.

Kabak, Ö., \& Ülengin, F. (2011). Possibilistic linear-programming approach for supply chain networking decisions. European Journal of Operational Research, 209(3), 253-264.

Kalaitzidou, M. A., Longinidis, P., \& Georgiadis, M. C. (2015). Optimal design of closed-loop supply chain networks with multifunctional nodes. Computers \& Chemical Engineering, 80, 7391.

Kaya, O., Urek, B. (2016). A mixed integer nonlinear programming model and heuristic solutions for location, inventory and pricing decisions in a closed loop supply chain. Computers \& Operations Research, 65, 93-103.

Keyvanshokooh, E., Ryan, S. M., \& Kabir, E. (2016). Hybrid robust and stochastic optimization for closed-loop supply chain network design using accelerated Benders decomposition. European Journal of Operational Research, 249(1), 76-92.

Kim, K. B., Song, I. S., and Jeong, B. J. (2006). Supply planning model for remanufacturing system in reverse logistics environment, Computers \& Industrial Engineering, 51 (2), 279-287.

Kisomi, M. S., Solimanpur, M., Doniavi, A. (2016). An integrated supply chain configuration model and procurement management under uncertainty: A set-based robust optimization methodology. Applied Mathematical Modelling, 40 (17), 7928-7947.

Ko, H. J., \& Evans, G. W. (2007). A genetic algorithm-based heuristic for the dynamic integrated forward/reverse logistics network for 3PLs. Computers \& Operations Research, 34(2), 346-366. 
Kusi-Sarpong, S., Sarkis, J., \& Wang, X. (2016). Assessing green supply chain practices in the Ghanaian mining industry: A framework and evaluation. International Journal of Production Economics, 181, 325-341.

Lambert, D. M., Cooper, M. C., \& Pagh, J. D. (1998). Supply chain management: implementation issues and research opportunities. The international journal of logistics management, 9(2), 1-20.

Lieckens, K., \& Vandaele, N. (2007). Reverse logistics network design with stochastic lead times. Computers \& Operations Research, 34(2), 395-416.

Litvinchev, I., Rios, Y. A., Özdemir, D., \& Hernández-Landa, L. G. (2014). Multiperiod and stochastic formulations for a closed loop supply chain with incentives. Journal of Computer \& Systems Sciences International, 53(2), 201.

Lundin, J. F. (2012). Redesigning a closed-loop supply chain exposed to risks. International Journal of Production Economics, 140(2), 596-603.

Mentzer, J. T. (1993). Managing channel relations in the 21st century. Journal of Business logistics, 14(1), 27.

Mirakhorli, A. (2014). Fuzzy multi-objective optimization for closed loop logistics network design in bread-producing industries. The International Journal of Advanced Manufacturing Technology, 70, 349-362.

Miroshnychenko, I., Barontini, R., \& Testa, F. (2017). Green practices and financial performance: A global outlook. Journal of Cleaner Production.

Mohajeri, A., \& Fallah, M. (2016). A carbon footprint-based closed-loop supply chain model under uncertainty with risk analysis: A case study. Transportation Research Part D: Transport and Environment, 48, 425-450.

Mohammed, F., Selim, S. Z., Hassan, A., Syed, M. N. (2017). Multi-period planning of closedloop supply chain with carbon policies under uncertainty. Transportation Research Part D: Transport and Environment, 51, 146-172. 
Nilashi, M., Ahmadi, H., Ahani, A., Ravangard, R., \& bin Ibrahim, O. (2016). Determining the importance of hospital information system adoption factors using fuzzy analytic network process (ANP). Technological Forecasting and Social Change, 111, 244-264.

Oh, J., \& Jeong, B. (2014). Profit analysis and supply chain planning model for closed-loop supply chain in fashion industry. Sustainability, 6(12), 9027-9056.

Özceylan, E. (2016). Simultaneous optimization of closed- and open-loop supply chain networks with common components. Journal of Manufacturing Systems, 41, 143-156.

Özceylan, E., Demirel, N., Çetinkaya, C., Demirel, E. (In press). A closed-loop supply chain network design for automotive industry in Turkey. Computers \& Industrial Engineering.

Paksoy, T., Bektaş, T., \& Özceylan, E. (2011). Operational and environmental performance measures in a multi-product closed-loop supply chain. Transportation Research Part E: Logistics and Transportation Review, 47(4), 532-546.

Pishvaee, M. S., \& Torabi, S. A. (2010). A possibilistic programming approach for closed-loop supply chain network design under uncertainty. Fuzzy sets and systems, 161(20), 2668-2683.

Pishvaee, M. S., \& Razmi, J. (2012). Environmental supply chain network design using multiobjective fuzzy mathematical programming. Applied Mathematical Modelling, 36(8), 34333446.

Pham, T., Yenradee, P. (2017). Optimal supply chain network design with process network and BOM under uncertainties: A case study in toothbrush industry. Computers \& Industrial Engineering, 108, 177-191.

Ramezani, M., Kimiagari, A. M., Karimi, B., \& Hejazi, T. H. (2014). Closed-loop supply chain network design under a fuzzy environment. Knowledge-Based Systems, 59, 108-120.

RMC Technology. Retrieved from http://www.rawmaterials.com/page/technology/.

Rosenhead, J., Elton, M., \& Gupta, S. K. (1972). Robustness and optimality as criteria for strategic decisions. Journal of the Operational Research Society, 23(4), 413-431. 
Ruimin, M. A., Lifei, Y. A. O., Maozhu, J. I. N., Peiyu, R. E. N., Zhihan, L. V. (2016). Robust environmental closed-loop supply chain design under uncertainty. Chaos, Solitons \& Fractals, $89,195-202$.

Saaty, T. L. (1996). Decision making with dependence and feedback: The analytic network process (Vol. 4922). Pittsburgh: RWS publications.

Sari, K. (2017). A novel multi-criteria decision framework for evaluating green supply chain management practices. Computers \& Industrial Engineering, 105, 338-347.

Sasikumar, P., Kannan, G., \& Haq, A. N. (2010). A multi-echelon reverse logistics network design for product recovery-a case of truck tire remanufacturing. The International Journal of Advanced Manufacturing Technology, 49(9), 1223-1234.

Scur, G., \& Barbosa, M. E. (2017). Green supply chain management practices: Multiple case studies in the Brazilian home appliance industry. Journal of Cleaner Production, 141, 1293-1302.

Shakourloo, A., Kazemi, A., Javad, M. O. M. (2016). A new model for more effective supplier selection and remanufacturing process in a closed-loop supply chain. Applied Mathematical Modelling, 40 (23), 9914-9931.

Sharma, V. K., Chandna, P., \& Bhardwaj, A. (2017). Green supply chain management related performance indicators in agro industry: A review. Journal of Cleaner Production, 141, 11941208.

Sheu, J. B., Chou, Y. H., and Hu, C. C. (2005). An integrated logistics operational model for green-supply chain management, Transportation Research Part E, 41 (4), 287-313.

Shimada, T., Van Wassenhove, L. N. (In press). Closed-Loop supply chain activities in Japanese home appliance/personal computer manufacturers: A case study. International Journal of Production Economics.

Snyder, L. V. (2006). Facility location under uncertainty: a review. IIE Transactions, 38(7), 547564. 
Soleimani, H., Govindan, K., Saghafi, H., Jafari, H. (2017). Fuzzy multi-objective sustainable and green closed-loop supply chain network design. Computers \& Industrial Engineering, 109, 191-203.

Soleimani, H., Seyyed-Esfahani, M., \& Shirazi, M. A. (2016). A new multi-criteria scenariobased solution approach for stochastic forward/reverse supply chain network design. Annals of Operations Research, 242(2), 399-421.

Sorting and processing. (2017). Retrieved from www.batterysolutions.com.

Statistics Canada. (2017). Retrieved from http://www5.statcan.gc.ca/cansim/a26?lang=eng\&id= 3260009.

Subulan, K., Taşan, A. S., Baykasoğlu, A. (2015). Designing an environmentally conscious tire closed-loop supply chain network with multiple recovery options using interactive fuzzy goal programming. Applied Mathematical Modelling, 39 (9), 2661-2702.

Talaei, M., Moghaddam, B. F., Pishvaee, M. S., Bozorgi-Amiri, A., Gholamnejad, S. (2016). A robust fuzzy optimization model for carbon-efficient closed-loop supply chain network design problem: a numerical illustration in electronics industry. Journal of Cleaner Production, 113, $662-673$.

Tramarico, C. L., Salomon, V. A. P., \& Marins, F. A. S. (2017). Multi-criteria assessment of the benefits of a supply chain management training considering green issues. Journal of Cleaner Production, 142, 249-256.

Uygun, Ö., \& Dede, A. (2016). Performance evaluation of green supply chain management using integrated fuzzy multi-criteria decision making techniques. Computers \& Industrial Engineering, $102,502-511$.

Vahdani, B., Tavakkoli-Moghaddam, R., Jolai, F., \& Baboli, A. (2013). Reliable design of a closed loop supply chain network under uncertainty: An interval fuzzy possibilistic chanceconstrained model. Engineering Optimization, 45(6), 745-765. 
Vahdani, B., Mohammadi, M. (2015). A bi-objective interval-stochastic robust optimization model for designing closed loop supply chain network with multi-priority queuing system. International Journal of Production Economics, 170, 67-87.

Vanalle, R. M., Ganga, G. M. D., Godinho Filho, M., \& Lucato, W. C. (2017). Green supply chain management: An investigation of pressures, practices, and performance within the Brazilian automotive supply chain. Journal of Cleaner Production, 151, 250-259.

Wan, S. P., \& Dong, J. Y. (2014). Possibility linear programming with trapezoidal fuzzy numbers. Applied Mathematical Modelling, 38(5), 1660-1672.

Wang, H. F., \& Hsu, H. W. (2010a). A closed-loop logistic model with a spanning-tree based genetic algorithm. Computers \& operations research, 37(2), 376-389.

Wang, H. F., \& Hsu, H. W. (2010b). Resolution of an uncertain closed-loop logistics model: An application to fuzzy linear programs with risk analysis. Journal of environmental management, 91(11), 2148-2162.

Xu, Z., Elomri, A., Pokharel, S., Zhang, Q., Ming, X. G., Liu, W. (2017). Global reverse supply chain design for solid waste recycling under uncertainties and carbon emission constraint. Waste Management, 64, 358-370.

Zarandi, M. H. F., Sisakht, A. H., \& Davari, S. (2011). Design of a closed-loop supply chain (CLSC) model using an interactive fuzzy goal programming. The International Journal of Advanced Manufacturing Technology, 56(5), 809-821.

Zeballos, L. J., Méndez, C. A., Barbosa-Povoa, A. P., \& Novais, A. Q. (2014). Multi-period design and planning of closed-loop supply chains with uncertain supply and demand. Computers \& Chemical Engineering, 66, 151-164.

Zhalechian, M., Tavakkoli-Moghaddam, R., Zahiri, B., \& Mohammadi, M. (2016). Sustainable design of a closed-loop location-routing-inventory supply chain network under mixed uncertainty. Transportation Research Part E: Logistics and Transportation Review, 89, 182-214.

Zhao, R., Liu, Y., Zhang, N., \& Huang, T. (2017). An optimization model for green supply chain management by using a big data analytic approach. Journal of Cleaner Production, 142, 10851097. 